\title{
North American extreme precipitation events and related large-scale meteorological patterns: a review of statistical methods, dynamics, modeling, and trends
}

\author{
Mathew Barlow' ${ }^{1}$. William J. Gutowski Jr. ${ }^{2}$. John R. Gyakum ${ }^{3} \cdot$ Richard W. Katz $^{4}$. Young-Kwon Lim ${ }^{5}$. \\ Russ S. Schumacher ${ }^{6} \cdot$ Michael F. Wehner $^{7} \cdot$ Laurie Agel $^{1} \cdot$ Michael Bosilovich $^{8} \cdot$ Allison Collow $^{9}$. \\ Alexander Gershunov ${ }^{10} \cdot$ Richard Grotjahn $^{11} \cdot$ Ruby Leung $^{12} \cdot$ Shawn Milrad $^{13} \cdot$ Seung-Ki Min $^{14}$
}

Received: 20 December 2018 / Accepted: 26 August 2019 / Published online: 20 September 2019

(c) The Author(s) 2019

\begin{abstract}
This paper surveys the current state of knowledge regarding large-scale meteorological patterns (LSMPs) associated with short-duration (less than 1 week) extreme precipitation events over North America. In contrast to teleconnections, which are typically defined based on the characteristic spatial variations of a meteorological field or on the remote circulation response to a known forcing, LSMPs are defined relative to the occurrence of a specific phenomenon-here, extreme precipitationand with an emphasis on the synoptic scales that have a primary influence in individual events, have medium-range weather predictability, and are well-resolved in both weather and climate models. For the LSMP relationship with extreme precipitation, we consider the previous literature with respect to definitions and data, dynamical mechanisms, model representation, and climate change trends. There is considerable uncertainty in identifying extremes based on existing observational precipitation data and some limitations in analyzing the associated LSMPs in reanalysis data. Many different definitions of "extreme" are in use, making it difficult to directly compare different studies. Dynamically, several types of meteorological systems-extratropical cyclones, tropical cyclones, mesoscale convective systems, and mesohighs—and several mechanisms-fronts, atmospheric rivers, and orographic ascent—have been shown to be important aspects of extreme precipitation LSMPs. The extreme precipitation is often realized through mesoscale processes organized, enhanced, or triggered by the LSMP. Understanding of model representation, trends, and projections for LSMPs is at an early stage, although some promising analysis techniques have been identified and the LSMP perspective is useful for evaluating the model dynamics associated with extremes.
\end{abstract}

\section{Introduction}

Considerable previous research, surveyed in this paper, has shown that short-term extreme precipitation is often associated with distinct synoptic and larger-scale circulation patterns. Within the larger-scale environment, extreme precipitation is often directly forced by local and mesoscale factors, with the larger environment playing a crucial role in providing a favorable environment for, and then organizing or triggering, the smaller-scale factors. While the full spectrum of scales is important, we focus here on the synoptic and subcontinental scales of circulation, which are well-resolved in

Mathew Barlow

mathew_barlow@uml.edu

Extended author information available on the last page of the article both weather and climate models, have greater predictability than smaller scales, and can provide the potential for statistical downscaling in seasonal and climate change contexts.

We frame our consideration in terms of large-scale meteorological patterns (LSMPs), in parallel to Grotjahn et al. (2016), which considered the link between LSMPs and extreme temperature. Both Grotjahn et al. (2016) and the current study are outputs from the US Climate and Ocean-Variability, Predictability, and Change (CLIVAR) Extremes Working Group and a related workshop (Grotjahn et al. 2014). In contrast to teleconnections, which are typically defined based on the characteristic spatial variations of a field [e.g., empirical orthogonal functions (EOFs) of $500 \mathrm{hPa}$ heights] or on the remote circulation response to a known forcing [e.g., El Niño-Southern Oscillation (ENSO)], LSMPs are recurrent meteorological patterns defined relative to the occurrence of a specific phenomenon-here, 
Table 1 Frequently-used acronyms

\begin{tabular}{ll}
\hline Extreme definitions & \\
ETCCDI & Expert Team on Climate Change Detection and Indices \\
Rx1 day & Seasonal or annual maximum of 24-h (1-day) precipitation \\
Rx5 day & Seasonal or annual maximum of pentad (5-day) precipitation \\
Statistics & \\
GEV & Generalized extreme value \\
POT & Peaks-over-threshold \\
Geographic & \\
CONUS & Contiguous United States (excludes Hawaii and Alaska) \\
Meteorology and climate & \\
LSMP & Large-scale meteorological pattern \\
CMIP5 & Coupled Model Intercomparison Project, Phase 5 \\
AR & Atmospheric river \\
IVT & (Vertically) integrated (water) vapor transport \\
LLJ & Low level jet \\
MCS & Mesoscale convective system \\
TC & Tropical cyclone (includes hurricanes) \\
WCB & Warm conveyor belt \\
\hline
\end{tabular}

extreme precipitation - and with an emphasis on the synoptic scale that has a primary influence in individual events. As noted in Grotjahn et al. (2016), there are at least three ways of defining LSMPs for extreme events: compositing based on the events, pattern-based analysis of circulation or thermodynamic fields during periods when the events occurred, or case studies.

The definition of extreme precipitation also introduces considerable complexity. A definition of "extreme" generally has three distinct aspects: a metric (e.g., top 1\%, values greater than $5 \mathrm{~cm}$, recurrence interval of 5 years), a timescale (e.g., accumulation over hours, days, or the total event), and a spatial scale (e.g., station-based, grid box, areaaverage, extent of contiguous rain area). Different values for each aspect may be expected to correspond to different impacts, e.g., flash flooding, riverine flooding, stormwater management, agricultural damage, water management, etc., at local or regional levels, and to be of varying importance depending on season and region. As a result, a wide variety of extreme precipitation definitions are in use, complicating the construction of general conclusions of the role of LSMPs.

The local factors governing extreme precipitation are controlled by basic physical considerations: moisture availability, lift, stability, and duration. The LSMPs that determine or influence these factors are much more complex, are both regionally- and seasonally-dependent, and vary considerably based on the definition of extreme. Here we review the current literature on the links between extreme precipitation and LSMPs for North America. Acronyms are in wide use for this topic and, while they are all defined upon first use in this review, for convenience we also provide a list of the most frequently-used acronyms in Table 1 . We consider the substantial issues regarding definitions, data, and methodology for both LSMPs and extreme precipitation in Sect. 2, the LSMPs and related dynamical mechanisms in Sect. 3, observed and projected trends in Sect. 4, and model representation of the observed relationships and dynamical mechanisms in Sect. 5. We end with a summary and perspectives for future work in Sect. 6.

\section{Data, definitions, and methodology}

This section considers precipitation data in Sect. 2.1, fitness of reanalysis data in Sect. 2.2, definitions of "extreme" in Sect. 2.3, the methodology of extreme value statistics and trend analysis in Sect. 2.4, and methods for identifying LSMPs in Sect. 2.5. The consideration of data sources is important context for LSMP analysis, as data-related limitations can influence the results. Model output data is considered separately in Sect. 5.

\subsection{Precipitation data}

The depth of our understanding of the connections between LSMP and precipitation extremes is limited by the quality of high-frequency observations of precipitation. Gauge data from weather stations is a principal source of precipitation observations over land. The Global Historical Climate Network (GHCN) daily dataset (Menne et al. 2012) is a multi-decadal quality controlled collection of weather station measurements, including precipitation. Measurements over the contiguous US (CONUS) region (downloadable at 


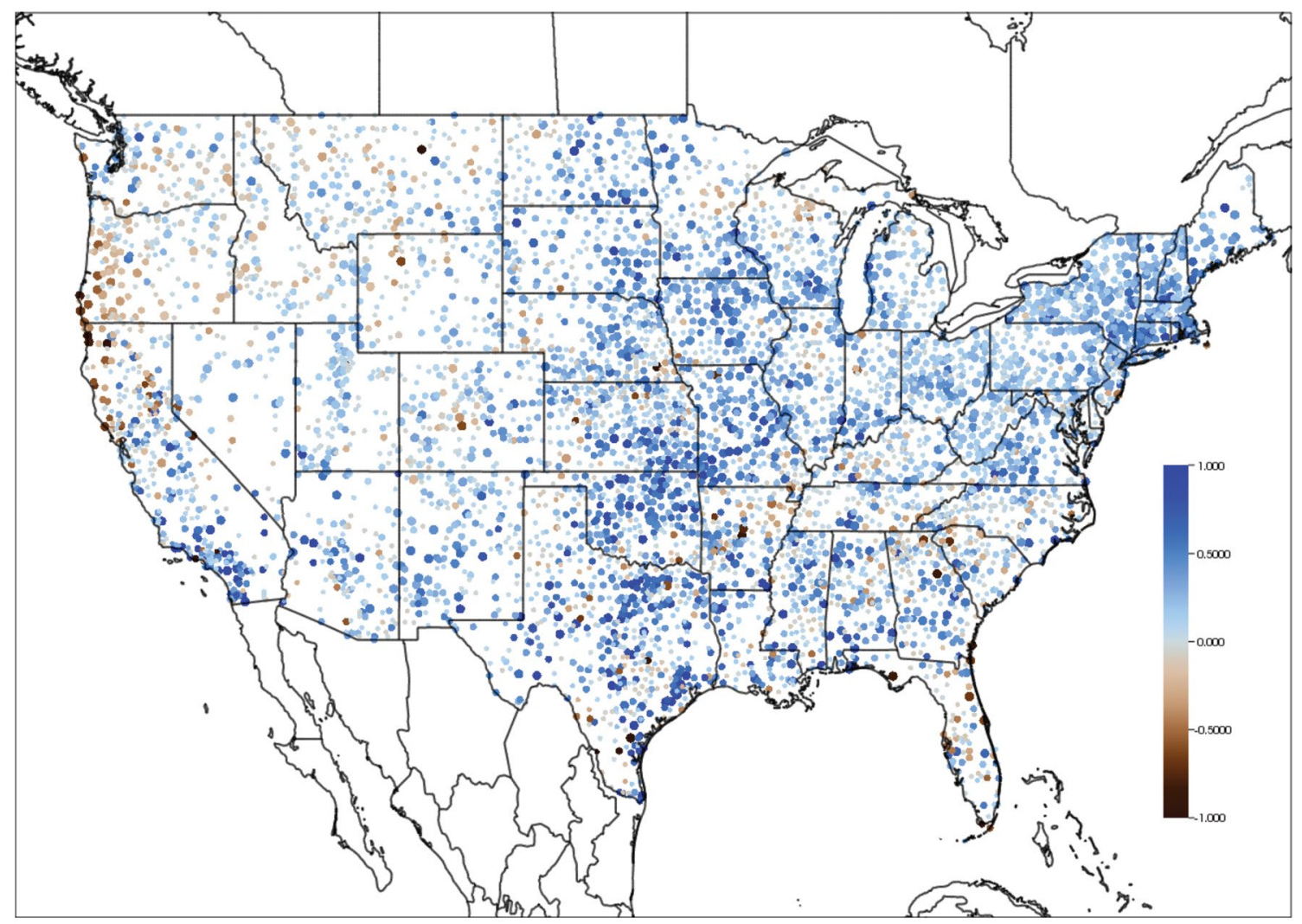

Fig. 1 Changes from 1948 to 2010 in observed 20 year return value of the daily accumulated precipitation for stations from the Global Historical Climate Network-daily dataset in the contiguous US. Units: in. Only locations for which data from at least $2 / 3$ of the days in the
1948-2010 period were recorded are included in this analysis. The change in return period threshold at each station is shown by a circle whose relative size portrays its statistical significance. The color bar ranges from - 1.0 to 1.0. From Kunkel et al. (2013) http://www.ncdc.noaa.gov/oa/climate/ghen-daily/) are of particularly high density compared to the rest of the world. Figure 1 (discussed in detail in Sect. 4) shows GHCN station locations; note that station density is higher in the eastern part of the country compared to the western part.

To connect extreme precipitation to LSMPs as simulated through reanalyses or climate models, gridded precipitation products are often required. Several such products constructed from station data are available from various sources for selected parts of the globe. Differing techniques to transform daily precipitation station data to grids result in different estimates of long period return values (Wehner 2013). (The definition of return periods and other extreme metrics are discussed in Sect. 2.3.) While satellite based products of daily precipitation offer more complete spatial coverage than stations, their ability to reproduce the extreme precipitation derived from station data is severely deficient (Timmermans et al. 2018), likely due to complications in the retrieval algorithms at the extreme end of the precipitation distribution as well as the infrequent temporal sampling of polar orbits. These differences form a crude estimate of the observational uncertainty (Covey et al. 2002) but do not provide information about common systematic errors. Due to the intermittent nature of precipitation, the gridding process is more challenging than it is for smoothly varying fields like surface air temperature. Cavanaugh and Gershunov (2015) assessed the impact of spatio-temporal averaging on the tail structure of precipitation distributions and showed that spatial averaging can result in greater reduction in volatility than does temporal averaging, in regions where relatively long-lived extreme precipitation-producing systems such as atmospheric rivers are important. Due to the fractal nature of daily or sub-daily precipitation, the wisdom of gridding such a heterogeneous function has been called into question by Risser et al. (2018) who offer an alternative approach using spatial statistics to grid precipitation extremes from station data directly.

Comparing extreme precipitation between observations, model output, and reanalysis products—or indeed between different datasets within each category-is not 
straightforward. Among gridded observational datasets, station density, interpolation methodology, and spatial resolution are all important sources of uncertainty (e.g., Herold et al. 2016; Herrera et al. 2018), comparable for some indices to the spread between CMIP5 models (Herold et al. 2016). For models, the processes underlying precipitation are a mix of point quantities and area-averaged parameterizations, and an argument can be made that the most consistent comparison to observations should be with gridded data rather than station data (Chen and Knutson 2008). However, many uses of model projections are applied at specific locations, where point data is more relevant than area-averages. For the most effective analysis, these factors should be considered relative to the intended interpretation.

At least two different gridded daily precipitation products are available for the CONUS based on the same weather station observations. The Daily US Unified Precipitation is a product spanning 1948 to present from the National Oceanic and Atmospheric Administration's (NOAA) Climate Prediction Center (CPC) (Higgins et al. 2000a, b). The dataset uses the daily rain gauge reports from a combination of stations monitored by NOAA's National Centers for Environmental Information (NCEI), data from additional stations collated by the CPC from River Forecast Centers, and daily accumulations from hourly precipitation measurements. For this dataset, the precipitation rates from individual stations are mapped onto a regular $0.25^{\circ} \times 0.25^{\circ}$ grid using a Cressman Scheme (Cressman 1959; Charba et al. 1992; Higgins et al. 2000a, b).

A second station-based CONUS gridded dataset ${ }^{1}$ is available from 1949 to 1999 from the Surface Water Modeling group at the University of Washington (UW) on a finer $1 / 8^{\circ}$ grid. This product been recently replaced with a $1 / 16^{\circ}$ product covering 1915-20112 (Livneh et al. 2013). An elevation correction (Daly et al. 1997) in these datasets is likely responsible for higher values and more finer-grained structures of extreme precipitation in western US mountainous regions where many of the weather stations are at lower altitudes than the average gridded elevation (Wehner 2013). However, when aggregated annually and over the entire CONUS region, as discussed below, these differences from the CPC dataset are less significant. The UW group also provides a similar $0.5^{\circ}$ gridded daily precipitation global land dataset $^{3}$ (Adam and Lettenmaier 2003; Maurer et al. 2009).

In regions with adequate spatial coverage by groundbased radars, such as in the US, radar-estimated rainfall can be merged with rain gauge data to produce precipitation estimates with high spatial resolution. Examples of these

\footnotetext{
${ }^{1}$ http://www.hydro.washington.edu/Lettenmaier/Data/gridded/.

2 http://www.esrl.noaa.gov/psd/data/gridded/data.livneh.html.

3 http://www.engr.scu.edu/ emaurer/global_data/.
}

datasets for the US include the National Centers for Environmental Prediction (NCEP) Stage IV (Lin and Mitchell 2005; Nelson et al. 2016), the NOAA Multi-Radar MultiSensor (MRMS; Zhang et al. 2016), and the North American Land Data Assimilation System (NLDAS) hourly precipitation, which is based on Doppler radar, CMORPH products, and CPC hourly CONUS/Mexico gauge data. ${ }^{4}$ The NCEP Stage IV data has a spatial resolution of approximately $4 \mathrm{~km}$, a temporal resolution of $1 \mathrm{~h}$, and is available from 2002 onwards; the MRMS data has a spatial resolution of $0.01^{\circ}$; a temporal resolution as short as $2 \mathrm{~min}$, and began operational availability in 2014; and the NLDAS data has a spatial resolution of $1 / 8^{\circ}$, a temporal resolution of $1 \mathrm{~h}$, and is available from 1979 onwards.

Geosynchronous satellite-derived precipitation products have the advantage of complete spatial and temporal coverage but such remote sensing requires a conversion from the irradiances actually measured to an estimate of the precipitation at the surface. The Global Precipitation Climatology Project (GPCP) $1^{\circ} \times 1^{\circ}$ daily precipitation, version 1DD V1.1 (Huffman et al. 2001; Bolvin et al. 2009) provides an observational estimate over the entire globe. The GPCP 1DD precipitation product is an empirical estimate obtained by combining station-based rainfall measurements and satellite imagery collected by geosynchronous-orbit IR sensors (geoIR), low-orbit IR imagers (leo-IR), the TIROS Operational Vertical Sounders (TOVS), and the Atmospheric Infrared Sounder (AIRS). The statistics are first obtained from a combination of monthly in situ precipitation data from GPCP and the Climate Prediction Center (CPC) and the fractional occurrence of precipitation from the Special Sensor/Microwave Imager (SSMI). These statistics are accumulated in the GPCP Version 2.1 Satellite-Gauge (SG) data set. Raw TOVS and AIRS datasets tend to have too many rain days and correspondingly lower daily rain rates. In GPCP 1DD, the local number of TOVS (AIRS) rain days in each month is reduced by the ratio of the total number of TMPI and TOVS (AIRS) rain days. The non-zero daily rain intensities are rescaled to start at zero and summed over the month to the (local) SG value (Huffman et al. 2001).

The Tropical Rainfall Measuring Mission (TRMM) is a product from a NASA satellite mission monitoring tropical and subtropical precipitation over both land and ocean areas from 1997 to the present. The TRMM data used in this study is the 3B42 daily TRMM-adjusted merged-infrared (IR) precipitation (Huffman et al. 2007). ${ }^{5}$ The monthly TRMM data is used to adjust the rainfall estimates from the Special Sensor Microwave/Imager (SSM/I) and empirically infer precipitation from geosynchronous IR collected by the

\footnotetext{
${ }^{4}$ https://ldas.gsfc.nasa.gov/nldas/NLDAS2forcing.php.

${ }^{5}$ https://pmm.nasa.gov/trmm.
} 
Fig. 2 Five available estimates of the observed annual probability density distributions of daily precipitation over CONUS from GPCP, TRMM, UW-Global, UW-CONUS, CPC. Daily precipitation rates were remapped onto a $1.9^{\circ} \times 2.6^{\circ}$ grid before computing the distributions

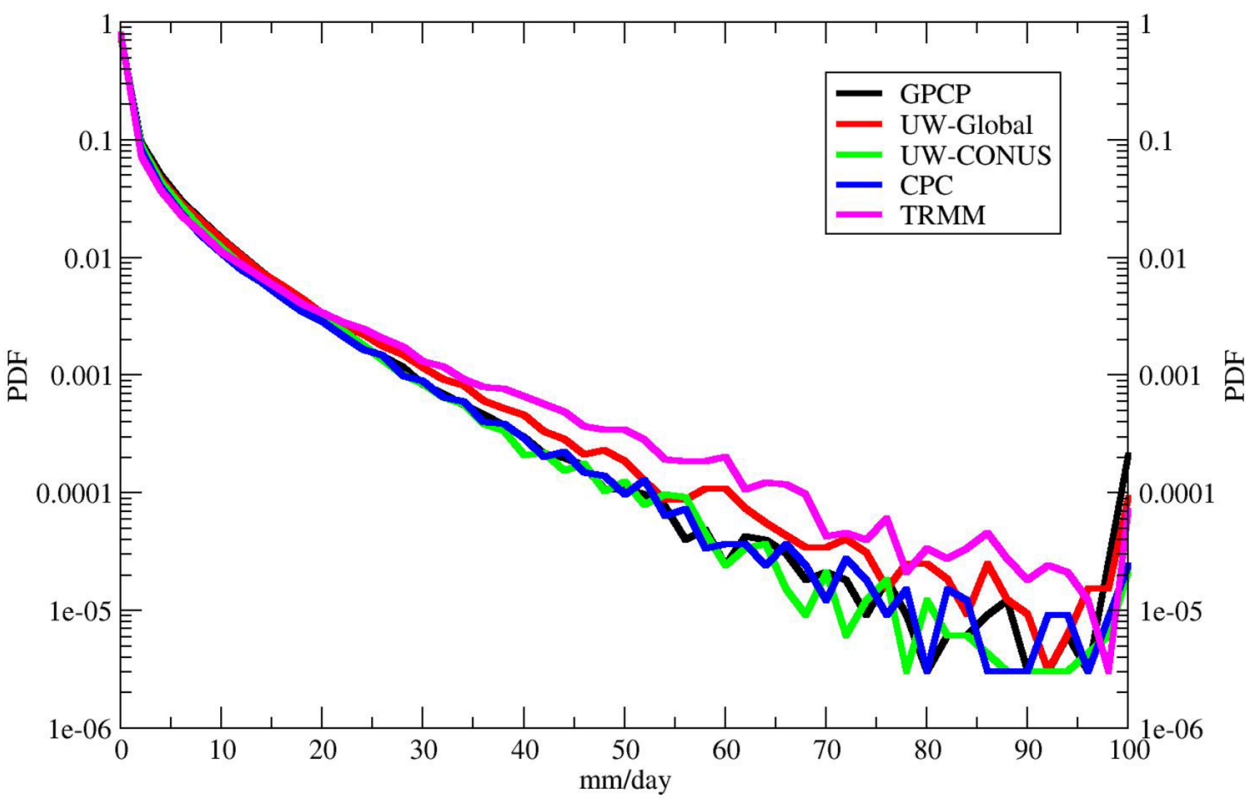

Geostationary Meteorological Satellite (GMS), the Geostationary Operational Environmental Satellites (GOES), and other satellite platforms. The gridded daily-accumulated precipitation product is derived from 3-h infrared imagery. It has a $0.25^{\circ} \times 0.25^{\circ}$ spatial resolution and extends from approximately $50^{\circ} \mathrm{S}$ to $50^{\circ} \mathrm{N}$ covering the CONUS region. Since the launch of the Global Precipitation Measurement (GPM), rainfall estimates are available from the IMERG data that combines data from all passive-microwave instruments in the GPM Constellation. Data are provided at $0.1^{\circ}$ spatial resolution and $30 \mathrm{~min}$ temporal resolution between $60 \mathrm{~S}$ and $60 \mathrm{~N} .^{6}$

We compare several of these daily precipitation gridded products by regridding daily accumulated precipitation over the CONUS region onto a roughly $2^{\circ}$ grid, followed by an aggregation over all seasons into $2 \mathrm{~mm} \mathrm{day}^{-1}$ bins from 0 to $100 \mathrm{~mm} \mathrm{day}^{-1}$ over the period 1979-2005. Precipitation rates larger than $100 \mathrm{~mm} \mathrm{day}^{-1}$ are assigned to the last bin for normalization purposes. The five gridded estimates of the daily distribution of precipitation are shown in Fig. 2. Below daily precipitation rates of $20 \mathrm{~mm} \mathrm{day}^{-1}$, all five gridded products are in good agreement by this measure. Because the GPCP product is not completely independent of the station data used to produce the CPC and UW products, these three distributions are reasonably consistent with each other over the range of precipitation rates considered here. Interestingly, the UW-Global distribution is higher than the finer UW-CONUS distribution at precipitation rates greater than $60 \mathrm{~mm} \mathrm{day}^{-1}$. The TRMM distribution has a heavier tail than

\footnotetext{
$\overline{{ }^{6} \text { https://pmm }}$.nasa.gov/data-access/downloads/gpm.
}

the other distributions consistent with the analysis of Nesbitt et al. (2004). However, these differences are considerably smaller than those for the other two regions with available gridded observations (Wehner et al. 2014).

\subsection{Fitness of reanalysis data}

LSMPs are often identified using reanalysis data. Several options are available, including National Aeronautics and Space Administration's (NASA) Modern Era Retrospective Reanalysis for Research and Application (MERRA; Rienecker et al. 2011), and MERRA Version 2 (MERRA2; Gelaro et al. 2017), European Center for Medium-range Weather Forecasting (ECMWF) ERA-Interim (Dee et al. 2011), and NOAA's Climate Forecasting System Reanalysis (CFSR; Saha et al. 2014). Reliability is much higher for some reanalysis variables than others, depending on the underlying data and assimilation methodology. For instance, upper-air horizontal winds are strongly constrained by observations and so considered in the most reliable class of variables, moisture is influenced by both observations and the underlying model and so has more uncertainty, and diabetic heating is not directly constrained by observations and is highly model dependent (Kalnay et al. 1996). Additionally, some reanalyses assimilate precipitation while others do not. The uncertainty introduced into LSMP analysis will therefore depend both on which variables and which reanalysis products are used, and especially whether reanalysis precipitation or closely-related quantities (e.g., vertical velocity, diabetic heating, etc.) are considered.

While investigating the interannual variability of MERRA, Bosilovich (2013) found regional differences in 
the ability of all reanalyses to reproduce summertime precipitation variability, which is generally more difficult to forecast. In particular, the Midwestern US was poorly represented in all reanalyses discussed. MERRA underestimated the precipitation with low precipitation maxima and too high precipitation minima. ERA-Interim exhibits a persistent decreasing trend of precipitation over the continental US (Simmons et al. 2010). CFSR Southeast summer seasonal precipitation has low correlation to observations. On the other hand, the Northwest (NW) US precipitation variability is well reproduced by all of the more recent reanalyses compared with gauge observations (Bosilovich 2013). This may be related to ENSO - the ENSO signal in the NW tends to persist into summertime, so that with strong large-scale teleconnections, the reanalyses will tend to agree better with observations - or perhaps with the more stratiform precipitation of the region, which is more easily captured by reanalysis than convective precipitation.

MERRA-2 has now superseded MERRA. Bosilovich et al. (2015) provide a summary of the MERRA-2 climate compared to observations and other reanalyses. In particular, it is noted that both dry days, and extreme precipitation (using the 99th percentile of the daily rainfall) in JJA are much closer to gauge observations for MERRA-2 than for MERRA for the US. The maximum amount of rainfall in a 5 -day period during a season ( $\mathrm{R} \times 5$ day) captures one aspect of extreme precipitation related to synoptic scale weather. Figure 3 shows US summertime Rx 5 day area averaged for a few regions of the US from CPC Unified gauge observations, MERRA-2 and MERRA reanalysis precipitation. MERRA systematically underestimates the extreme amounts. While it might be convenient to explain this from the $0.5^{\circ}$ spatial resolution of the background forecast model and its ability to resolve the intensity of convection, MERRA-2's $0.5^{\circ}$ model produces much higher extreme rainfall rates, closer to the gauge observations. Numerous updates to the model physics, including the boundary and surface layer parameterizations were implemented that could contribute to the increased precipitation (Molod et al. 2015). MERRA-2 also uses observation corrected precipitation forcing for the land surface parameterization (Reichle and Liu 2014). With this improvement in summertime extreme precipitation reanalysis for the Midwestern US, there is enhanced confidence in using MERRA-2 to evaluate the atmospheric conditions during such events, especially for variables most affected by the assimilation of precipitation, such as vertical velocity.

More recently, the European Center for Medium Range Weather Forecast (ECMWF) developed a new generation of global reanalysis product that provides hourly estimates of a large number of atmospheric, land, and oceanic climate variables at a $30 \mathrm{~km}$ grid. Information about uncertainties are provided for all variables at reduced spatial and temporal resolutions. Data are available from 2008 to within 3 months of real time. This high resolution reanalysis product fills an important gap in providing meteorological information for analysis of LSMPs globally, as similar resolution products were only available for North America at a $32 \mathrm{~km}$ grid.

\subsection{Definitions of "extreme"}

Measures of extreme precipitation can be quite diverse and often are chosen to best exemplify the spatial or temporal scale of the question being asked, or the methodology being employed. The choice of spatial scale in large part reflects the domain of the region being studied, while the temporal scale chosen can uniquely emphasize intensity, duration, or frequency of extreme precipitation.

A large number of different definitions of "extreme" have been used in the previous literature surveyed in this paper. Two common classes of definition are those based on local frequency of occurrence (e.g., a $1 \%$ chance of occurrence, a 50-year return period, etc.) and those based on a fixed magnitude threshold (e.g., $5 \mathrm{~cm}$ ). These definitions require a choice of accumulation period (e.g., 24-h) and sometimes spatial considerations (e.g., requiring a greater that $25 \mathrm{~mm}$ average over a $12,500 \mathrm{~km}^{2}$ area). Two common approaches for identifying extremes are "block maxima", where the single greatest value within a set time period, the block, is selected (e.g., annual or seasonal highest daily precipitation), and the peaks-over-threshold (POT) approach, in which all values over a given threshold define the set of extremes (e.g., the top $1 \%$ of daily precipitation values). In the latter case, Generalized Pareto Distributions (GPD) are fitted to the extreme value sample data after declustering to avoid auto-correlation and can potentially sample the tail of the parent distribution more precisely (Coles 2001). However, a judicious choice of threshold can be complicated. It must be high enough to be in the tail of the distribution but not too high in order to have a sample large enough to fit. Furthermore, whether the threshold includes all days or just wet days is an issue (Schär et al. 2016) as is non-stationarity, described below. In addition, flooding is also sometimes used as an aggregated measure of extreme precipitation. While a variety of factors can be involved in flooding, many flash flooding events are directly related to heavy short-term precipitation [see, e.g., the discussion in Maddox et al. (1979)]. Whether using block maxima or POT methods, seasonality must be considered as the processes controlling North American extreme precipitation vary accordingly.

Some of the nomenclature can create confusion. The return period (also known as the recurrence interval or repeat interval) is the average time between events of a given magnitude and is the inverse of the probability of the event. For instance, an event with a 100 -year return period has a probability of occurrence of $1 /(100$ years $)$ or $1 \%$ annual 
Fig. 3 Time series of JJA area averaged maximum 5 day precipitation total anomalies (RX5DAY) derived from CPC Unified gauge observations, MERRA and MERRA-2 reanalysis for the US regions of a Northeast, b Southeast, c Midwest and $\mathbf{d}$ Northern Great Plains, defined as in Bosilovich (2013) Fig. 1. Mean values removed to plot anomalies are provided in the legend. Correlation of the time series are provided in the lower right corner

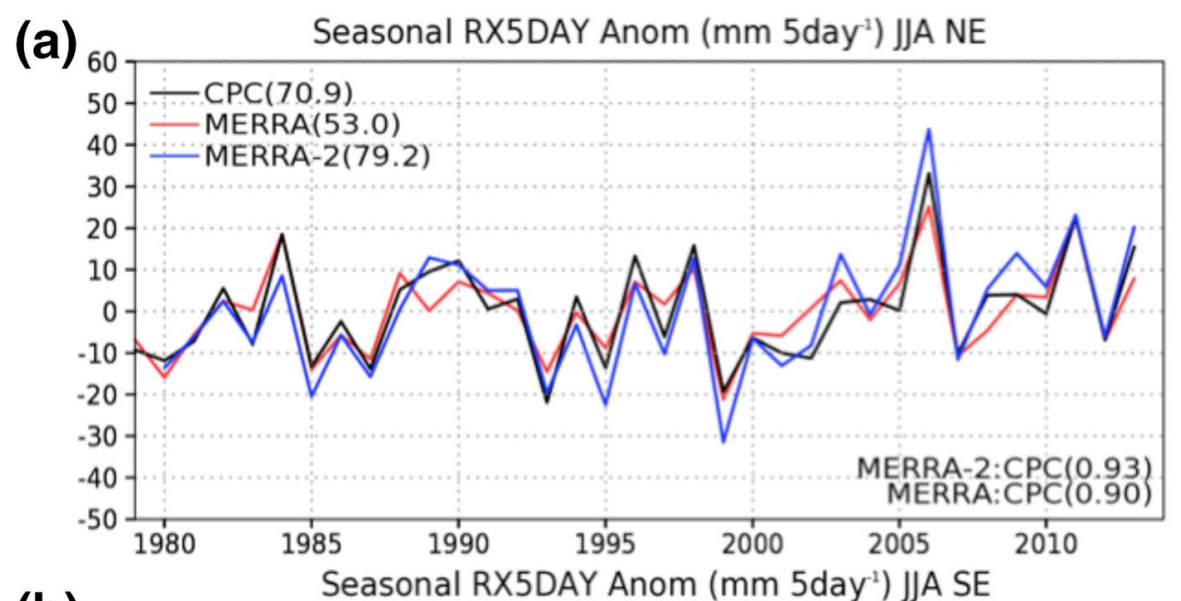

(b)

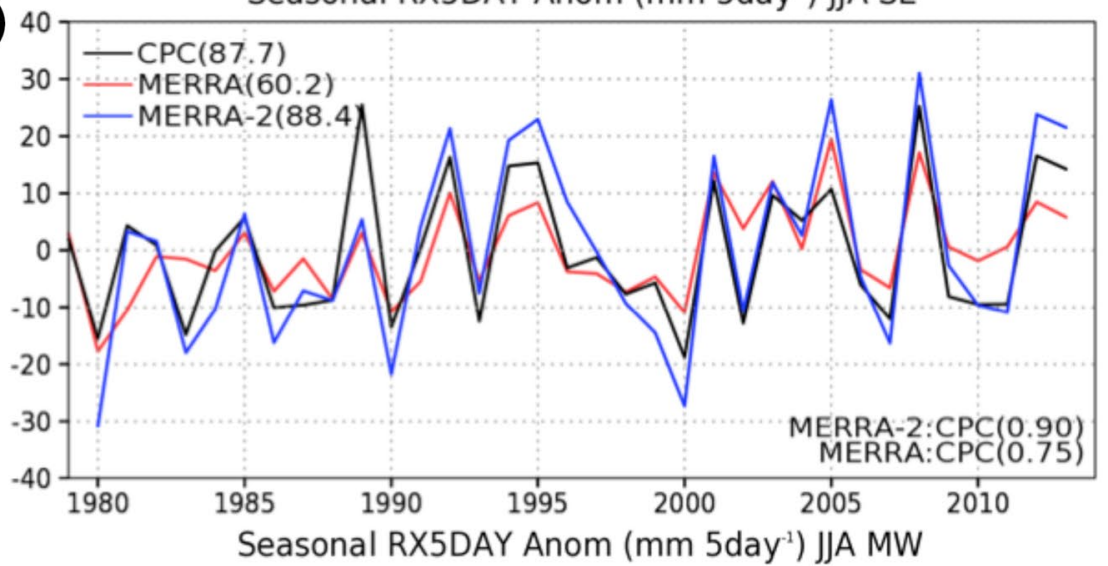

(c)

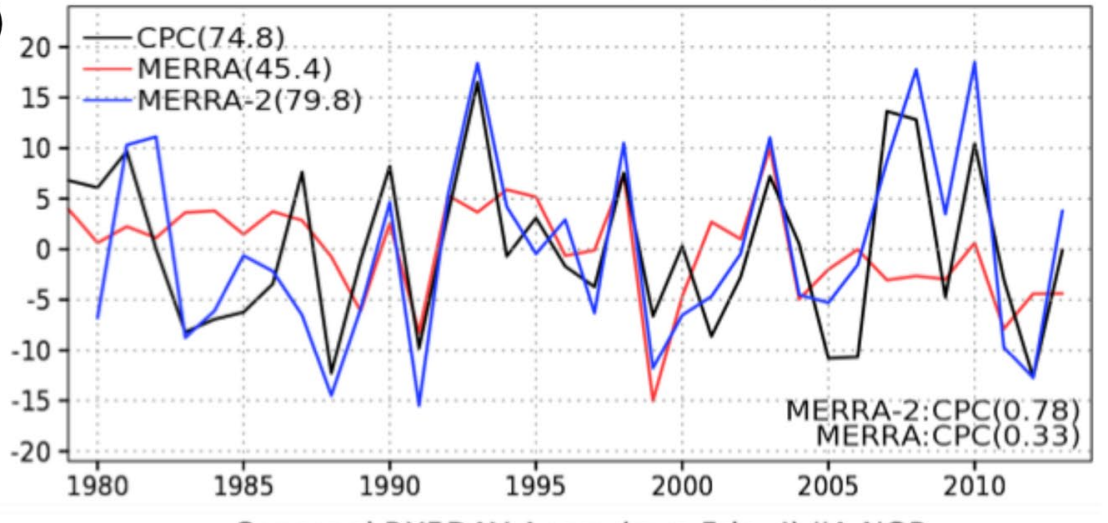

(d)

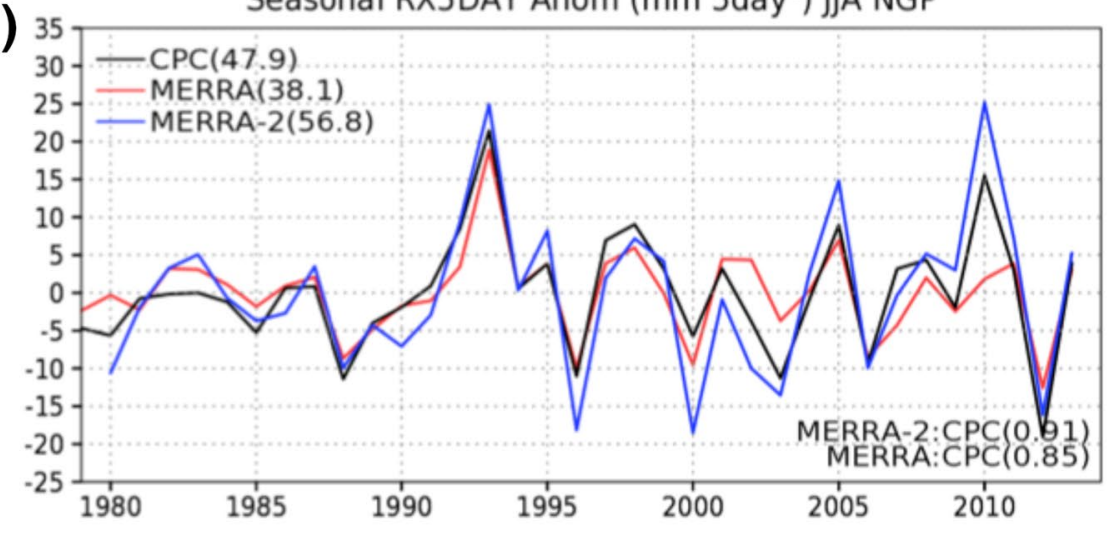


Table 2 Definitions of extreme precipitation in different studies

\begin{tabular}{|c|c|}
\hline References & Extreme description \\
\hline Agel et al. $(2017,2019)$ & Top $1 \%$ of precipitating days \\
\hline Bradley and Smith (1994) & At least $12.5 \mathrm{~mm}$ at a station in $24 \mathrm{~h}$, with a greater than $25 \mathrm{~mm}$ average over $12,500 \mathrm{~km}^{2}$ \\
\hline Ely et al. (1994) & Flood-producing rain events \\
\hline Groisman et al. (2005) & Daily thresholds $90-99.9 \%$, area averaged \\
\hline Grotjahn and Faure (2008) & $24+$ hour precipitation exceeding $63.5 \mathrm{~mm}$ total or $50.8 \mathrm{~mm} \mathrm{day}^{-1}$ \\
\hline Hamada et al. (2015) & $\begin{array}{l}\text { Effective radar reflectivity pixels with maximum near-surface rainfall rate or maximum } \\
40 \text {-dBZ echo-top height }\end{array}$ \\
\hline Higgins et al. (2000a) & 25 largest 3-day precipitation events \\
\hline Keim (1996) & 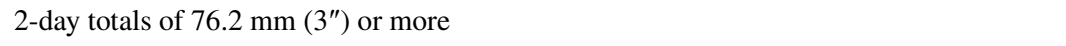 \\
\hline Kharin et al. (2013) & Annual daily maximum \\
\hline Kunkel et al. (2012) & Daily precipitation exceeding 5 -year recurrence interval \\
\hline Kunkel et al. (2013) & Station-specific 97th percentile \\
\hline Lackmann and Gyakum (1999) & Flood-producing rain events \\
\hline LaPenta et al. (1995) & Three largest floods 1860-1989 \\
\hline Maddox et al. $(1979,1980)$ & NOAA flash flooding reports \\
\hline Milrad et al. $(2010 \mathrm{a}, \mathrm{b})$ & Median extreme 2-day precipitation exceeding $33.78 \mathrm{~mm}$ \\
\hline Milrad et al. (2014) & Top $10 \% 1-3$ day precipitation \\
\hline Min et al. (2011) & Annual 1- and 5-day maximum precipitation ( $\mathrm{Rx} 1$ day, $\mathrm{Rx} 5$ day) \\
\hline Moore et al. (2012) & 48-h precipitation exceeding 1000-year recurrence interval \\
\hline Moore et al. (2015) & 99th and 99.9th percentiles of daily precipitation, plus areal extent above median size \\
\hline Schumacher and Johnson (2005) & Daily precipitation exceeding 50-year recurrence interval \\
\hline Sillmann et al. (2013a) & Various ETCCDI indices \\
\hline Toredi et al. (2013) & P90 (daily 90th percentile) \\
\hline Warner et al. (2012) & Top 50 48-h station precipitation \\
\hline Westra et al. (2013) & Annual daily maximum \\
\hline Zhang et al. (2010) & Annual winter maximum, $+2 \mathrm{nd}$ and $3 \mathrm{rd}$ maxima \\
\hline
\end{tabular}

probability, although sometimes the occurrence or absence of such an event is misinterpreted as changing the likelihood of subsequent events. The return period has proven to be a problematic metric for communicating risk (e.g., Highfield et al. 2013; Serinaldi 2015). It is important to emphasize that these measures assume that the underlying variability is stationary.

It is also important to note that all observational estimates of extreme parameters have uncertainty associated with them, although this is unfortunately not always made explicit with confidence intervals, and the shorter the period of record relative to the occurrence frequency of interest, the greater the uncertainty. This observational uncertainty can also make it difficult to identify trends in rare events (Ceres et al. 2017). Given the importance of trends in extremes, discussed further in Sect. 4.1, nonstationary is an important issue (e.g., Vogel et al. 2011; Read and Vogel 2015; Serinaldi and Kilsby 2015).

Examples of extreme definitions used in the literature considered in this paper are provided in Table 2. Note the broad range: a definition resulting in a large number of extremes in a given period is the $1 \%$ daily definition, which would identify 365 events in a 100 year period, on average, while a definition resulting in relatively few extremes is the 50-year recurrence interval, which would identify two events in a 100 year period, on average. Several of the definitions in Table 2 are from the Expert Team on Climate Change Detection and Indices (ETCCDI). ${ }^{7}$ For precipitation, these include block maxima measures such as Rx1 day (seasonal or annual maximum of daily precipitation) and Rx5 day (same, for pentad precipitation), POT measures such as R99pTOT (annual total precipitation for days when precipitation is over the top $99 \%$ of wet days), frequency measures such as $\mathrm{R} 20 \mathrm{~mm}$ (annual count of days when precipitation is greater than $20 \mathrm{~mm}$ ), and intensity measures such as SDII (annual mean daily intensity on wet days). The full set of ETCCDI indices as well as software to calculate them are available at http://etccdi.pacificclimate.org and are described in Alexander et al. (2006) and Zhang et al. (2011).

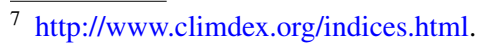




\subsection{Extreme value statistics and trend analysis}

Extreme value statistics, methods based on the statistical theory of extreme values (Coles 2001), can be used to quantify the likelihood of very extreme precipitation and its trends. A fundamental result of the statistical theory of extreme values is that seasonal or annual maxima are well described by the three-parameter (location, scale, and shape) generalized extreme value (GEV) distributions under suitable conditions. The upper tail of the fitted distribution, described by the shape parameter, can either be heavy (the Fréchet distribution), exponential (the Gumbel distribution), or bounded (the reverse Weibull distribution). Alternatively, the GPD can be used to describe a sample drawn from over a high threshold as described in Sect. 2.3. In the asymptotic limit, these approaches are equivalent and a transformation from one fitted distribution to the other can be made. Now a standard approach, implementation details can be found in Coles (2001), Katz (2013), Kharin et al. (2013), Westra et al. (2013), Easterling et al. (2016) and many other recent papers. The extRemes software package, ${ }^{8}$ written in the statistical programming language $\mathrm{R}$, is a useful resource to calculate fitted extreme value distributions and other derivative quantities (Gilleland and Katz 2016).

The best fit to both observed or modeled extreme precipitation samples is often an unbounded and heavy tailed distribution (e.g., Katz 2013). However, this is clearly unphysical as there cannot exist an infinite precipitation rate, and the unbounded nature of such fits leads to large uncertainties when extrapolating past the limits of the raw data, including overestimation of long return periods (Panorska et al. 2007). Wilson and Toumi (2005) and Furrer and Katz (2008) attempted to resolve this apparent conflict between physical and statistical considerations through more refined extreme value approximations.

An important recent development in extreme value methods is the introduction of physical covariates as additional parameters in the fitted distributions (Coles 2001; Katz 2010). Covariates can be used to identify non-stationarities including human forced trends and the natural links between extreme precipitation and LSMPs. For example, van Oldenborgh et al. (2017) used global mean temperature inspired by the Clausius-Clapeyron relationship to identify a trend in Gulf Coast extreme precipitation. Zhang et al. (2010) considered the links between North American winter maximum daily precipitation and modes of climate variability including ENSO, the Pacific Decadal Oscillation (PDO), and the North Atlantic Oscillation (NAO). Sun et al. (2015) used covariate methods to find that extreme precipitation is increased during strong El Niño events from the central

\footnotetext{
${ }^{8}$ https://cran.r-project.org/package=extRemes.
}

US and Canadian border to Mexico but decreased in the southwestern US and Mexico during strong La Niña events. Risser and Wehner (2017) used both $\ln \left(\mathrm{CO}_{2}\right)$ and Niño3.4 to isolate the anthropogenic and natural sources of non-stationarity in coastal Texas extreme rainfall. While POT methods can also be constructed to exploit such physical covariates, non-stationary thresholds (Acero et al. 2010; Kyselý et al. 2010; Roth et al. 2012; Solari et al. 2017) may be required to ensure that the threshold values are consistent with the tail of the distribution at any given time. The efficient selection of physical covariates in extreme value methods is a rapidly developing area and offers much promise in furthering our understanding of the relationship between LSMPs and extreme precipitation.

\subsection{Methods for identifying LSMPs}

A number of methods have been utilized for identifying LSMPs associated with extreme precipitation. Grotjahn et al. (2016), which surveyed the techniques used to identify LSMPs for temperature extremes, also provides a useful resource in this case, as the same techniques have been widely used for both temperature and precipitation extremes-including composites, regression, EOFs or principal component (PC) analysis, self-organizing maps (SOMs), and cluster analysis - and Grotjahn et al. discusses the attributes, cautions, and significance testing for these different methods. Here, we provide some additional information relevant to the precipitation extreme studies considered here.

Composites based on manual synoptic typing is a common approach for distinguishing between different LSMPs. Manual (subjective) typing has been applied to a range of data types, including surface data, which provides the longest record (e.g., Kunkel et al. 2012), data at a range of levels (e.g., Bradley and Smith 1994), and radar data (Schumacher and Johnson 2005). Muller (1977) provided guidelines to categorize events based on surface weather maps. Calibrated analysis, where testing is done to assess whether different experts assign events similarly, provides the most robust approach to subjective analysis. Some studies have further sub-divided categories based on additional factors such as the magnitude of water vapor transport (e.g., Moore et al. 2015) and quasi-geostrophic analysis of vertical motion (e.g., Milrad et al. 2010a, b).

Classification of extratropical cyclones and their separation, or not, from fronts, is also common to several studies and a number of approaches have been taken: some studies only distinguish fronts, not storms (e.g., Keim 1996), some only have a cyclone category (e.g., Schumacher and Johnson 2005), some distinguish warm fronts from cold fronts (e.g., Milrad et al. 2014), and some distinguish multiple types of storm patterns (e.g., Agel et al. 2017). 
Finally, we note that most of the studies considered here analyze LSMPs based on their occurrence at the same time as extreme precipitation and use physical arguments to interpret the potential causal nature of the relationship (e.g., based on the relationship between the LSMP and conditions favorable for heavy precipitation). Without additional testing on whether specific aspects of the LSMP are a necessary and/or sufficient condition for the occurrence of extreme precipitation, care must be taken to consider a causal interpretation of the relationship as plausible or hypothetical rather than definitive.

\section{Large-scale meteorological patterns for extreme precipitation and their attendant mechanisms}

The general conditions necessary for extremes are reviewed in Sect. 3.1, studies that separate extreme events into a range of categories are discussed in Sect. 3.2, studies that focus primarily on a single mechanism or storm type are discussed in Sects. 3.3-3.9, and an overall discussion is provided in Sect. 3.10. The consideration of general conditions provides context on how the dynamics of extreme precipitation can be related to large-scale circulations. Section 3.2 then surveys studies that consider multiple mechanisms or categories: these studies generally have either relatively broad definitions or focus on a limited geographic region or time period but provide critical context on the relative importance of different mechanisms. This is followed by a consideration of LSMP and LSMP-related mechanisms in terms of specific individual categories that have been emphasized in previous research: extratropical cyclones (Sect. 3.3), fronts (Sect. 3.4), the Maddox et al. (1979) frontal and mesohigh categories (Sect. 3.5), the Maddox et al. (1979) western category (Sect. 3.6), tropical cyclones (Sect. 3.7), atmospheric rivers (ARs) (Sect. 3.8), and orographic ascent-related events (Sect. 3.9). Finally, the overlapping relationships between the different categories and outstanding questions and gaps in our current understanding are discussed in Sect. 3.10.

\subsection{General conditions}

A dynamic-thermodynamic foundation is crucial context for a discussion of the LSMPs associated with extreme precipitation. Perhaps the most succinct means of articulating this foundation exists in a more detailed expression for the precipitation rate, $R$ (Gyakum 2008), with the assumption that $R$ is identical to the condensation rate, and that the precipitation efficiency, $E$, is one:

$R=-(1 / \mathrm{g}) \int \omega\left(\mathrm{dr}_{\mathrm{s}} / \mathrm{dp}\right)_{\mathrm{ma}} \mathrm{dp}$ where $\mathrm{g}$ is gravity, the vertical integral extends from 1000 to $200 \mathrm{hPa}, \omega$ is vertical velocity in pressure coordinates, $\mathrm{r}_{\mathrm{s}}$ is the saturation mixing ratio, and the subscript, ma, represents the appropriate moist adiabat. It is further assumed that vertical velocity vanishes at both the 1000 and $200 \mathrm{hPa}$ levels, and that saturated air parcels ascend moist adiabatically. Equation (1) has a simple form but the underlying processes that determine its solution are complex. First, analyses and forecasts of dynamically-driven ascent are notoriously difficult to replicate, as this ascent, particularly large in extreme events, is driven by a hierarchy of synoptic-scale and mesoscale features not always easy to analyze, predict, or even to understand. Second, the analysis and forecasting of the saturated air mass, indicated by the vertical variation of $r_{s}$ along a moist adiabat, is often difficult to predict. Generally, extreme precipitation events are associated with a combination of potent ascent and relatively warm, moist air masses, yet there also exists a balance between ascent that is strong enough to produce heavy precipitation but not so strong that most of the precipitation processes occur in the ice phase (e.g., Davis 2001; Hamada et al. 2015).

Furthermore, the resulting extreme precipitation rates often persist for extended time periods. Thus, the duration of extreme precipitation rates often plays a crucial role in producing an extreme precipitation event. Precipitation duration is a complicated function of the size, speed of motion, and organization of the precipitation system. For convective events, Corfidi et al. (1996) and Corfidi (2003) show that the motion of a precipitation system can be described as the sum of vectors representing the motion of individual cells and the propagation of those cells (i.e., where new cells form in relation to the previous ones).

Although Doswell et al. (1996) note that the importance of these ingredients - ascent, moisture, and duration-do not change from place to place, the ways in which they are brought together in the atmosphere do differ substantially across North America and the world. Given Eq. (1), it is not surprising that much of the research on the mechanisms responsible for extreme precipitation research focuses on factors relating to one or more of (1) ascent mechanisms, (2) the air mass, and (3) a persistent LSMP facilitating a lengthy duration of ascent in a relatively warm, moist air mass, with typically weak or neutral stratification. Understanding the ways that these atmospheric ingredients for extreme precipitation are typically combined within the context of a characteristic large-scale circulation is one of the primary subjects of this discussion.

\subsection{Range in LSMP types}

Several studies have attempted to characterize the range of LSMPs or LSMP-related processes important for precipitation extremes in different sub-regions of North America. 
These studies provide useful context on the relative importance of the different LSMPs for the studies in the next section, which focus on individual LSMP types.

These multiple-LSMP studies have focused on several different geographic regions within North America: Maddox et al. (1979) and Kunkel et al. (2012) considered the coterminous US, while Bradley and Smith (1994) considered the southern plains; LaPenta et al. (1995), the NWS Eastern Region; Keim (1996), the southeastern US; Schumacher and Johnson (2005), the eastern US; Milrad et al. (2010a, b), St. John's, Newfoundland; Milrad et al. (2014), Montreal, Canada; Moore et al. (2015), the southeastern US; and Collow et al. (2016) and Agel et al. (2017, 2019), the northeastern US. The results are somewhat difficult to directly compare, due not only to the different geographic regions, but also to considerable differences in the definition used to identify extreme precipitation events, the period considered, and the methodology used. In fact, no two of the studies share the same definition of extreme. (The extreme definitions for these studies are available in Table 2.) We note that Maddox et al. (1979) was the first study to make a systematic analysis of mechanisms relating to extreme precipitation for a broad area within North America, and subsequent studies frequently refer to their results as a benchmark.

Despite the differences among the studies, several commonalities can be identified. Synoptic/frontal events were the leading mechanisms for each of these studies, with the exception of Schumacher and Johnson (2005), which identified Mesoscale Convective Systems (MCS; Houze 2004) as the leading factor based on events defined as exceeding the 50-year recurrence interval in the US midwest. How synoptic storm influence was distinguished from frontal influence varied considerably among the studies, and is discussed further in Sects. 3.3 and 3.4. In addition to synoptic/ frontal and MCS, the other identified classifications in these studies were: tropical cyclone, airmass convection, upslope flow, North American Monsoon, Maddox et al. "mesohigh", and Maddox et al. "western". The Maddox et al. mesohigh category was comprised of events associated with a thunderstorm outflow boundary, with the heaviest rains at the boundary of a meso-scale surface high pressure circulation, while the western category was primarily defined geographically (roughly, events occurring west of $104^{\circ} \mathrm{W}$ ), although most of the events could be categorized as occurring within relatively weak large-scale patterns. The relative importance of the different classifications and the method of separation varied considerably between the studies, but synoptic/frontal, MCS, and tropical cyclones were identified as important in the majority of the studies.

GEV distributions fitted to extreme precipitation can also reveal information about the range of LSMPs linked to the extreme events. The automated test of Panorska et al. (2007) and Kozubowski et al. (2009) applied to precipitation observed at hundreds of meteorological stations allowed for examination of geographic patterns in heavy vs. light tail behavior of precipitation extremes. The result is that the vast majority of North American stations experience heavy tailed extremes and that the most volatile precipitation (associated with the heaviest tails) occurs in regions with a great diversity of precipitation-producing meteorological systems. On the other hand, light tails are observed at locations where precipitation is produced by predominantly one type of storm system, e.g., midlatitude cyclones with orographic uplift on the west slopes of the Sierra Nevada, or convective cells over the Mexican Plateau.

In addition to the expected importance of region and season which can be seen in the two coterminous US studies (Maddox et al. 1979; Kunkel et al. 2012), there is a clear sensitivity of the results to the definition of extreme, although this has not yet been addressed in much detail. The least restrictive definition in this group of studies considers the top $1 \%$ of 24 -h precipitation values and the most restrictive considers the 50 -year return period for 24-h precipitation (or approximately the top $0.0055 \%$ of values), so there is a very large difference in the types of events being considered.

Most of these studies have focused on analyzing the LSMPs occurring contemporaneously with extreme precipitation, with less emphasis on testing the causal nature of the identified relationships. As one approach to addressing this, Agel et al. (2019) compared the strength of different factors within the same LSMP between days with extreme precipitation and days without extreme precipitation for the Northeast US, with the largest difference occurring in integrated moisture transport, low-level moisture convergence, occurrence of warm conveyor belts, and quasi-geostrophic forcing, with the relative importance varying between patterns.

Among the wide variety of approaches in these studies, a few clear themes can be identified: (1) fronts and synoptic storms are important factors in many extreme events, although the extreme precipitation is usually realized through mesoscale processes organized, enhanced, or triggered by the larger-scale circulation; (2) the same general category (e.g., synoptic storms) can have both important regional differences as well as multiple sub-types, with significant differences in the associated dynamical mechanisms; and (3) most of the studies naturally focused only on the occurrence of extreme events, so it is not clear how the identified features potentially relate to non-extreme events; that is, to what degree the identified features are necessary and/ or sufficient conditions for extremes. While these studies considered the role of factors directly relevant to LSMPs, not all of the studies analyzed the patterns themselves, which is an opportunity for further research. 


\subsection{Extratropical cyclones}

The relationship of extratropical cyclones to extreme precipitation has been considered both as part of several of the general studies discussed in the previous section (Maddox et al. 1979; Kunkel et al. 2012; Moore et al. 2015; Bradley and Smith 1994; Schumacher and Johnson 2005; Agel et al. 2017; LaPenta et al. 1995; Milrad et al. 2010a, b, 2014), as well as a global study focusing solely on them as a single mechanism (Pfahl and Wernli 2012). Sometimes they are also implicitly considered as part of a frontal category (e.g., Keim 1996), although here we consider fronts separately in the following section. Often, they are considered as a single category (Maddox et al. 1979; Kunkel et al. 2012; Schumacher and Johnson 2005; LaPenta et al. 1995) but studies that have examined variations of structure and mechanism within the general category of extratropical cyclone have shown important differences of structure within this category (Milrad et al. 2010a, b, 2014; Agel et al. 2017); that is, multiple distinct types of extratropical cyclones.

Pfahl and Wernli (2012) examined the global relationship between extratropical cyclones and extreme precipitation, using ERA-interim reanalysis data from 1989 to 2009 on a $1.0^{\circ} \times 1.0^{\circ}$ grid for both precipitation and circulation. Precipitation extremes were defined as the top $1 \%$ of 6 -h accumulated prognostic precipitation and an automated objective approach was used to identify cyclones based on sea level pressure. A cyclone area was defined based on the outermost closed sea level pressure (SLP) contour that encloses one or more SLP minima and any extreme precipitation event that occurred within that area was counted. Over North America, there was a large difference in the relationship, with less than $10 \%$ of precipitation extremes linked with cyclones in the southwestern part and more than $80 \%$ linked in the northeast part of the region. In the areas where extreme precipitation was most closely associated with the cyclones, however, stronger storms (as measured by minimum sea level pressure) were not associated with more extreme precipitation than weaker storms. That is, while the presence of a storm was important, the storm strength did not provide additional information about the likelihood of precipitation extremes.

The Maddox et al. (1979) "synoptic" type event (Fig. 4; Peters and Schumacher 2014) was developed based on events in different parts of the country and results in other studies often are characterized as similar to this pattern (e.g., Bradley and Smith 1994; Moore et al. 2015), so we use it as one of our baselines here. In this pattern, the extreme precipitation occurs to the east of an amplified upper-level trough, such that there is strong southerly flow at low levels, which is responsible for the poleward transport of warm, moist air, along with a southerly component to the midand upper-tropospheric winds that facilitates the repeated passage of convective systems over the same area (Peters and Schumacher 2014). Although these events can occur throughout the year, they are most common in the spring and autumn when amplified troughs frequently traverse the US. A prominent example occurred in Tennessee and Kentucky in May 2010 with deadly and destructive flash flooding in Nashville, Tennessee (e.g., Moore et al. 2012; Durkee et al. 2012; Lackmann 2013; Lynch and Schumacher 2014). Moore et al. (2012) showed that the extreme rainfall in this case occurred in association with poleward transport of deep tropical moisture ahead of an upper-tropospheric trough, and that two long-lived MCSs over a 2-day period embedded within this synoptic pattern were responsible for the bulk of the rainfall (Fig. 5). These findings emphasize that even within the favorable synoptic-scale environment, mesoscale processes help to determine the precise location and distribution of the precipitation. In addition, several dynamicallyoriented analyses emphasize the perspectives of strength of dynamic forcing (Fig. 6; Bradley and Smith 1994), strength of water vapor transport (Fig. 7; Moore et al. 2015), quasigeostrophic analysis (Fig. 8; Milrad et al. 2014), and the relationship between the dynamic tropopause (Agel et al. 2017) and multiple precipitation factors (Fig. 9; Agel et al. 2019).

Finally, we note that these studies highlight the range of circulation patterns and associated mechanisms that occur within the overall category of extratropical cyclones, both between regions and between different storm types for the same region (cf. Figs. 4, 5, 6, 7, 8, 9).

\subsection{Fronts}

As with extratropical cyclones, fronts have also been considered as a category within the general studies of Sect. 3.2, as well as the subject of individual focus for a global study (Catto and Pfahl 2013). A distinction has not always been made between fronts where the parent cyclone is nearby and fronts where the parent cyclone is far from the extreme precipitation.

Catto and Pfahl (2013) examined the global link between fronts and extreme precipitation, based on 6-h ERAInterim reanalysis data for $1979-2011$, on a $2.5^{\circ} \times 2.5^{\circ}$ grid. Extreme precipitation was defined as the 99th percentile of the 6-h accumulated precipitation, and fronts were identified based on an objective approach and analyzed in terms of cold fronts, warm fronts, quasi-stationary fronts, and all fronts. The extreme precipitation was considered to be associated with a front if occurring within the same or adjacent $2.5^{\circ} \times 2.5^{\circ}$ gridbox. Over North America, a strong longitudinal variation was observed, with more than $70 \%$ of extreme precipitation events linked to fronts on the eastern side of the continent, and fewer than $50 \%$ of extreme precipitation events linked to fronts on the western side. In terms of front type, warm fronts were the most important, 

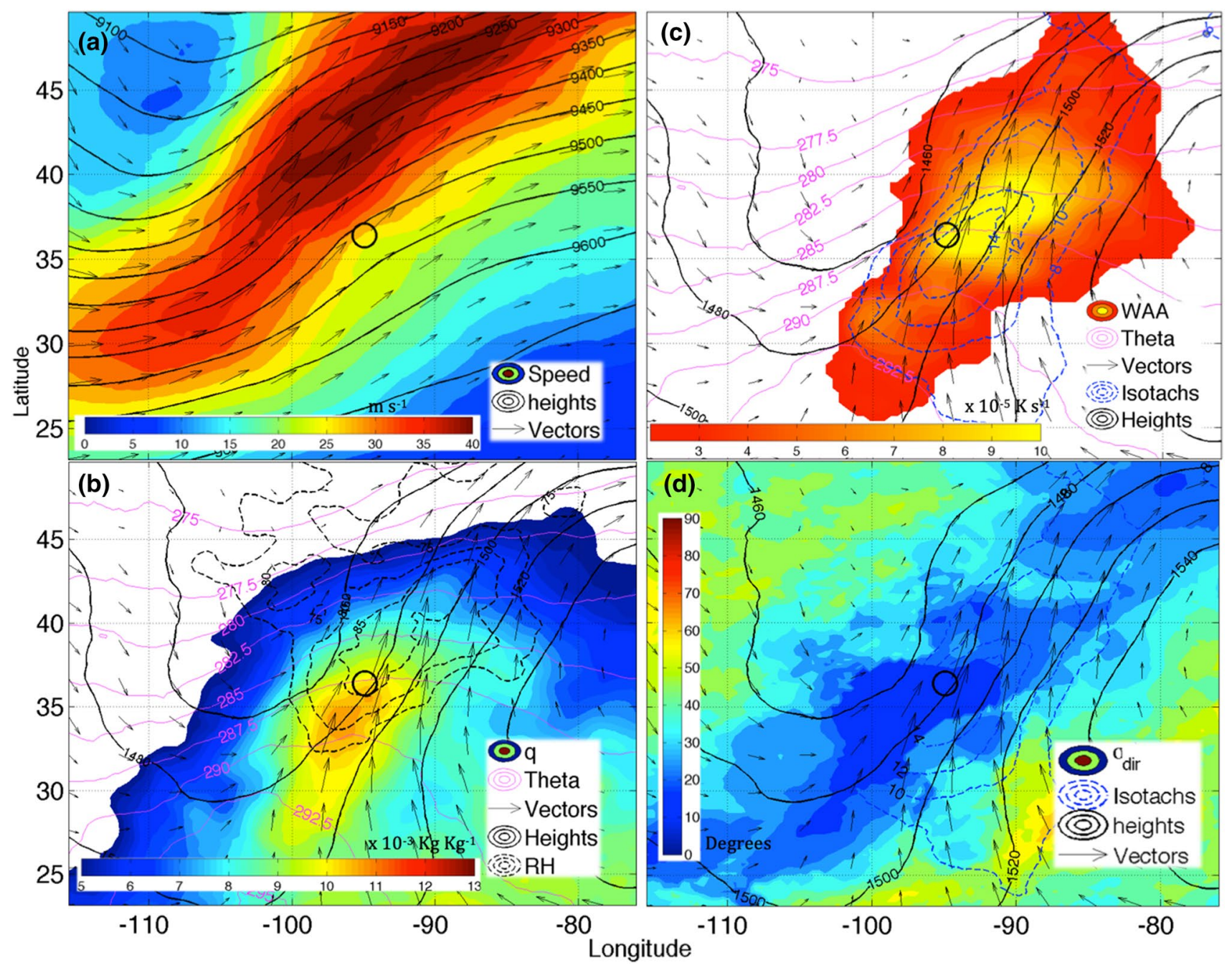

Fig. 4 Event-centered composites of 24 synoptic-type heavy-rainproducing convective systems. a 300-hPa wind speed ( $\mathrm{m} \mathrm{s}^{-1}$, shading), wind vectors (arrows), and geopotential height (black lines at intervals of $50 \mathrm{~m})$. b $850-\mathrm{hPa}$ potential temperature advection $(\times$ $10^{-5} \mathrm{~K} \mathrm{~s}^{-1}$, shading; values below $2 \times 10^{-5} \mathrm{~K} \mathrm{~s}^{-1}$ have been removed; derivatives were computed from composite atmospheric fields), wind speed (blue dashed contours at intervals of $2 \mathrm{~m} \mathrm{~s}^{-1}$, starting at $8 \mathrm{~m} \mathrm{~s}^{-1}$ ), wind vectors (black arrows), geopotential height (black lines at intervals of $20 \mathrm{~m}$ ), and potential temperature (K, magenta contours). c 850-hPa mixing ratio (shading, $\times 10^{-3} \mathrm{~kg} \mathrm{~kg}^{-1}$ ), relative humidity (\%, black dashed contours at intervals of 5\% starting

followed by cold fronts, and then quasi-stationary fronts. In addition to considering the fraction of extremes related to fronts, they also considered the fraction of fronts that resulted in extreme precipitation, and found that only about $5-10 \%$ of fronts resulted in an extreme event. For much of eastern North America, most extreme precipitation occurs in association with a front, but the large majority of fronts occur without extreme precipitation. They did find that front strength is related to an increased occurrence of extremes, in contrast to storm strength which, as mentioned above, has at $75 \%$ ), wind vectors (black arrows), geopotential height (black lines at intervals of $20 \mathrm{~m}$ ), and potential temperature ( $\mathrm{K}$, magenta contours). d Standard deviation of $850-\mathrm{hPa}$ wind direction (shading), geopotential height (solid black contours, $\mathrm{m}$, at intervals of $40 \mathrm{~m}$ ), wind vectors (black arrows), and wind speed (blue dotted contours, $\mathrm{m} \mathrm{s}^{-1}$ starting at $8 \mathrm{~m} \mathrm{~s}^{-1}$ and at intervals of $2 \mathrm{~m} \mathrm{~s}^{-1}$ ). A black circle at the center of each frame indicates the point location of maximum 1-h rainfall accumulation. The specific latitudes and longitudes shown are arbitrarily selected to illustrate the spatial scale. Adapted from Peters and Schumacher (2014)

not been shown to have a clear association with the occurrence of extremes, at least when storm strength is measured in terms of SLP. Finally, they distinguished between the occurrence of fronts combined with cyclones, fronts alone, and cyclones alone. The combined cases were most closely linked to extremes, followed by front-only, with cycloneonly having a notably weaker relationship than the other two, although the patterns over North America were more complicated in this part of the relationship. The combined case was defined as when fronts occurred within the closed SLP 


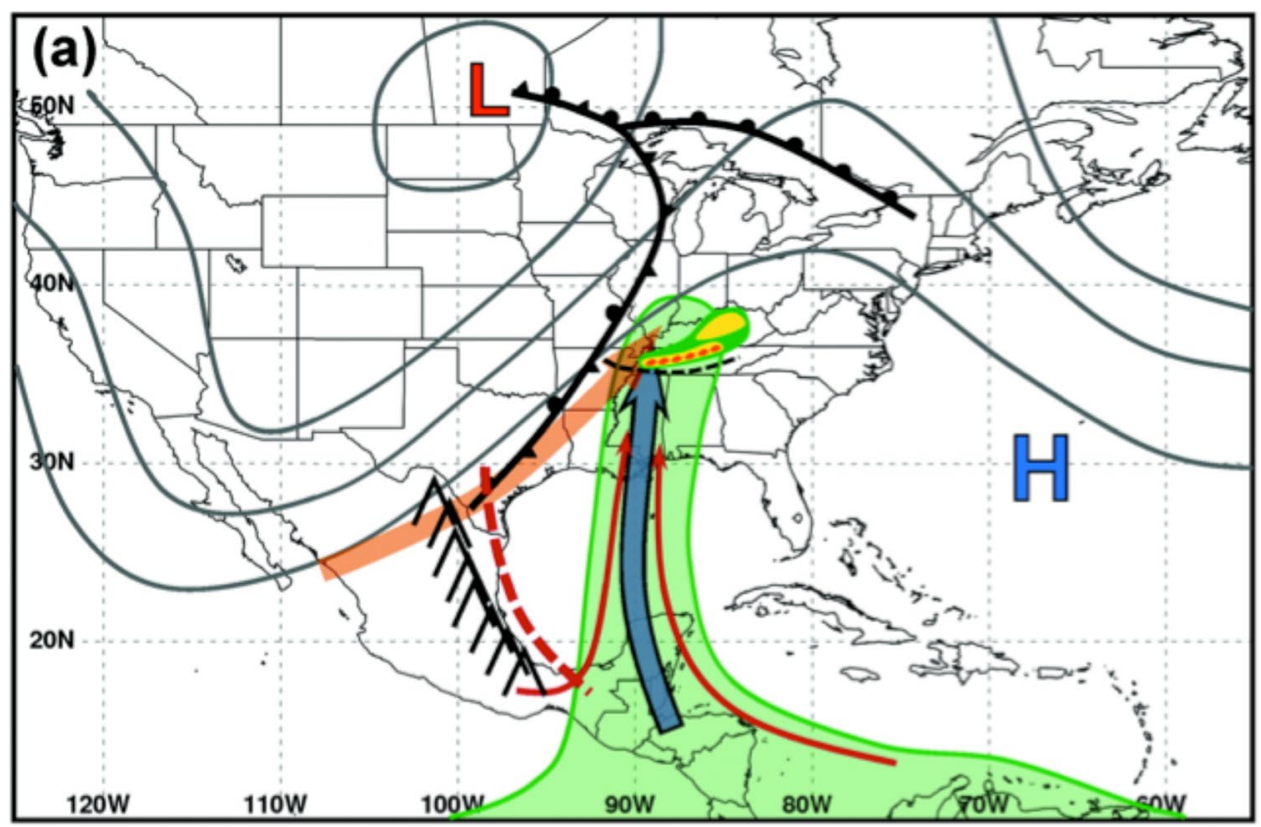

Fig. 5 Schematic illustrations of the key features and processes for the MCS on 1 May 2010, which is a representative example of a portion of a Maddox et al. (1979) "synoptic" type flash flood. The gray contours denote the $250-\mathrm{hPa}$ geopotential height distribution. The red arrows represent $850-\mathrm{hPa}$ streamlines. The positions of the surface fronts are shown in standard frontal notation, while the positions of the maxima and minima in 850-hPa geopotential height are marked by the " $\mathrm{H}$ " and the "L" symbols, respectively. The axis of the $850-\mathrm{hPa}$ lee trough is denoted by the dashed red line. The light green shad-

contours associated with a low pressure and were located relatively close to the center of a storm. They verified that, as expected, most of the "front-only" cases do have a cyclone at some point along the front.

Fronts are closely related to two other phenomena that are linked to the occurrence of extreme precipitation. ARs, whose impact on extreme precipitation is discussed further in Sect. 3.9, develop in close association with cold fronts (e.g., Dacre et al. 2015). Warm Conveyor Belts (WCBs) also develop in close association with fronts, and fronts with WCBs are, on average, 2-10 times more likely to result in extreme precipitation than fronts without a WCB (Catto et al. 2015).

In summary, fronts are an important factor for the occurrence of extreme precipitation in North America, especially in the eastern part of the continent, both in local association with a cyclone center and when remote from the parent cyclone. The strength of the front is important to the occurrence of an extreme, as are some closely associated mechanisms, such as warm conveyor belts and mesoscale mechanisms discussed in the multiple mechanism studies of Sect. 3.2. While the spatial scale and dynamics underlying fronts makes them relevant to understanding LSMPs, most studies to date have considered the average relationship ing outlines the regions with IWV values $>45 \mathrm{~mm}$. The thick orange arrows represent the stream of dry midlevel air, while the thick blue arrows represent the AR. The " $\wedge$ " symbols mark the location of the Sierra Madre Oriental Mountains. The dashed black lines mark the positions of the convectively generated outflow boundaries, and the dark green, gold, and orange shaded regions over TN and KY represent radar reflectivity thresholds of 20,35 , and $50 \mathrm{dBZ}$, respectively. Figure from Moore et al. (2012)

to fronts rather than the actual structure of the associated LSMPs. One of the exceptions is the analysis of Maddox et al. (1979) study considered in the next section, which identified a specific frontal category.

\subsection{Maddox frontal and mesohigh}

Maddox et al. (1979) identified "frontal" and "mesohigh" types of flash floods, which share a number of common characteristics. They found that flash floods occur most frequently in the warm season near the axis of a mid- to uppertropospheric ridge, rather than a mid-level trough that is the most common mid-level feature for mid-latitude precipitation. In "frontal" events (Fig. 10; Peters and Schumacher 2014), the heavy rain typically falls on the cool side of a west-east-oriented baroclinic zone, whereas in the "mesohigh" cases the rain falls on the cool side of an outflow boundary left behind by a previous convective system or systems. In both cases, a southerly or southwesterly low-level jet (LLJ) intersects the boundary such that there is focused ascent of warm, moist air on the cool side of the boundary. Furthermore, there is veering of the winds with height associated with this warm advection, which supports convective cells moving parallel to the boundary and resulting in 
(a)

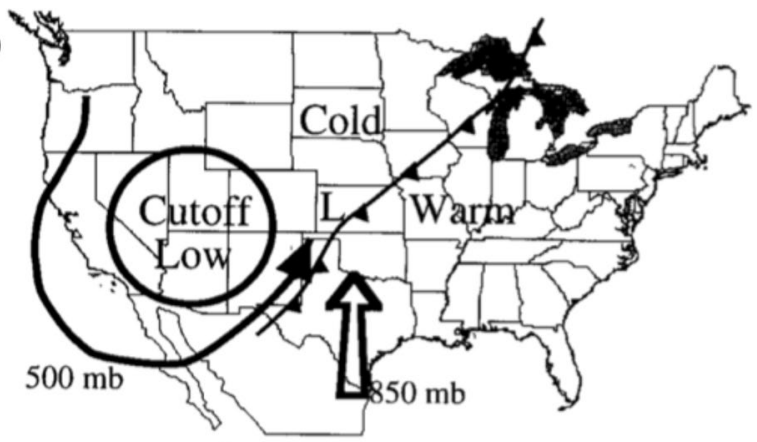

FIG. 6. Schematic showing the key features of strong dynamic forcing extreme rainstorms.

(b)

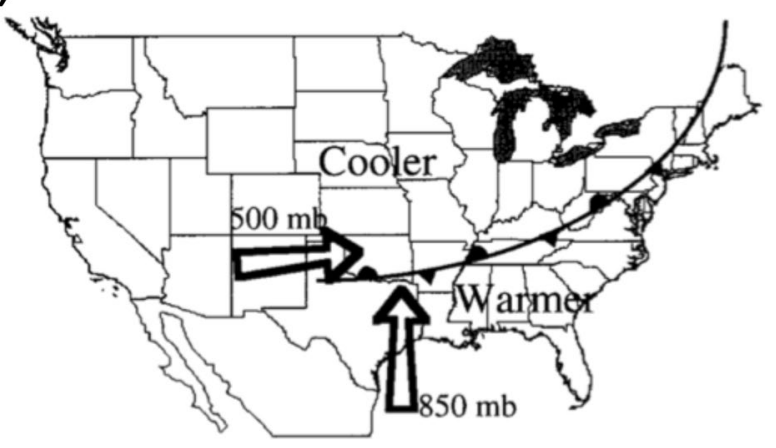

Fig. 6 Schematics of the key features of storms producing extreme precipitation in the southern plains with a strong dynamic forcing, and $\mathbf{b}$ weak dynamic forcing. Figure from Bradley and Smith (1994)

so-called "echo training": the repeated passage of convective cells over a particular geographic area.

Studies by Chappell (1986), McAnelly and Cotton (1989), Junker et al. (1999), Laing and Fritsch (2000), Sanders (2000), Moore et al. (2003), Schumacher and Johnson $(2005,2006)$ and Peters and Schumacher (2014), among others, explored the initiation, development, organization, and maintenance of the MCSs associated with the frontal and mesohigh patterns. Schumacher and Johnson (2005) showed that in the frontal pattern, a linear MCS typically forms on the cool side of a warm or stationary front and then moves parallel to that front (Fig. 11a), whereas in the mesohigh pattern a cluster of convection develops on the cool side of the outflow boundary and new cells repeatedly develop upstream (Fig. 11b).

The patterns described by Maddox et al. (1979) and refined by others are favorable for extreme precipitation because they bring together the ingredients for both high rain rates and long rainfall durations. They tend to be associated with tropospheric water vapor values that are $2+$ standard deviations above normal (e.g., Hart and Grumm 2001; Bodner et al. 2011); with anomalous moisture that is often transported poleward by a low-level jet (e.g., Dirmeyer and Kinter 2009).
In addition to the synoptic and mesoscale patterns identified by Maddox et al. (1979), another process in the central US that is less common but also associated with extreme rain events is the mesoscale convective vortex (MCV). Bosart and Sanders (1981), Zhang and Fritsch (1987), Fritsch et al. (1994), Davis and Trier (2002), Nielsen-Gammon et al. (2005), Schumacher and Johnson (2008), and Schumacher et al. (2013) all described extreme rainfall events in association with MCVs or similar slow-moving circulations. In particular, when a nocturnal LLJ transports warm, moist air that is lifted at the periphery of the MCV circulation, ascent can be focused and sustained near the MCV center and a nearly stationary, heavily raining MCS can occur. In rare cases, this process can even occur repeatedly over multiple diurnal cycles resulting in a series of extreme rainfall events (e.g., Fritsch et al. 1994; Schumacher et al. 2013).

The results of these in-depth analyses for the Maddox frontal and "mesohigh" categories highlight the importance of mesoscale processes as the mechanisms that actually produce the extreme precipitation within the favorable, triggering environment of the LSMP.

\subsection{Maddox Western}

Maddox et al. (1980) examined 61 flash flood events over the western US, identified from the NOAA Storm Data reports for the 1973-1978 period. In contrast to Maddox et al. (1979), which categorized events based on surface data, this study categorized events based on $500 \mathrm{hPa}$ data, due to the challenges with surface analysis in the western domain. Four characteristic types of events were identified, with strong geographic and seasonal dependence, and differences in amount and daily timing relative to events in the eastern US. Weak, slow-moving, mid-level, short-wave troughs triggered the precipitation in three of the four types, in an environment of high moisture and instability, while the other type featured a strong mid-level trough and intense cyclonic surface system, and was associated with what was later understood to be the pattern supporting a landfalling atmospheric river (discussed further in Sect. 3.9). The relationship of the slow-moving trough categories to the western categories of Kunkel et al. (2012) is not yet clear.

\subsection{Tropical cyclones}

Tropical cyclones (TC) and their extratropical transitions (ET) are particularly efficient mechanisms to transport warm, high-moisture subtropical air masses poleward. Corbosiero et al. (2009) examined the role of eastern North Pacific tropical cyclones as important contributors to the rainfall climatology of the southwest US. Bosart and Carr (1978), Carr and Bosart (1978) and Bosart and Dean (1991) discussed the heavy rainfall distributions associated with 
Strong IVT

(a) 250-hPa Z (dam), wind speed ( $\mathrm{m} \mathrm{s}^{-1}$ ), hourly precip (mm)

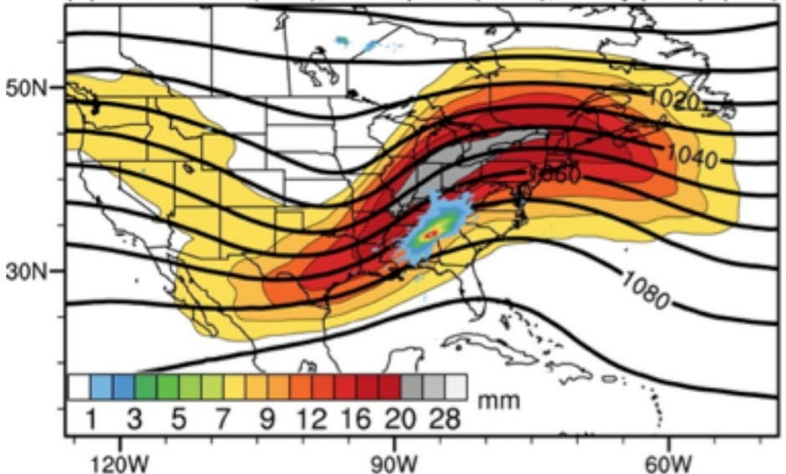

(c) PMSL (hPa), 1000-500-hPa $\Delta Z$ (dam), 925-hPa V $\left(\mathrm{m} \mathrm{s}^{-1}\right.$ )

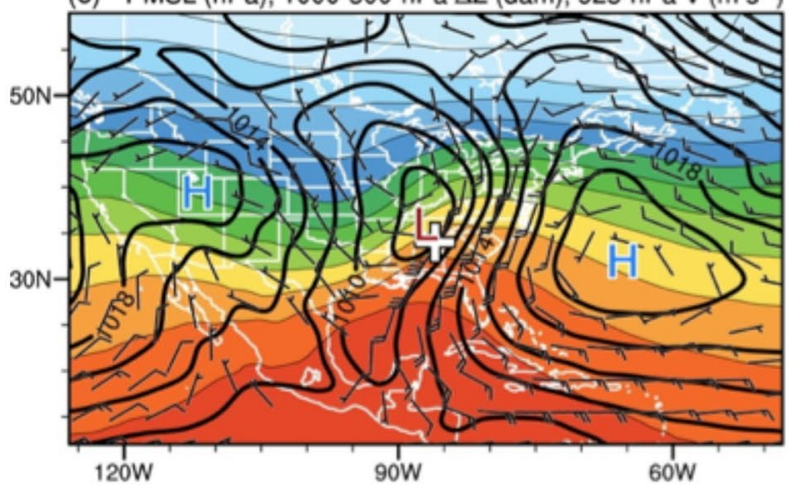

(e)

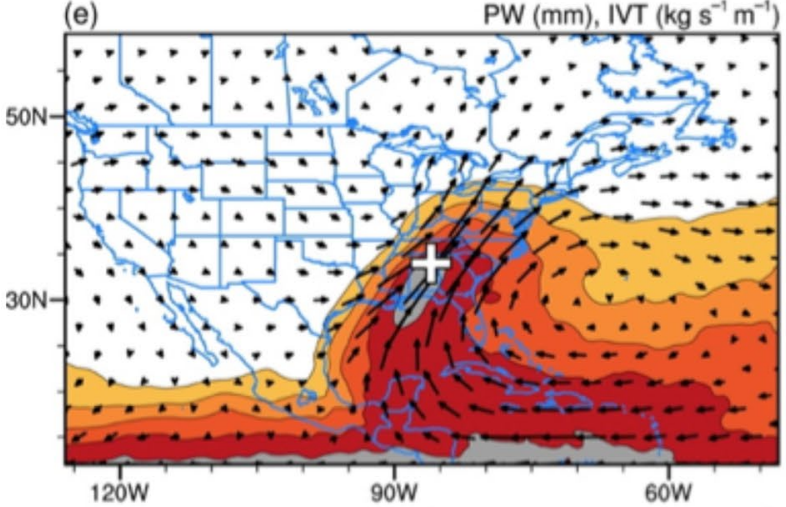

(g)

CAPE $\left(\mathrm{J} \mathrm{kg}^{-1}\right), 1000-500-\mathrm{hPa}$ shear $\left(\mathrm{m} \mathrm{s}^{-1}\right)$

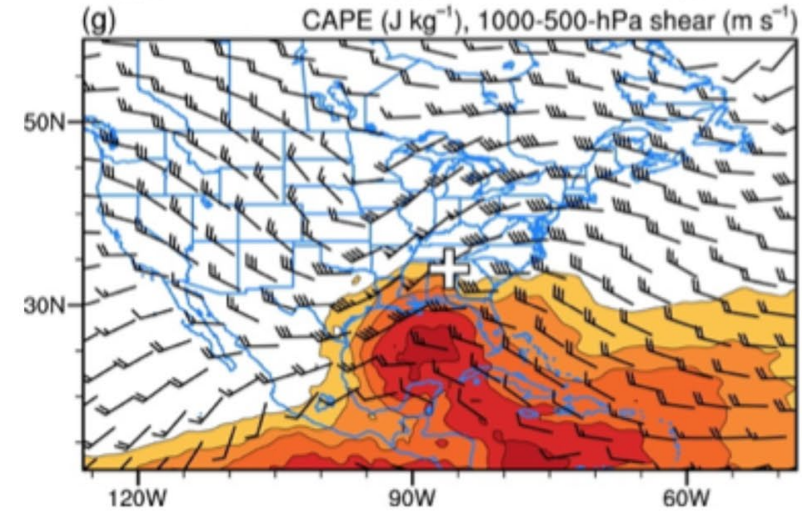

Hurricane Agnes (1972) that impacted the eastern US. More recently, Archambault et al. (2013) explored the impacts of recurving extratropically transitioning North Pacific
Weak IVT

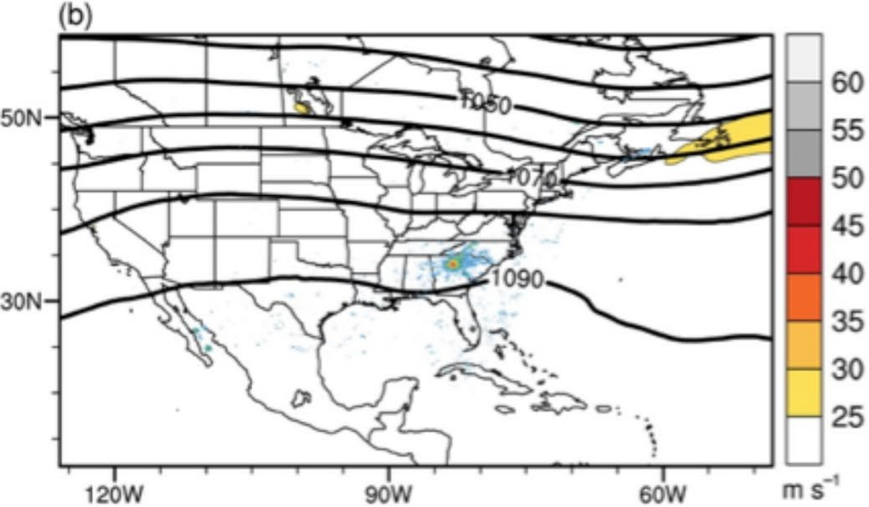

(d)
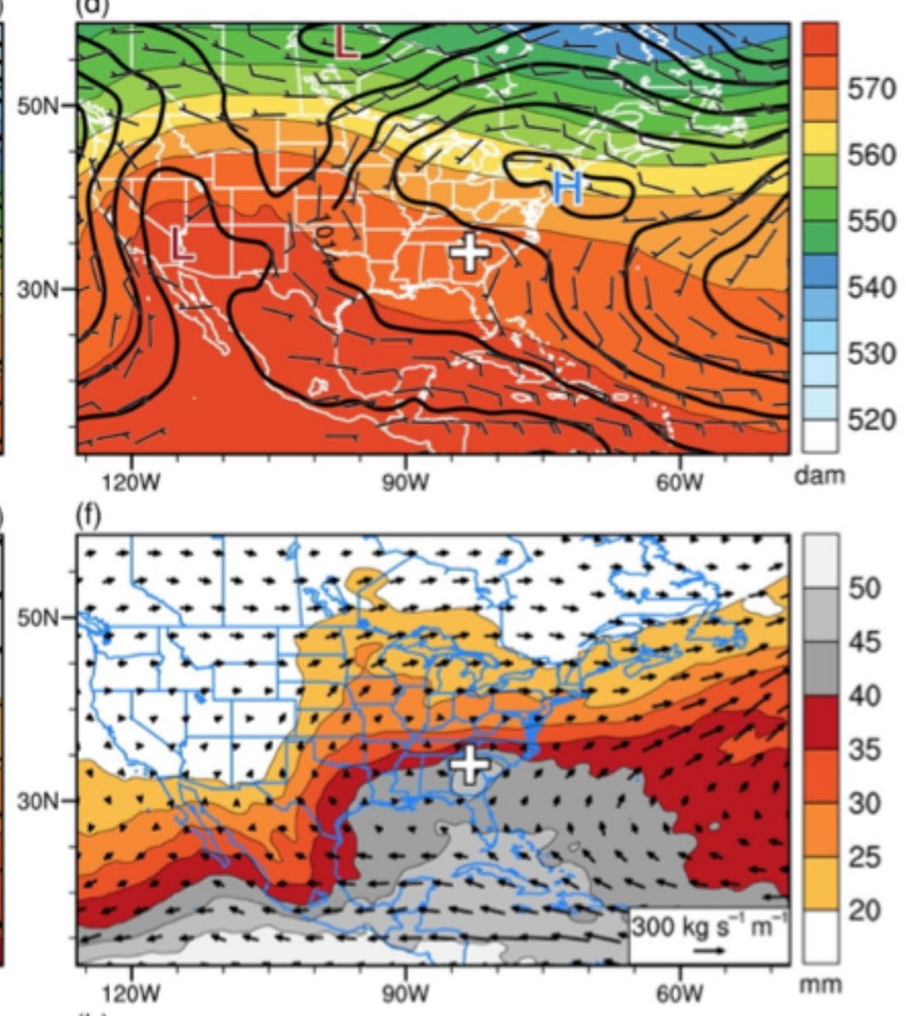

(h)

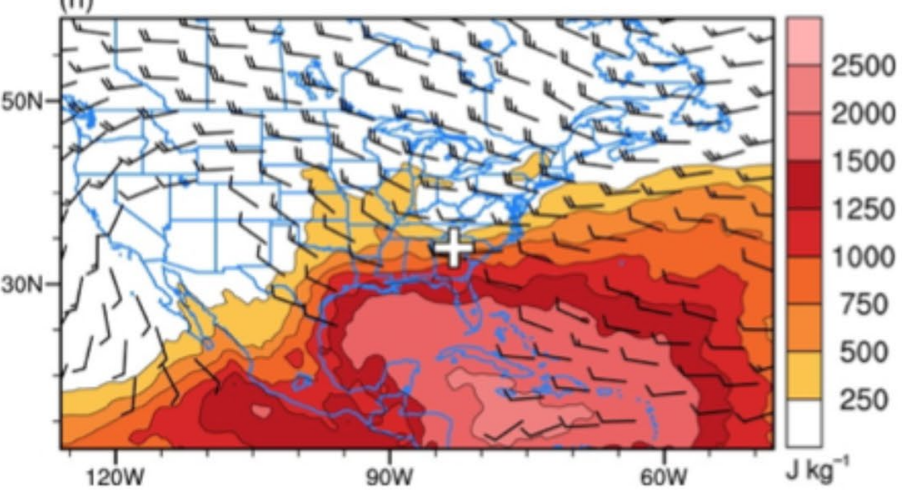

typhoons in producing extreme weather events downstream over North America. Barlow (2011) examined the influence of tropical cyclones on extreme precipitation for all of North 
4Fig. 7 Composites for the (left) top 50 (strong IVT) and (right) bottom 50 (weak IVT) nontropical EPEs with respect to IVT magnitude showing: a, b 250-hPa geopotential height (contoured in black every $10 \mathrm{dam}$ ), wind speed (shaded in $\mathrm{m} \mathrm{s}^{-1}$ according to the color bar), and stage-IV hourly precipitation (shaded in $\mathrm{mm}$ according to the inset color bar in a); c, d SLP (contoured in black every $2 \mathrm{hPa}$; minima and maxima denoted by the "L" and "H" symbols), 1000-500$\mathrm{hPa}$ thickness (shaded in dam according to the color bar), and 925$\mathrm{hPa}$ wind (plotted for wind speed $\geq 2.5 \mathrm{~m} \mathrm{~s}^{-1}$; half barb: $2.5 \mathrm{~m} \mathrm{~s}^{-1}$; full barb: $5 \mathrm{~m} \mathrm{~s}^{-1}$; pennant $25 \mathrm{~m} \mathrm{~s}^{-1}$ ); e, f PW (shaded in $\mathrm{mm}$ according to the color bar) and IVT vectors $\left(\mathrm{kg} \mathrm{m}^{-1} \mathrm{~s}^{-1}\right.$; reference vector in bottom right of $\mathbf{f}$ ); and $\mathbf{g}, \mathbf{h}$ surface-based CAPE (shaded in $\mathrm{J} \mathrm{kg}^{-1}$ according to the color bar) and $1000-500-\mathrm{hPa}$ wind shear (plotted for shear magnitude $\geq 5 \mathrm{~m} \mathrm{~s}^{-1}$; same barb convention as in $\mathbf{c}, \mathbf{d}$ ). The plus symbol in $\mathbf{c}-\mathbf{h}$ marks the location of the EPE. From Moore et al. (2015)

America south of $55 \mathrm{~N}$, showing some influence over much of the domain and a large influence in several coastal areas, with the largest influence observed when a fixed definition of extreme was used (at least 4 in. of precipitation in 24-h).

The motion of tropical cyclones generally has more of an influence on rainfall production than the intensity of the cyclone itself, such that even very weak tropical cyclones that move slowly may trigger extreme rains. This was the case for Tropical Storm Marco (1990), in which more than $300 \mathrm{~mm}$ of rain fell in 2 days (Srock and Bosart 2009); Hurricane Mitch (1998) that led to devastating flooding in Mexico and Central America; Tropical Storm Allison (2001) and Hurricane Harvey (2017), which set new national records for extreme precipitation in the US with over 50" (1270 mm) of rain over portions of the Texas and Louisiana Gulf Coast (Blake and Zelinsky 2018; see therein for a comparison of the rainfall from Allison and Harvey). Hurricane Floyd (1999), with its extreme rains along the US east coast, proved to be a particularly difficult forecast challenge (Atallah and Bosart 2003; Atallah et al. 2007). Barlow (2011) considered the relationship to extreme precipitation in terms of different subsets of tropical cyclones: those that had undergone extratropical transition, those with high maximum wind speed (greater than $50 \mathrm{kt}$ ) based on the track data, and those with strong large-scale rising motion (pressure vertical velocity less than $0.2 \mathrm{~Pa} \mathrm{~s}^{-1}$ ) as resolved in the $2.5^{\circ} \times 2.5^{\circ}$ gridded NCEP/NCAR Reanalysis 1 data. All three factors were important, with large-scale vertical velocity showing the closest association with the occurrence of extreme precipitation.

Often, in association with TCs, extreme rains are located at considerable distances from the cyclone circulation center. The rainfall rate and duration in these situations can be enhanced even further when there is a direct supply of moisture from the tropics, such as ahead of a recurving tropical cyclone in what has been termed a "predecessor rain event" (PRE, e.g., Galarneau et al. 2010; Schumacher et al. 2011; Schumacher and Galarneau 2012; Moore et al.
2013), or in an inland AR (e.g., Moore et al. 2012; Lavers and Villarini 2013). Subsequent case studies (Schumacher et al. 2011; Bosart et al. 2008) and composite studies (Moore et al. 2013) have confirmed the importance of juxtaposed moist, weakly stable tropical air in the presence of synopticscale ascent forcing as being crucial processes associated with such extreme rains.

Composite dynamic-thermodynamic LSMPs for PREs, associated with 38 Atlantic Basin TCs, are given by Moore et al. (2013). The authors found that the synoptic-scale environments associated with these PREs form at a median distance of approximately $1000 \mathrm{~km}$ from the TC center, and in a region characterized by a very moist, subtropical air mass that ascends in a frontal zone located in the equatorward entrance region of an upper-tropospheric jet streak. As a result of the authors' detailed dynamic-synoptic analyses, a conceptual model comprised of the details of the LSMPs are shown in Fig. 12 for three categories: "Jet in Ridge" (JR), "Southwesterly Jet" (SJ), and "Downstream Confluence" (DC). 55 PREs were identified in the 1988-2010 period, with 25 categorized as SJ events, 17 as DC events, 8 as JR events, and 5 unclassified. Each of the three categories shares the same characteristic of a warm, moist air mass being forcibly lifted in a favorably configured synopticscale environment, as suggested by Eq. (1). Median values of rainfall range from $80 \mathrm{~mm}$ in the SJ composite, $100 \mathrm{~mm}$ in the DC composite, to $200 \mathrm{~mm}$ in the JR composite. The TC plays a particularly crucial role in the PRE's extreme rain production, through its poleward transport of maritime subtropical air into a synoptic-scale environment conducive to ascent.

In summary, in addition to the well-known direct influence of tropical cyclones on extreme precipitation, TCs can also interact with the large-scale flow to form the PRE LSMP, as well as have an important influence after transitioning to an extratropical cyclone. How LSMPs may be connected to the vertical velocity relationship shown in Barlow (2011) remains to be explored.

\subsection{Orographic ascent-related}

Especially in the high terrain of the western US, the flow of moist air up sloped terrain is an important factor in the generation of extreme precipitation. Orographic ascent, therefore, provides a mechanism for LSMPs because of the spatially-fixed nature of the favorable orientation for regional-scale circulations relative to local orography. In the warm season, moist upslope flow has been responsible for several of the most devastating flash floods in US history, although the spatial extent of the extreme precipitation in these events is often very limited. For example, the Rapid City, South Dakota flash flood of 1972, the Big Thompson flood in Colorado in 1976 (see Maddox et al. 1978 for a 
Fig. 8 At the time of heaviest precipitation at Montreal, Quebec (black star), NCEP Reanalysis-2 1000-500 hPa layer-averaged $\mathrm{Q}_{\mathrm{S}}(\mathrm{left})$ and $\mathrm{Q}_{\mathrm{n}}$ divergence (right) $\left(\times 10^{-17}\right.$ $\mathrm{K} \mathrm{m}^{-2} \mathrm{~s}^{-1}$, shaded cool colors for convergence), MSLP (hPa, solid contours), and 1000-500 hPa thickness (dam, dashed contours) for a sample event of a, b Type A (cyclone, 0600 UTC 6 October 1995), c, d Type B (warm front, 1200 UTC 1 November 1994), e, f Type C (cold front, 1800 UTC 8 November 1996), and $\mathbf{g}$, h Type D (convective, 0000 UTC 31 July 2004). From Milrad et al. (2014)
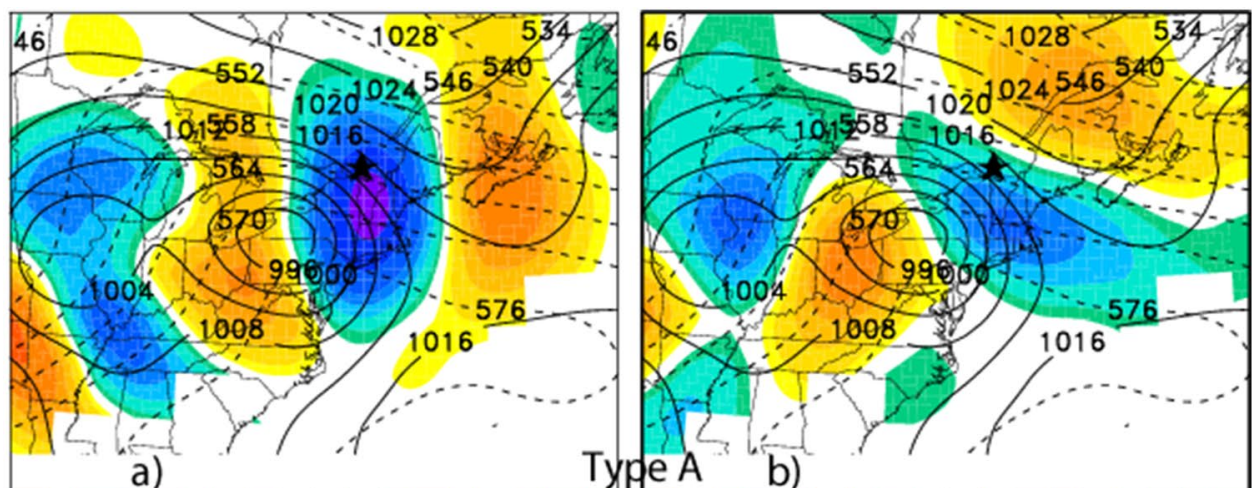

$\begin{array}{lllllllll}-200 & -120 & -60 & -20 & 0 & 20 & 60 & 120 & 200\end{array}$

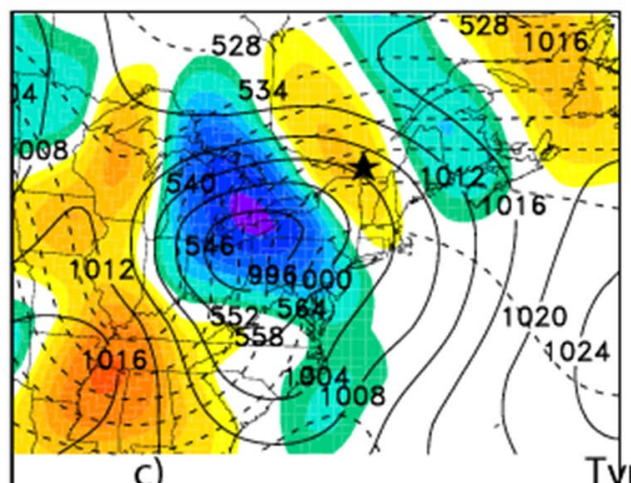

c)

Type B
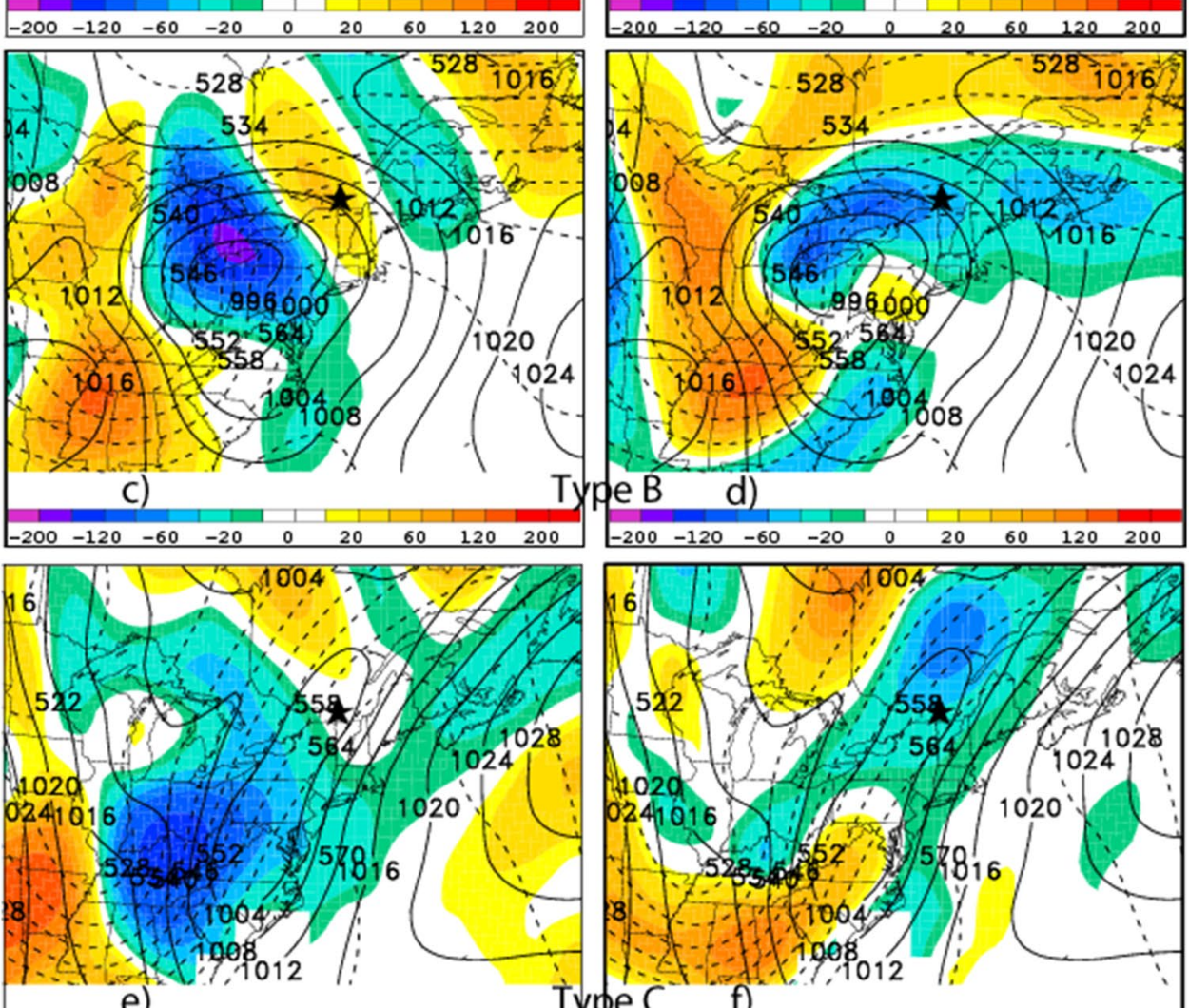

e)

Type C

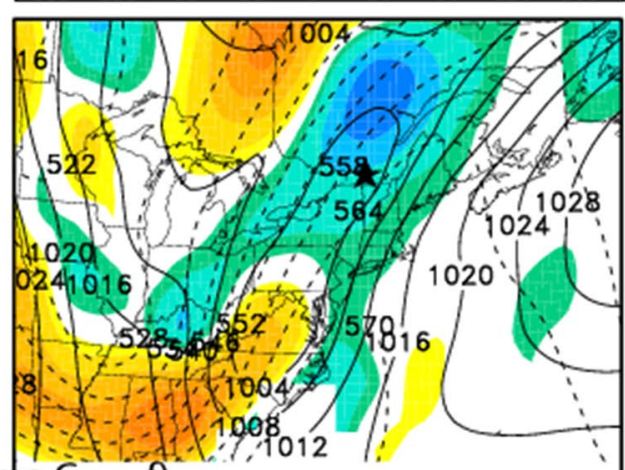

pe $\mathrm{C}^{\mathrm{f}}$ )

\begin{tabular}{lllllllll}
-200 & -120 & -60 & -20 & 0 & 20 & 60 & 120 & 200 \\
\hline
\end{tabular}

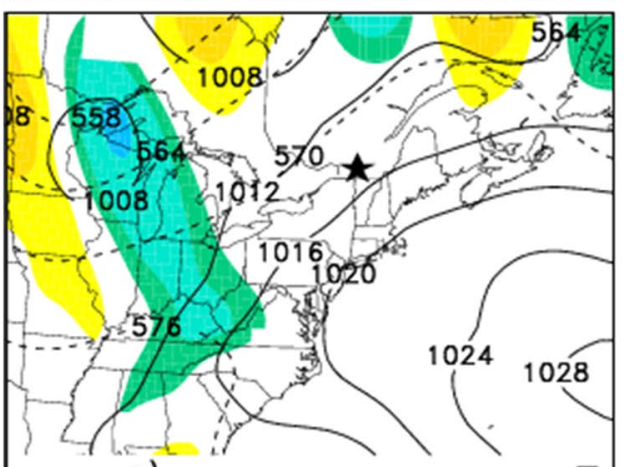

g)

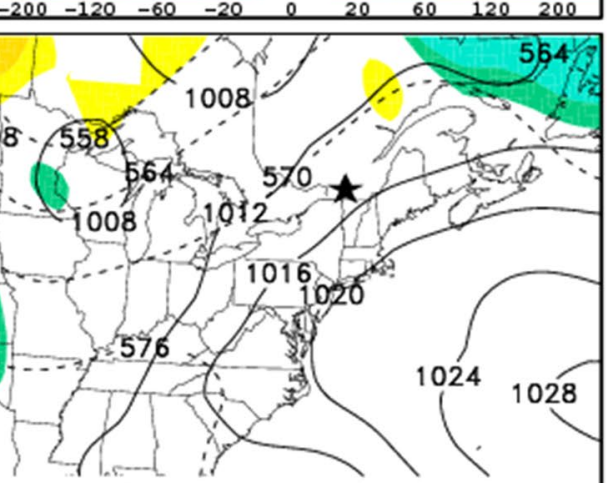

Type D h)

\begin{tabular}{lllllllll}
-200 & -120 & -60 & -20 & 0 & 20 & 60 & 120 & 200 \\
\hline
\end{tabular} 
(a)

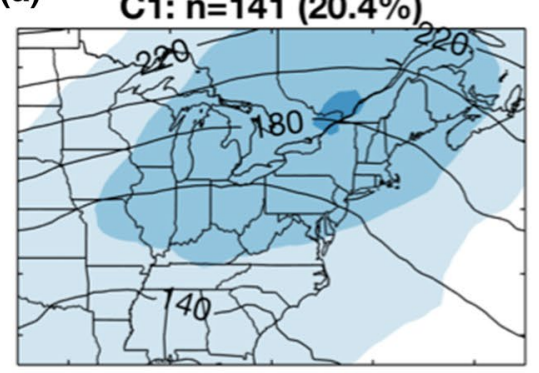

C4: $n=167(24.2 \%)$

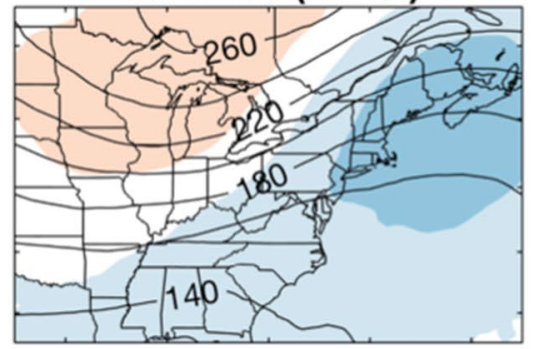

(b)

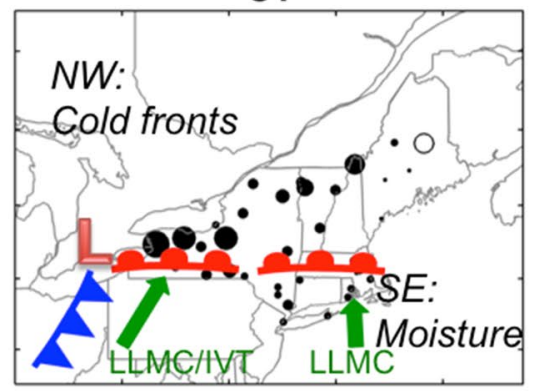

C4

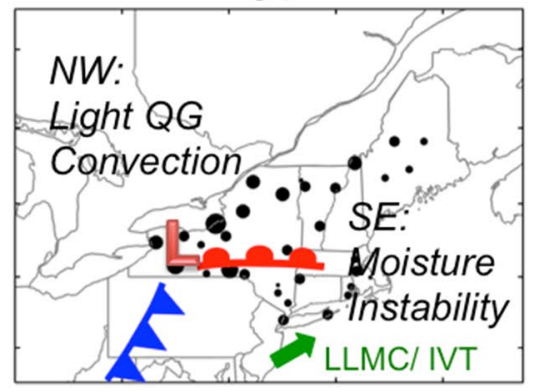

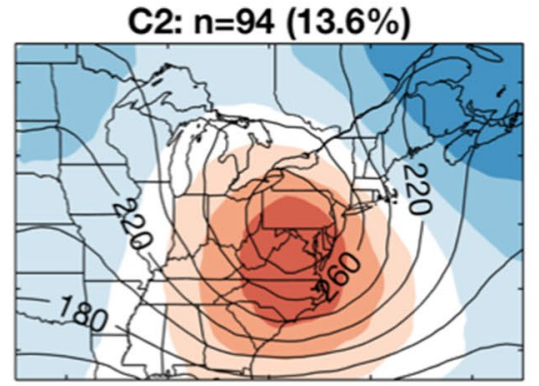
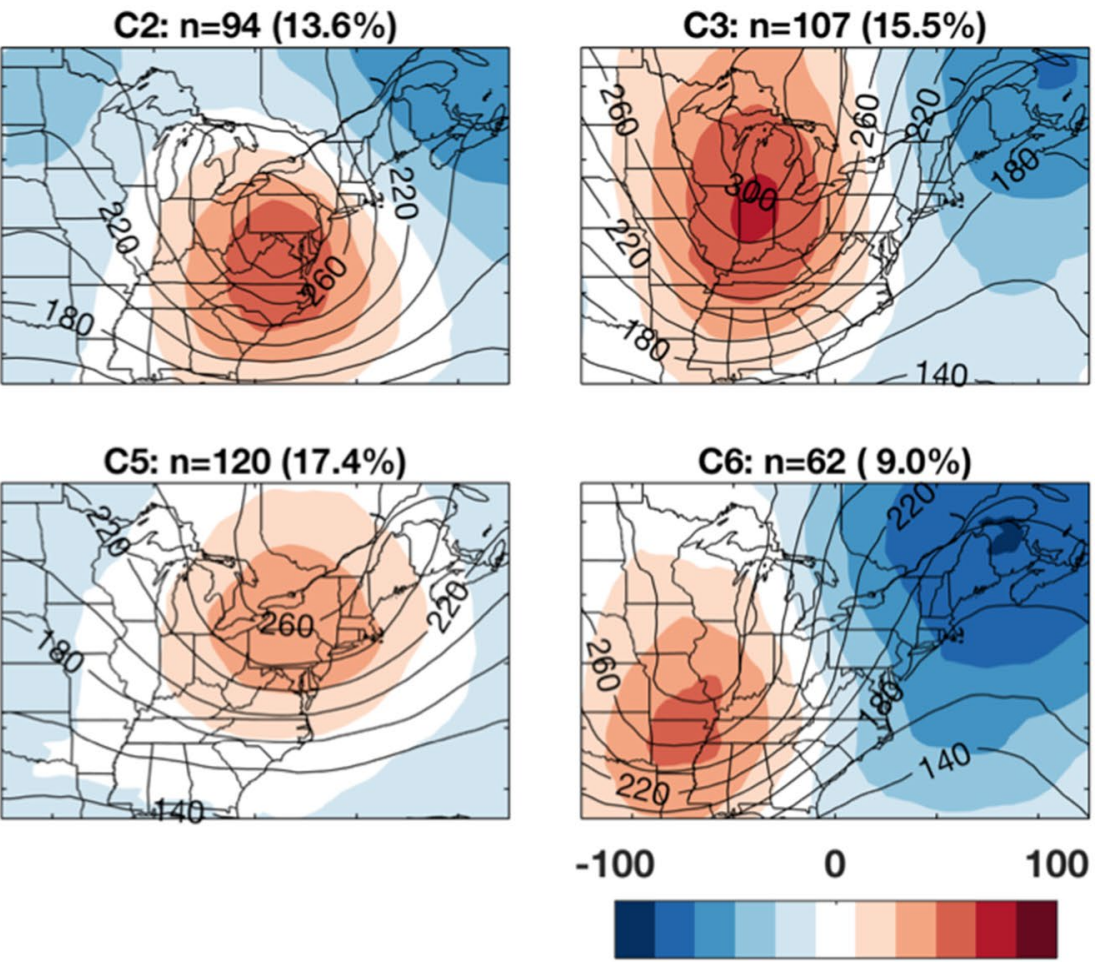

C2

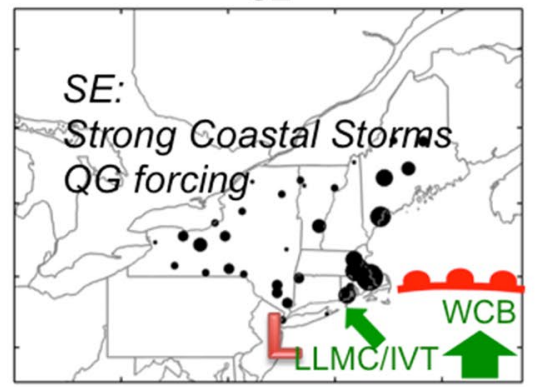

C3

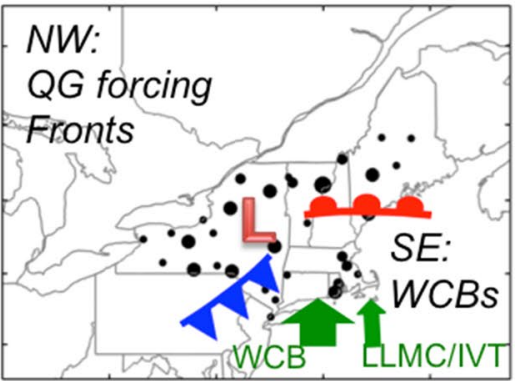

C6
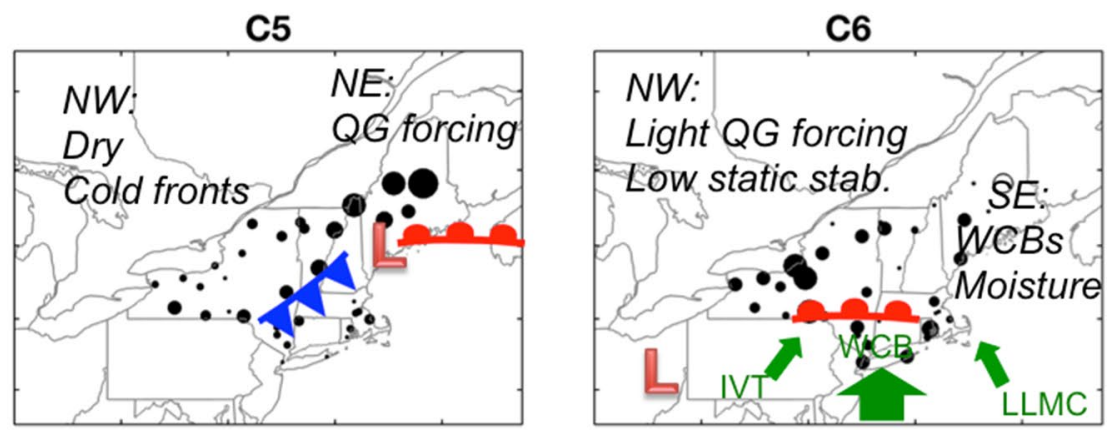

Fig. 9 The six extreme precipitation LSMPs identified for the Northeast US in Agel et al. (2017, 2019), shown in terms of a tropopause pressure (Agel et al. 2019, Fig. 1a), and b associated mechanisms (Agel et al. 2019, Fig. 15)

comparison of these two floods), and the Fort Collins, Colorado flash flood of 1997 (Petersen et al. 1999) all occurred on the east side of the Rocky Mountains with weak flow aloft, a shortwave trough upstream, and moist easterly flow at low levels. A similar scenario occurred on the east side of the Appalachians in the Madison County, Virginia flash flood of 1995 (Pontrelli et al. 1999). Lin et al. (2001) summarized the ingredients that are common to heavy orographic rainfall around the world. In particular, the warm, moist upslope flow with a relatively high melting level allows for a deep warm cloud layer and for efficient warm-rain processes (rather than mixed-phase rain formation) to occur. 


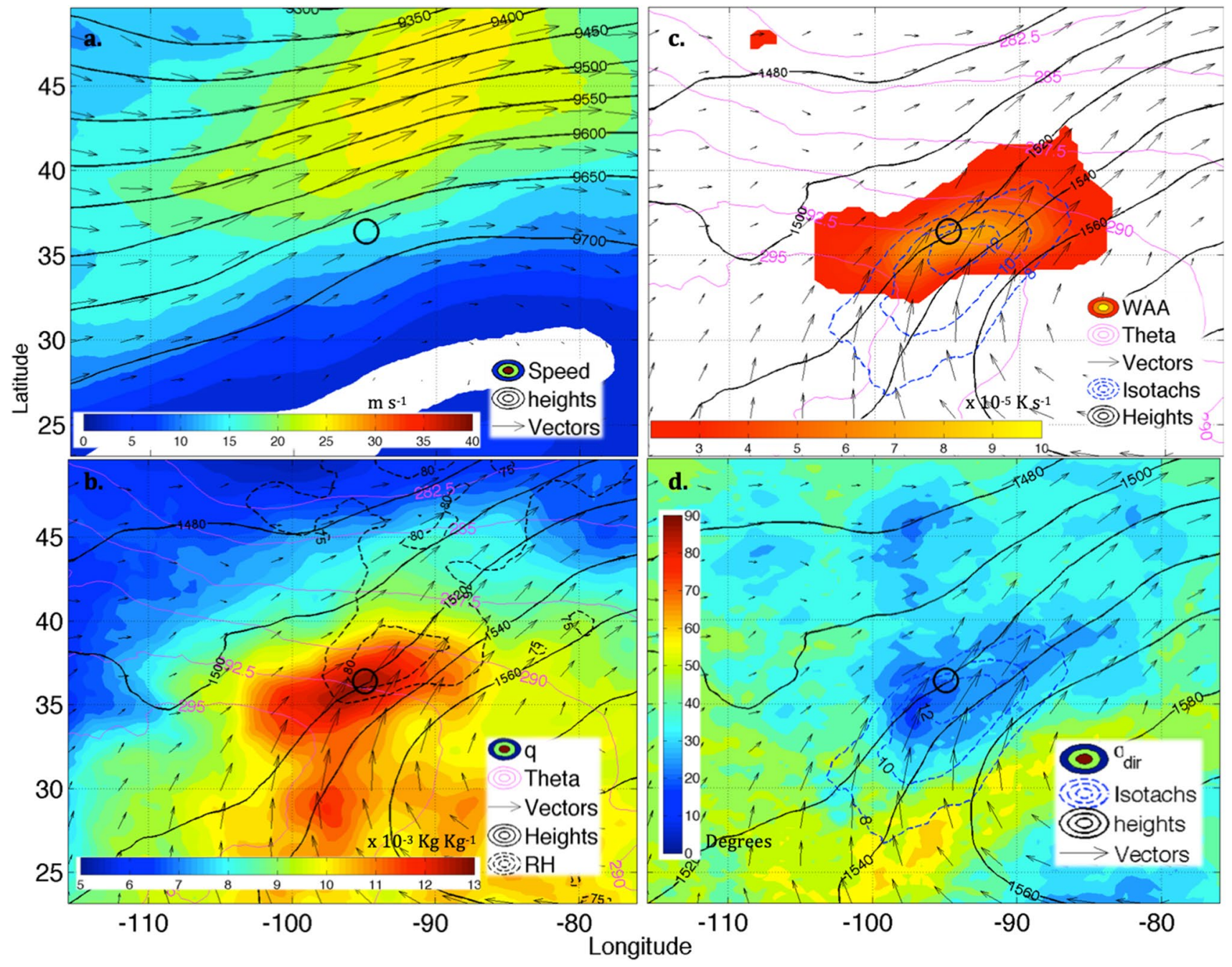

Fig. 10 As in Fig. 4, except for warm-season events, which correspond closely to the Maddox et al. (1979) "frontal" pattern. Adapted from Peters and Schumacher (2014)

A schematic representation of the pattern that was common to all of the aforementioned extreme rain events is given in Fig. 13a, and a representative cross-section based on the Big Thompson flood (from Caracena et al. 1979) is shown in Fig. 13b. The 2013 extreme rain event in Calgary, Alberta (Milrad et al. 2015) also developed under a similar scenario.

The moist upslope events mentioned above primarily occur during the warm season, and the heaviest rainfall is generally quite localized. However, larger-scale orographic extreme rain events also occur, both during the warm season and the cool season. For example, the historic rainfall in northern Colorado during September 2013 (Gochis et al. 2015) and the aforementioned event in Alberta in June 2013 (Milrad et al. 2015) occurred with a blocking high pressure ridge to the north and a cutoff low to the west, both of which persisted for several days and supported long-lived, widespread heavy rainfall on the east side of the Rocky Mountains. Milrad et al. (2017) used WRF model sensitivity experiments to show that while large-scale ascent-forcing mechanisms set the stage for the Alberta Flood and the blocking pattern increased event duration, precipitation amounts were $30-50 \%$ greater due to orographic forcing that acted to focus the heaviest precipitation in the Alberta foothills. During the cold season, prolonged moist westerly flow, often associated with atmospheric rivers, often encounter the Sierra Nevada and other mountain ranges along the West Coast of the US and lead to persistent heavy rains. Atmospheric rivers are discussed in detail in the next section.

\subsection{Atmospheric rivers}

An atmospheric river (AR) is a plume of moisture flux with relatively narrow width compared to its along-flow length. A formal definition has recently been added to the Glossary of Meteorology (Ralph et al. 2018). Such filamentary structures were noticed by Newell et al. (1992) and originally referred 
(a) TRAINING LINE -- ADJOINING STRATIFORM (TL/AS)

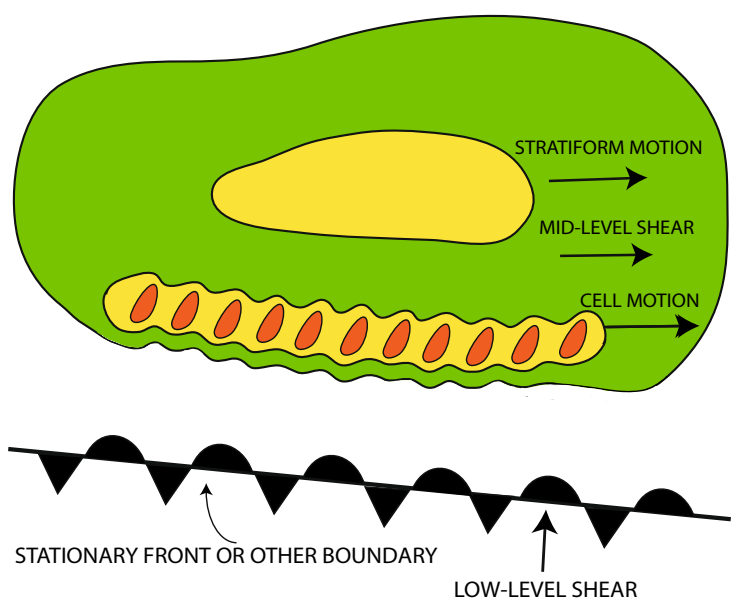

(b) BACKBUILDING / QUASI-STATIONARY (BB)

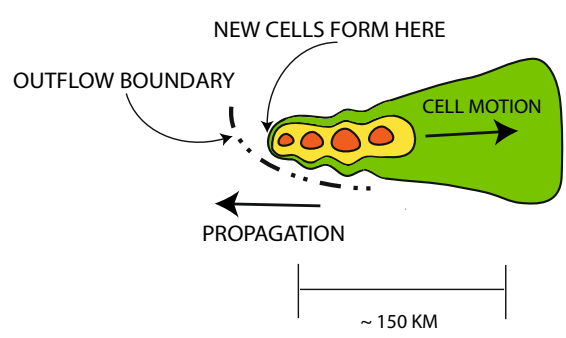

Fig. 11 Schematic diagram of the radar-observed features of the a TL/AS and b BB patterns of extreme-rain-producing MCSs. Contours (and shading) represent approximate radar reflectivity values of 20 , 40 , and $50 \mathrm{dBZ}$. In a, the low-level and midlevel shear arrows refer to the shear in the surface- $925-\mathrm{hPa}$ and $925-500-\mathrm{hPa}$ layers, respectively. No consistent relationship was found between the direction of the shear and the orientation of the convection for BB MCSs; thus, no such vectors are shown in $\mathbf{b}$. The dash-dot line in $\mathbf{b}$ represents an outflow boundary; such boundaries were observed in many of the BB MCS cases. The length scale at the bottom is approximate and can vary substantially, especially for BB systems, depending on the number of mature convective cells present at a given time. From Schumacher and Johnson (2005)

to as "tropospheric rivers", then later (Zhu and Newell 1998) as "atmospheric rivers". More than a decade before that terminology, local weather forecasters along the west coast referred to such bands of enhanced moisture flux as a "pineapple express" since, in a subset of ARs, the corresponding cloud band often extends back towards the general vicinity of Hawaii (e.g., Loukas and Quick 1996).

Numerous case studies of extreme precipitation (e.g., Lackmann and Gyakum 1999; Neiman et al. 2008b; Kingsmill et al. 2013) have demonstrated the importance of ARs to extreme precipitation events. More generally, ARs are associated with much of the western US precipitation climatology, and its most extreme events (e.g., Roberge et al. 2009; Rutz et al. 2014). In general, ARs tend to (a) Jet in Ridge
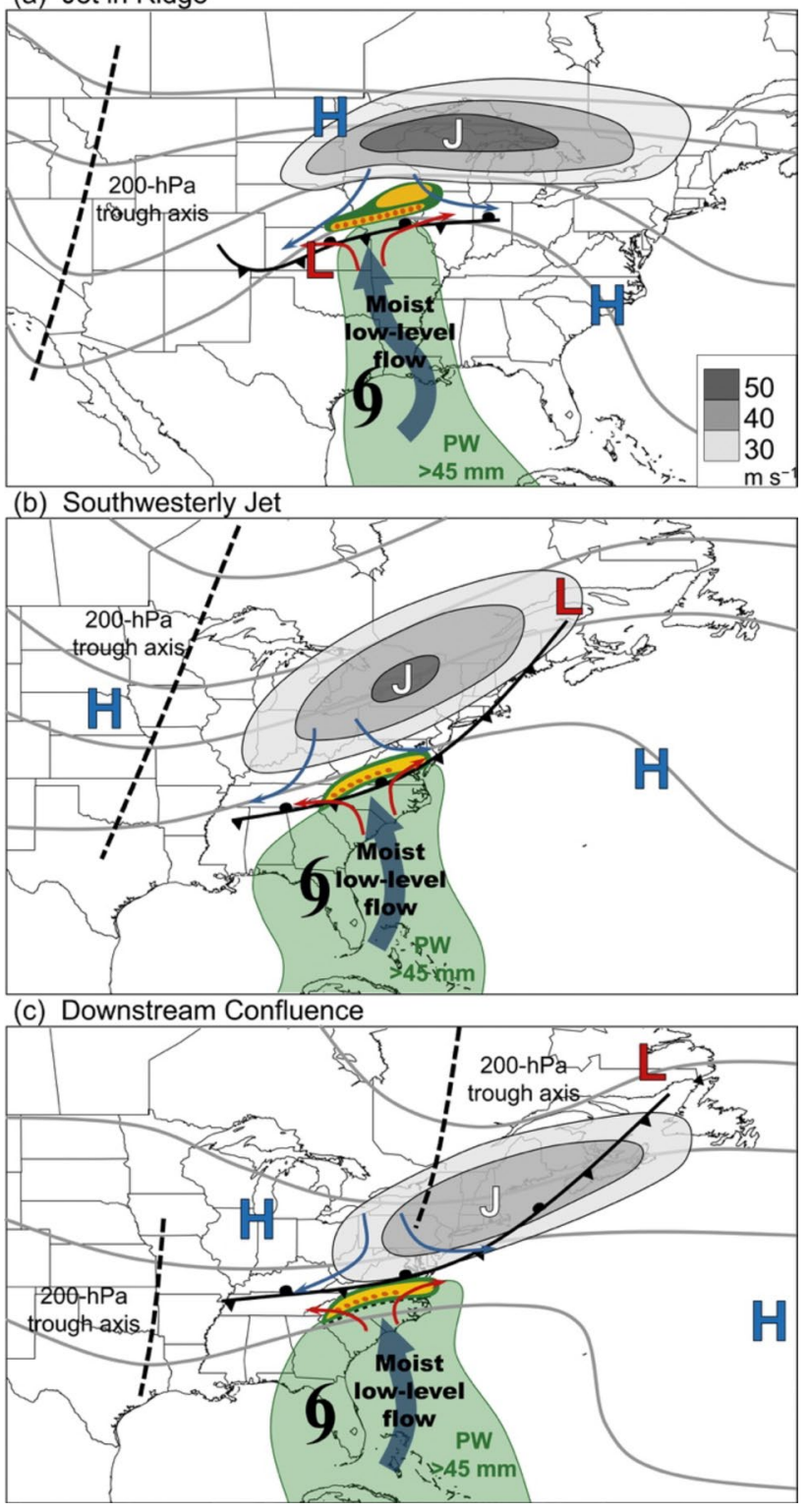

Fig. 12 Conceptual model of three categories of PREs, based upon the authors' composite dynamical analyses. The solid gray contours are 200-hPa geopotential heights, with the accompanying trough axes indicated by the heavy-dashed black line. The 200-hPa wind speed maximum is indicated by the ' $\mathrm{J}$ ', and the gray shadings indicate the wind speeds $\left(\mathrm{m} \mathrm{s}^{-1}\right)$. Warm and cold advections at $925 \mathrm{hPa}$ are shown with respective red and blue arrows. The TC location is indicated with the TC symbol, and ' $H$ ' and ' $L$ ' symbols indicate the centers of SLP highs and lows. Regions of precipitable water greater than $45 \mathrm{~mm}$ are shown in light green. Surface fronts are shown in standard notation. The moist low-level flow is shown by the thick blue arrow. Radar reflectivity thresholds of 20,35 , and $50 \mathrm{dBZ}$ are indicated by respective green, gold, and orange shaded regions. From Moore et al. (2013)

occur in winter, within an LSMP dominated by a cutoff low immediately to the west-northwest of the region experiencing heavy precipitation, a ridge to the southwest, 
(a)

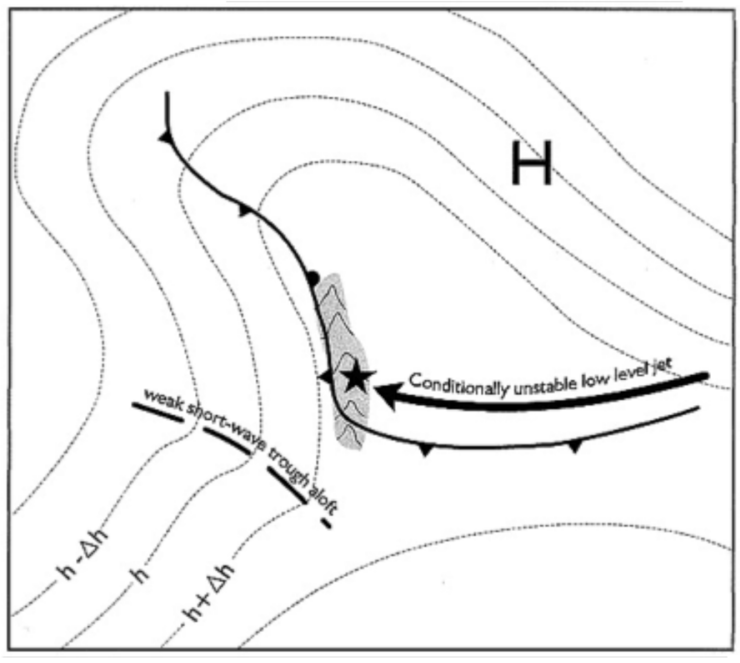

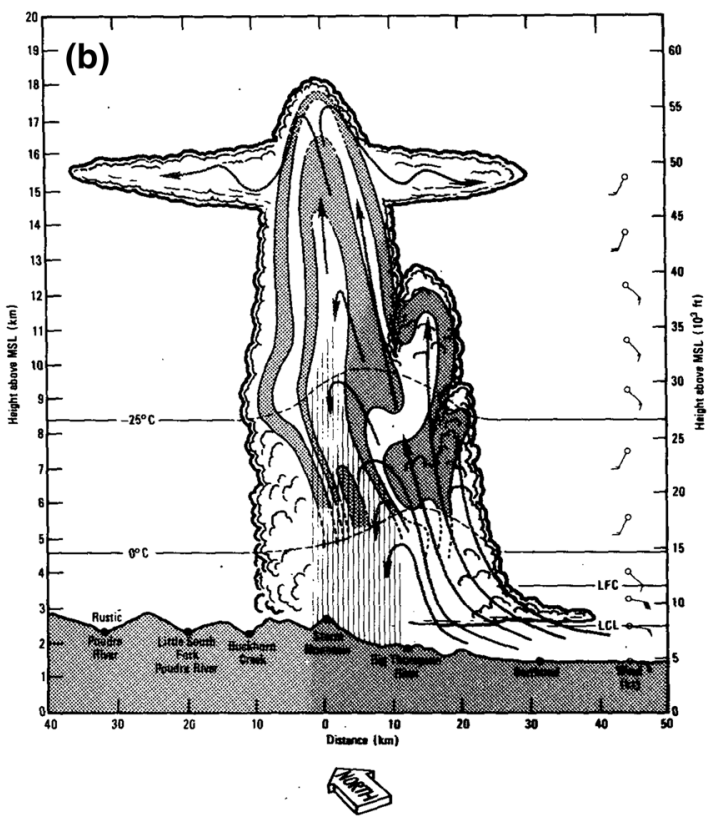

mountains (shaded). From Lin et al. (2001). b Schematic representation of the development of convective cells during the Big Thompson storm of July 1976. From Caracena et al. (1979)

an AR day occurs when the integral from 500 to $1000 \mathrm{hPa}$ of moisture transport (IVT) in a $5^{\circ}$ latitude range along the west coast exceeds the $85 \%$ level. Similarly, Grotjahn and Faure (2008) investigated $500 \mathrm{hPa} \mathrm{Z}$ composites of 14 events with heavy precipitation over a central California region, and find unusual heights (the lowest or highest $2 \%$ of ensemble average values) locally for the trough and at lower levels of the ridge to the southeast. These patterns accentuate the large-scale upward motion over the region. Typically, the duration is extended by several smaller vorticity centers rotating around the larger cut-off low just offshore. In general, the LSMPs have an equivalentbarotropic structure. Hence, generally southwesterly flow occurs through the depth of the troposphere at the coast between the main trough-ridge pair. The further south the extreme precipitation, the more pronounced the offshore trough is in the anomaly field, while the further north the extreme precipitation, the more pronounced the ridge is to the southeast (although not all studies find an upstream ridge). Specifically, Lackmann and Gyakum (1999) investigated $500 \mathrm{hPa} \mathrm{Z}$ composites for 46 heavy precipitation events affecting the northwestern US, and find the ridge is prominent; while Ely et al. (1994) investigated $700 \mathrm{hPa} \mathrm{Z}$ patterns for heavy precipitation in the Mojave and Virgin Rivers in the western US, and find the anomalous trough is most prominent.

In Fig. 14c, d, Gao et al. (2015) carried their fall analysis even further north and the anomaly pattern is even more 

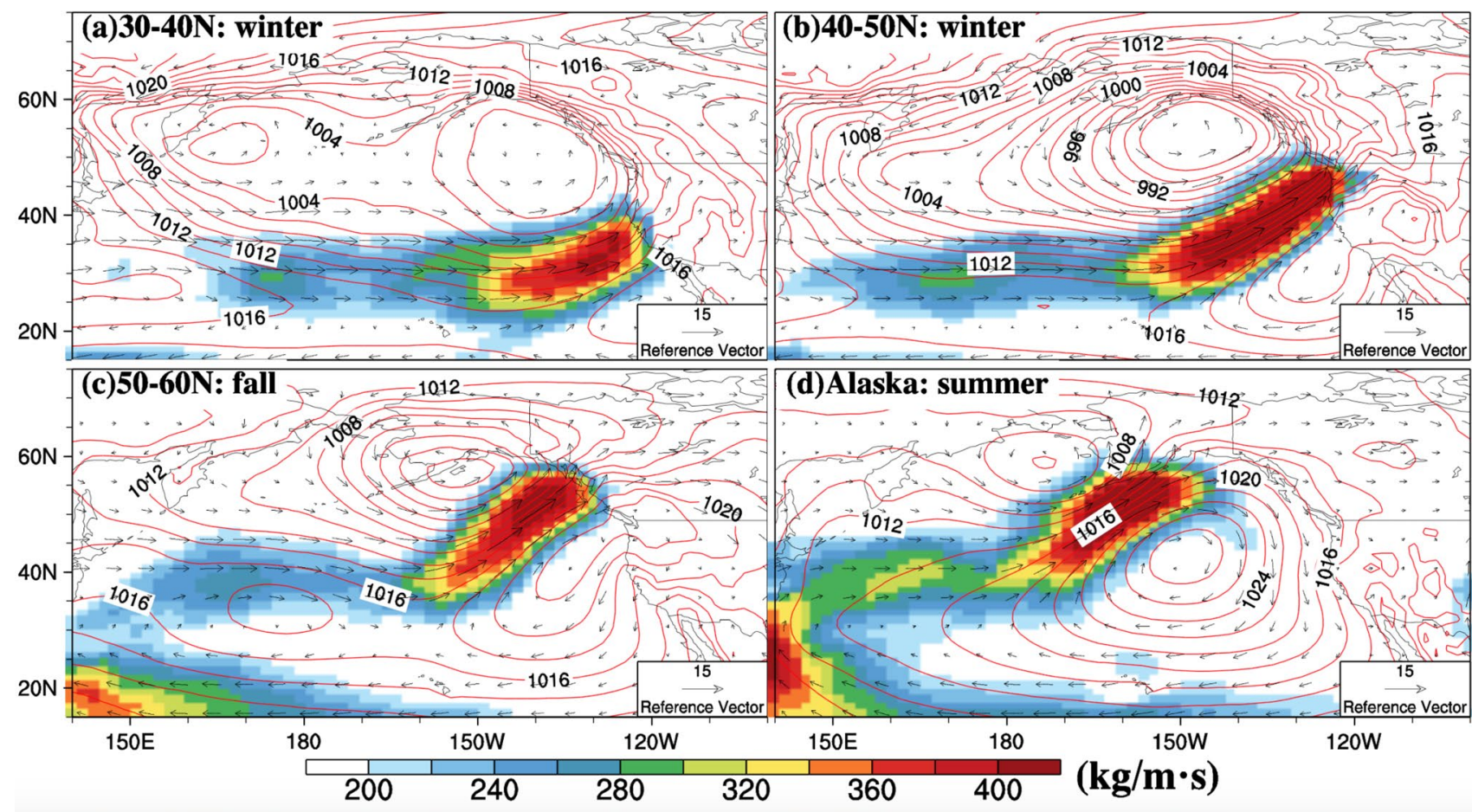

Fig. 14 Composite maps during 'AR days' during 1979-2004 within the indicated latitudinal ranges along the North American west coast. Orange contours are $500 \mathrm{hPa}$ geopotential height anomalies (with respect to seasonal averages). The colors are for column integrated water vapor transport. The wind vectors are at $850 \mathrm{hPa}$. The further

dominated by the ridge to the southeast. The reason for the change of emphasis is not surprising. Similar meteorological conditions are set up at each point of extreme precipitation, hence the anomalies reflect the necessary adjustments to climatology of low pressure to the north in the Gulf of Alaska vs. the subtropical high to the south. Indeed, the landfall of the moisture plume maximum is very nearly the same $500 \mathrm{hPa} \mathrm{Z}$ value in 29 "north" winter composites as in 35 "south" winter composites in Neiman et al. (2008a). Additional studies show similar patterns of the trough-ridge dipole extending through the depth of the atmosphere and an AR extending northeastward out of the tropics (Ralph et al. 2004; Junker et al. 2008; Gao et al. 2014). ARs are also evident in a self-organizing map (SOM) analysis of moisture transport associated with extreme precipitation in the Intermountain West (Swales et al. 2016). Analyses of the synoptic circulations associated with AR landfalls in Northern California further indicate that, although ENSO is not known to impact AR landfall frequencies in this region, it does impact AR orientations at landfall (Guirguis et al. 2018b), promoting southerly (westerly) orientations during El Niño (La Niña) winters, which bolsters canonical ENSO precipitation anomalies in West Coast precipitation. south the extreme precipitation, the more pronounced the trough is in the anomaly field, while the further north the ridge is more pronounced. ERA-Interim reanalysis data are shown. The numbers of events per year used for each panel during the 25-year period are: a 1.2, b 1.4, c 2.2, and d 4.0. From Gao et al. (2015)

ARs are also associated with extreme precipitation in other parts of the US such as southern Arizona (Rutz and Steenburgh 2012), the Midwest (e.g., Junker et al. 2009; Lavers and Villarini 2013), the Southeast (Mahoney et al. 2016) and the globe (e.g., Moore et al. 2012; Knippertz et al. 2013). Ralph and Dettinger (2011) also showed that mesoscale frontal activity was important for increasing the duration of AR conditions for the Pacific Northwest flooding of March 2005.

\subsection{Discussion}

Several types of meteorological systems (extratropical cyclones, tropical cyclones, mesoscale convective systems, mesohighs) and several mechanisms (fronts, atmospheric rivers, orographic ascent) have been shown to be important for LSMPs associated with extreme precipitation over North America. The specific structures of the LSMPs associated with these systems and mechanisms vary by location and season, and even for a specific location and season there may be multiple LSMPs associated with a single system or mechanism type. Multiple factors (e.g., extratropical cyclones and fronts) are often important in individual LSMPs, and occurrence of extreme precipitation within an LSMP is often 
due to mesoscale processes for which the LSMP provides a favorable environment and/or trigger.

The relationship between the strength of the LSMPs and the occurrence of extreme values of precipitation is not, in general, well understood. For instance, the strength of extratropical cyclones does not appear to have a close relationship to the occurrence of extreme precipitation, although the strength of fronts does.

While there is an extensive literature on teleconnections, there has been little analysis of how teleconnections may modulate the LSMPs associated with extreme precipitation over North America, although there has been some consideration of ENSO's influence on LSMPs (McCabe and Muller 2002; Feldl and Roe 2010; Brigode et al. 2013).

Direct comparison between the studies considered here is difficult due to different definitions of "extreme", different time periods, and different data sets. In particular, nearly every study uses a different definition of "extreme" and most vary in terms of time period and regional focus as well. Some generalities are reasonably clear: fronts and synoptic storms are important factors in many extreme events, although the extreme precipitation is usually realized through mesoscale processes organized, enhanced, or triggered by the largerscale circulation; the same general category (e.g., synoptic storms) has both important regional differences as well as multiple sub-types, with significant differences in dynamical mechanisms; and most of the studies naturally focused only on the occurrence of extreme events, so it is not clear how the identified features potentially relate to non-extreme events; that is, to what degree the identified features are necessary and/or sufficient conditions for extremes. Not surprisingly, moisture availability and reduced stability are factors common to most of the LSMPs. Individual case studies of significant rain events (e.g., Bosart and Sanders 1981; Bosart 1984, 1992; Schumacher and Johnson 2008) have also demonstrated the importance of extremely weak stratification, enhancing ascent in the presence of even weak synopticscale forcing, as a key heavy-rain producing process.

\section{Trends: observed and projected}

This section considers trends in observed precipitation extremes from a general perspective, for context, and then the role of LSMPs in those trends. The potential role of LSMPs in projected future changes is briefly discussed, although it has not yet been the subject of much analysis. Extreme value statistics has been used occasionally for trend analysis (Sillmann et al. 2013a). Because this method can identify trends in both frequency and intensity of extreme precipitation, it has certain advantages over other approaches to climate trend analysis. Consequently, here we focus on those few recent studies that make use of extreme value statistics in summarizing trend analysis of both observed and projected precipitation extremes. A practical issue, especially for engineering design, concerns how best to quantify the risk of extreme precipitation events under a changing climate, given that the standard concepts of "return period" and "return level" are based on the assumption of stationarity (as already pointed out in Sect. 2.3) — an unchanging climate (e.g., Rootzén and Katz 2013).

\subsection{Trends in observed precipitation extremes}

Recently, a few papers have made use of extreme value statistics in attempts to detect trends in observed precipitation extremes, either for the US alone or globally. Most notably, Min et al. (2011) and Zhang et al. (2013) performed formal detection and attribution analyses of changes in annual maximum daily ( $\mathrm{Rx} 1$ day) and pentad ( $\mathrm{R} \times 5$ day) precipitation totals. To facilitate comparison between the limited observations and climate model simulations, Min et al. (2011) defined a "probability-based index" (PI) by scaling the precipitation extremes to a range of $0-1$ using the cumulative density function values of the fitted stationary GEV distribution. A detectible change in the latter half of the twentieth century was attributed to human changes to the atmospheric composition only in the Northern hemisphere where observations are most extensive. Kunkel et al. (2013) performed a trend analysis of precipitation extremes for the US [Fig. 4 of Kunkel et al. (2013) reproduced here as Fig. 1]. Kunkel et al. (2013) applied the POT approach with a station-specific threshold corresponding to the 97th percentile (based only on days with measurable precipitation). To avoid temporal dependence of extremes, only the single highest daily total precipitation amount within a run of consecutive days exceeding the threshold was retained (Coles 2001). Using the equivalent parameterization in terms of the GEV distribution, a linear temporal trend in the location parameter of the GEV was fitted by the technique of maximum likelihood (Coles 2001), assuming that the scale and shape parameters were constant over time. Although the seasonality of precipitation extremes has been shown to be important both globally and in the US (Wehner 2013), seasonal trends in precipitation extremes have not been extensively analyzed.

This approach was applied to GHCN daily total precipitation data for stations in the CONUS over the time period 1948-2010. Stations with data missing on more than onethird of the days within this time period were removed from the analysis. Figure 1 shows the estimated change in 20-year return levels between 1948 and 2010, along with an indication of statistical significance. Over three-quarters of the stations have experienced increases. Although only about $15 \%$ of these increases are statistically significant based on station-specific hypothesis testing, a field significance test based on resampling that takes into account spatial 
dependence indicates overall statistical significance. A more powerful approach to trend detection would require "borrowing strength" within a region, making the physically plausible assumption that trends in extremes for adjacent stations attributable to large-scale forcings should be similar in magnitude (Hanel et al. 2009).

To treat trends in precipitation extremes for the remainder of North America (not included in Fig. 1), we make use of the Westra et al. (2013) global trend analysis. This study used the block maxima approach, rather than the POT approach, considering a shift in the parameters of the GEV distribution fit directly to the annual maximum of daily total precipitation. Instead of formulating the trend as an explicit function of time, they expressed the location parameter as a linear function of the global mean temperature for each year incorporating both natural and anthropogenic nonstationary influences. Westra et al. (2013) applied this technique to more than 8000 stations with more than 30 years of data within the time period 1900-2009. Globally, they showed that about $10 \%$ of the stations have a statistically significant positive association between the location parameter of the GEV distribution for annual maximum precipitation and global mean temperature. However, within North America, the spatial distribution of these significant increases lacks a clear pattern. Despite a considerably lower density of stations outside the US, there are quite a few stations in Canada that exhibit statistically significant increases, but barely any in Mexico.

The attribution of the human influence on individual extreme storms due to climate change is a rapidly developing field and will not be covered in detail here. The interested reader is pointed to the review and methodological articles of Stott et al. (2013), Zwiers et al. (2013), Pall et al. (2014) and Easterling et al. (2016), as well as the US National Academies report on extreme event attribution (NASEM 2016) and the annual reports on "Explaining Extreme Events from a Climate Perspective" in the Bulletin of the American Meteorological Society.

\subsection{Role of LSMPs and large-scale influences in trends}

Increasing trends in precipitation extremes have been observed for many parts of the CONUS and the world (e.g., Groisman et al. 2004, 2005). In the midwestern US, Feng et al. (2016) found an increasing trend in mean and extreme precipitation (95\%) associated with MCSs during spring in the past 35 years. The increase in MCS mean and extreme precipitation is supported by an increase in the strength of the Great Plains LLJ associated with an increase in sea level pressure gradient between the Rocky Mountain and west Atlantic Ocean due to the larger warming over land relative to the ocean. The increased moisture transport by the LLJ that converges moisture in the Midwest has been found to support longer-lived MCSs that produce heavier precipitation (Feng et al. 2016). An additional regional example can be seen in the Northeastern US where Collow et al. (2016) showed that increases in summertime extreme precipitation events in the area have been associated with closed low pressure systems, and not connected to tropical cyclones.

Global climate models project significant changes in the precipitation regime expressed in both the frequency and intensity of daily precipitation (e.g., Kharin et al. 2013; Polade et al. 2014, 2017). Large changes in the daily precipitation regime lead to a wide variety of impacts, but can become invisible when aggregated to annual mean precipitation. Such is the case in the Southwestern US where frequency is projected to decrease while intensity of the most intense precipitation is projected to increase, leading to increased risk of drought as well as flood (e.g., Dettinger 2011; Das et al. 2011). Moreover, in such arid regions, where precipitation is already infrequent, small numbers of wet storms lead to large variability of annual total precipitation-a natural feature of subtropical climate regimes that is projected to intensify in the future due to anthropogenic changes in the daily weather regime (Polade et al. 2014). The southwestern US, in particular, receives winter precipitation from tail ends of midlatitude cyclones which are projected to track further poleward with progressive non-uniform (polar-amplified) climate change (e.g., Barnes and Polvani 2013), thus decreasing the frequency of daily precipitation (Favre and Gershunov 2009). A progressively larger proportion of California's total annual precipitation is projected to be generated in heavy and extreme events (Polade et al. 2017), however, further increasing the natural volatility of the regional hydroclimate. This projected intensification of extremes has recently been attributed to mainly thermodynamic bolstering of ARs in a warming climate (Gershunov et al. 2019). This is one regional example, for a region with a diverse and growing population and over-allocated water resources that hinge on mountain snowpack, which is additionally affected by the warming trend. In the Southwestern US, already-stressed water resources are expected to become more scarce as the risk of persistent drought is projected to increase (Cayan et al. 2010), even as the risk of wintertime flooding may also be increasing (Dettinger 2011; Das et al. 2011).

The role of LSMPs in projected changes in precipitation extremes has not yet received much attention beyond analysis of ARs. In most regions of the US and globally, precipitation extremes are projected to increase (e.g., Groisman et al. 2005) and it is imperative to consider the daily precipitation regime (the intensity, duration, and frequency of daily precipitation), preferably in the context of specific storm systems, in order to understand impacts of climate change on natural climate variability as well as the influence 
of natural variability on local and regional anthropogenic trends in extremes. In California, for example, the frequency and intensity of heavy (above the 90th percentile) and especially extreme (above the 99th percentile) daily precipitation events are projected to increase, in contrast to most other Mediterranean climate regions around the world (Polade et al. 2017). The enhanced extremes in conjunction with decreasing frequency of low and medium intensity precipitation would lead to increasing volatility of water resources driven by increased year-to-year precipitation variability due to a narrowing sample of storms producing the annual total precipitation (Polade et al. 2014, 2017). In terms of future change relative to LSMPs, AR precipitation is clearly expected to intensify (Gershunov et al. 2013, 2019; Gao et al. 2015) as moisture concentration and transport is expected to increase in a warmer atmosphere (Lavers et al. 2015). Simulation of ARs is further discussed in Sect. 5.2.1. How other LSMPs may change in the context of both thermodynamic and dynamic changes remains to be explored.

\section{Climate modeling of extremes and associated circulation}

This section considers simulation of extreme precipitation, in general, in terms of global and regional climate models, for context, and then simulation of LSMPs associated with precipitation extremes, specifically. LSMPs are considered in terms of atmospheric rivers, other large-scale circulation features, and projections of LSMP behavior associated with precipitation extremes.

Analysis of simulated precipitation extremes is often motivated by engineering and water resources impacts, so precipitation analyses often focus on intensity-duration-frequency curves (e.g., Mirhosseini et al. 2013; Fu et al. 2013; Zareie and Nguyen 2013; Zhu et al. 2013; Notaro et al. 2015) or return periods of extreme events (e.g., Dominguez et al. 2012; Halmstad et al. 2013; Kuo et al. 2014; Mailhot et al. 2012; Monette et al. 2012; Wang et al. 2013; Wehner 2013; Kharin et al. 2013; Monjo et al. 2016), though analyses also consider percentiles of precipitation (e.g., Kawazoe and Gutowski 2013a, b; Alexander et al. 2013; Sillmann et al. 2013a, b; Glisan and Gutowski 2014a, b). As a consequence, simulation analyses typically look at subregions of model simulation domains, such as specific watersheds (Halmstad et al. 2013; Kawazoe and Gutowski 2013a, b; Monette et al. 2012; Alexander et al. 2013; Murdock and Sobie 2013), or just a few selected locations (Mishra et al. 2012). The engineering and water-resources needs also tend to motivate analyses focused on subdaily to multi-day precipitation amounts.
Note that not all extremes are clearly tied to LSMPs. Local convective events, such as squall lines, can also produce very intense precipitation, but these are also events that climate models will not simulate directly, except possibly for a limited number of regional simulations at very high (few $\mathrm{km}$ ) resolution. Thus, discussion here attempts to focus as much as possible on simulation characteristics resolved by climate models.

\subsection{Simulation of extreme precipitation}

\subsubsection{Global climate models}

Direct comparison of gridded output from Coupled Model Intercomparison Phase 5 (CMIP5) class global climate models with the corresponding observations at rain gauges is generally considered infeasible because of the difference in spatial scale (i.e., point versus $\sim 100 \mathrm{~km} \times 100 \mathrm{~km}$ cells). In principle, methods based on extreme value theory could be devised to adjust for this scale mismatch (MannshardtShamseldin et al. 2010), but are not yet operational. Instead, comparisons are often made with gridded analyses of precipitation or even gridded reanalyses, despite the recognized shortcoming that the precipitation observations are not generally assimilated as part of these reanalyses.

Kharin et al. (2013) applied the block maxima approach to annual maxima of daily precipitation amounts, comparing reanalyses with output from CMIP5 models for the late 20 th century. They found that magnitudes of 20-year return levels for precipitation extremes estimated from the CMIP5 multi-model ensemble for 1986-2005 are comparable to those for reanalyses, at least outside the tropics and subtropics including much of North America. Sillmann et al. (2013a) made similar comparisons between CMIP5, reanalyses and gridded observations for the recent climate, but in terms of a set of the ETCCDI indices, which are less extreme than considered by Kharin et al. (2013). They found improvements in the performance of CMIP5 over Coupled Model Intercomparison Phase 3 (CMIP3) in generating precipitation extremes including over North America, possibly attributable to slightly higher spatial resolution (Wehner et al. 2010).

A similar seasonal analysis confined to North American land points only is shown in Fig. 15 following Sillmann et al. (2013a) for two precipitation indices, the maximum daily ( Rx1 day) and pentad ( $\mathrm{Rx} 5$ day) total precipitation of the season. The models are compared to ERA-Interim (Dee et al. 2011), the reanalysis product most highly correlated with the observationally based ETCCDI indices (Donat et al. 2014). For consistency, the following definition is repeated from the companion paper, Grotjahn et al. (2016). As in Gleckler et al. (2008), errors are normalized by the median error of 


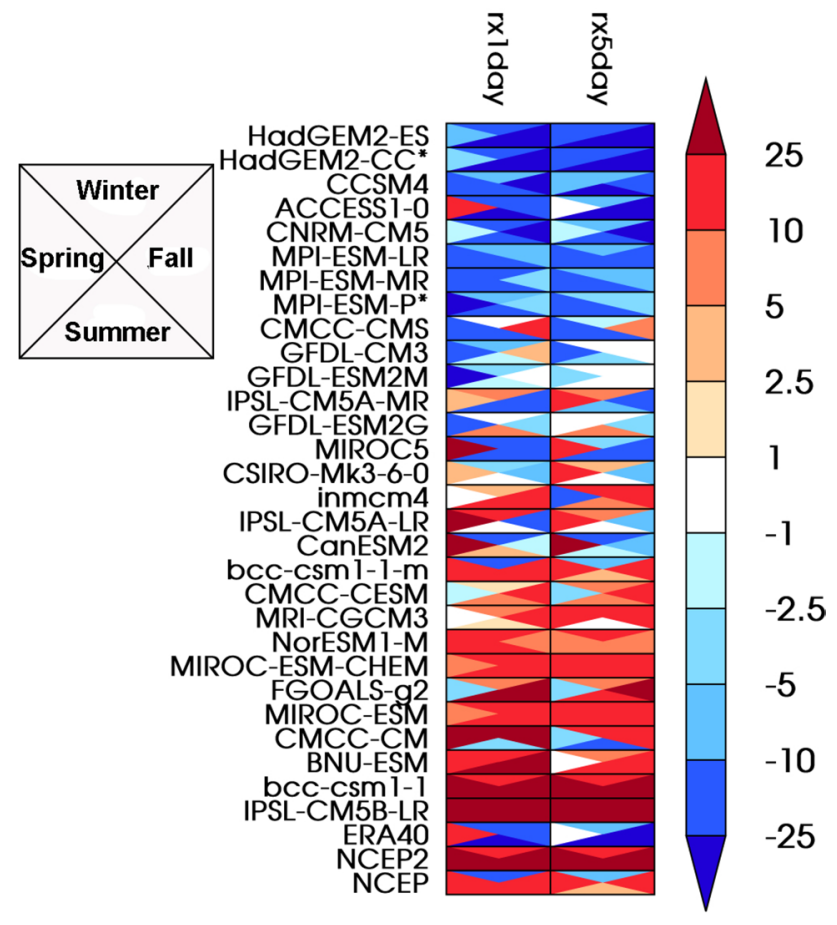

Fig. 15 Normalized root mean square error (RMSE) of the CMIP5 models relative to the multi-model median RMSE for daily and pentad seasonal maximum precipitation over North American land points. Models are compared to the ERA-Interim reanalysis and ordered from lowest to highest errors. Three other reanalyses are shown to place model errors in the context of the uncertainty in the reference dataset

the CMIP5 models to facilitate plotting multiple variables on the same scale, using the formula:

$E_{j}^{R}=100 \times \frac{\left(E_{j}-E_{\text {median }}\right)}{E_{\text {median }}}$

Here, $E_{\text {median }}$ is the median root mean square error (RMSE) of the CMIP5 models, $E_{j}$ is the RMSE of the $j$ th model and $E_{j}^{R}$ is that model's "relative RMSE" and is plotted for seasonal means of the indices. In this analysis, the model median RMSE in (2) is calculated for each variable over all seasons and then applied to normalize each season in order to assess the relative seasonal performance. Blue colors represent errors lower than the model median error, while red colors represent errors larger than the median error. Seasons are denoted by triangles within each square. The different models are arranged in order of increasing average relative error with the models with the lowest average relative error on the top. A comparison between ERA-Interim and 3 other reanalyses products is also shown at the bottom revealing that for these two extreme precipitation indices, many models agree with ERA-Interim better than the reanalyses do among themselves.
However, resolution constraints cause the magnitude of extreme precipitation events to remain underestimated by both the CMIP5-class ( $\sim 100 \mathrm{~km}$ resolution) models and the reanalyses as compared to the available observed gridded precipitation products. Modern high performance computing systems are just now enabling multi-decadal integrations of significantly higher resolution global atmospheric models. For the Community Atmospheric Model, Version 5.1 (CAM5.1) at a horizontal resolution of $25 \mathrm{~km}$, the distribution of extreme daily precipitation agrees much better with the range of gridded station observations than at coarser resolutions (Wehner et al. 2014). At such higher resolutions, limitations of the underlying mesh become less important exposing flaws in the physical parameterizations. This is apparent in the CAM5.1 results where simulated extreme daily precipitation agrees well in the winter with observations over the CONUS, but is too large in the summer. This is traceable to deficiencies in the cumulus convection parameterization, which plays a larger role in summer than in winter (Wehner et al. 2014).

Toredi et al. (2013), Kharin et al. (2013) and Sillmann et al. (2013b) analyzed future projections of precipitation extremes based on the CMIP5 multi-model ensembles. Toredi et al. (2013) apply the POT approach with a threshold corresponding to the 90th percentile. They compare the estimated 50-year return levels for the historical time period of 1966-2005 with those for two future periods 2020-2059 and 2060-2099, assuming stationarity within each 40-year period (a somewhat unrealistic assumption). For the middle and higher latitudes of North America, they find that increases in the estimated 50-year return level are greater in magnitude for the second future period than for the first but did not perform statistical significance tests on these differences.

For the CMIP5 multi-model ensembles, Kharin et al. (2013) compare the estimated 20-year return levels for the historical time period of 1986-2005 with those for the two future periods of 2046-2065 and 2081-2100, likewise assuming stationarity within each 20 -year period. For essentially all of North America, they find statistically significant increases in the 20-year return period (using a Wilcoxon signed-rank test). These increases tend to be somewhat higher for the second future time period. Sillmann et al. (2013b) find similar projected changes for indices that reflect more moderate extreme precipitation events of the ETCCDI indices. Figure 16 shows the CMIP5 multi-model average percent change in the mean seasonal maximum pentad total precipitation ( $\mathrm{Rx} 5$ day) at the end of the twenty-first century (2081-2100) relative to the recent past (1981-2005). The patterns of changes in Rx 5 day (southern decreases and northern increases) are very similar to the patterns of seasonal mean precipitation. For changes in rarer measures of extreme precipitation, such as the 20 year return values in 


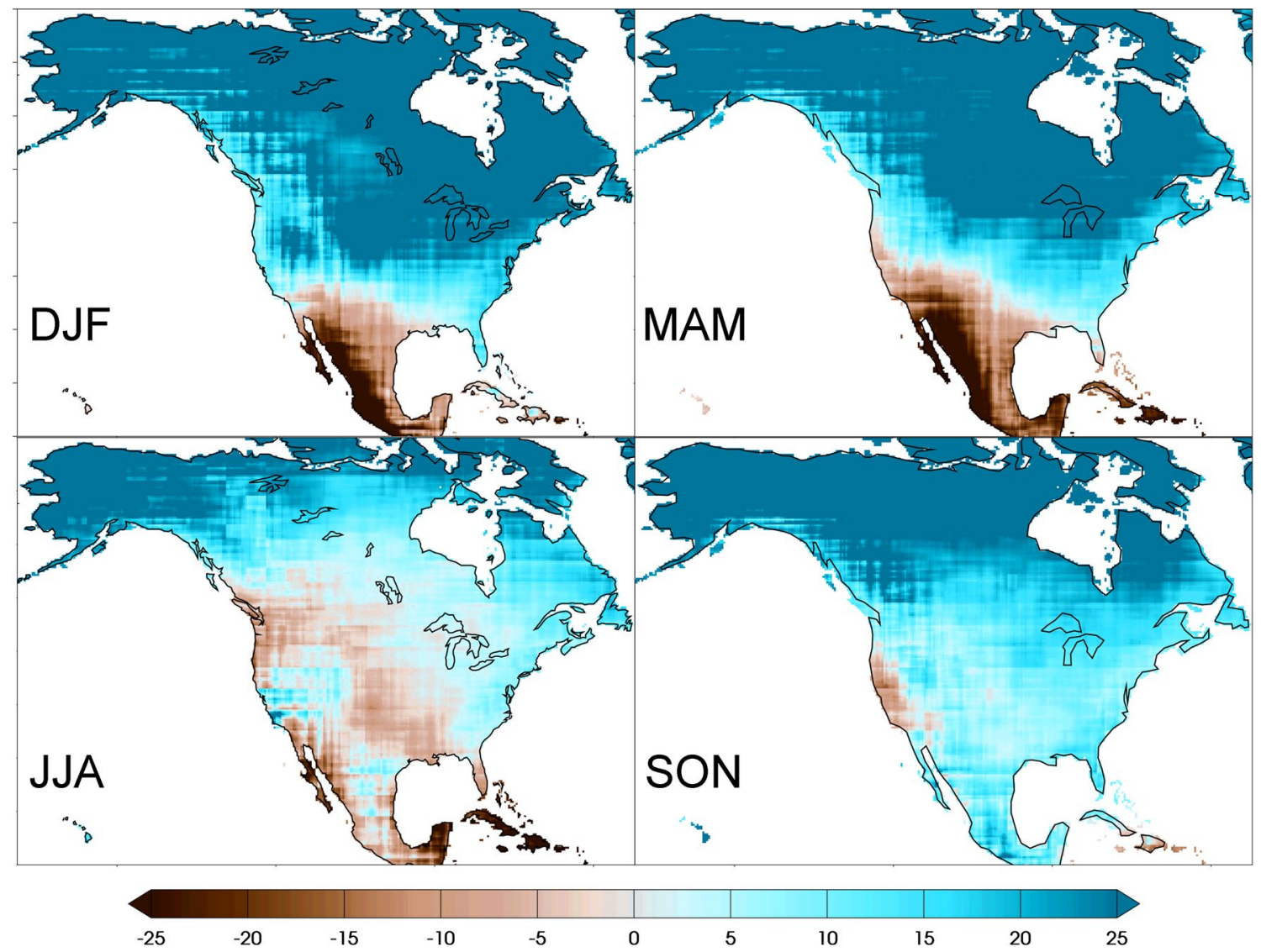

Fig. 16 CMIP5 multi-model average projected percent change in the mean seasonal maximum pentad total precipitation (Rx5 day) at the end of the 21 st century (2080-2100) relative to the recent past (1985-2005)

Kharin et al. (2013), increases in North America are more prevalent and are close to that determined by the local mean temperature change and the Clausius-Clapeyron relationship. However, we emphasize that projected changes from the CMIP5 models need to be treated with great caution given their tendency to severely underestimate observed precipitation extremes and the absence of certain classes of severe storms, such as tropical cyclones (Wehner et al. 2015). Comparison with results from the forthcoming higher-resolution CMIP6 model set will provide an assessment of the robustness of the results.

\subsubsection{Regional climate models}

One can distinguish regional climate model (RCM) simulations by whether they are "convection-permitting" simulations (grid spacing finer than $\sim 4 \mathrm{~km}$ ) or coarser (typically $25-50 \mathrm{~km}$ grid spacing). The former can simulate features of precipitation processes, such as convective systems, that coarser models relying on convection parameterizations can only marginally resolve at best. This can affect how LSMPs influence the production of extreme events. Because of the substantial computational burden of using fine-resolution, most RCM simulations are in the coarser category.

RCM performance in simulating extreme precipitation varies seasonally and regionally, with little correlation to model performance in simulating mean precipitation, for RCMs with $50 \mathrm{~km}$ resolution (Wehner 2013). For instance, only one of the RCMs in Wehner (2013) could reproduce the local summer seasonal minimum in extreme precipitation in the Southeast US. Again this deficiency likely has its origins in cumulus parameterizations not designed at high resolution nor for extreme precipitation. Evaluations of multi-model ensembles in some regions (e.g., Colorado-Alexander et al. 2013; northeastern Canada-Monette et al. 2012; Upper Mississippi region-Kawazoe and Gutowski 2013a, b; central Alberta-Kuo et al. 2014), reveal that observed extreme precipitation falls within the range of model results, suggesting that an appropriate ensemble mean of the extremes' statistics could be an acceptable approximation. In contrast, Dominguez et al. (2012) find the ensemble members generate too much extreme precipitation for broad areas of the western US. However, observational uncertainties in the tail of the distribution are large enough to obscure the precise target that models should aim for. Analysis of the models' 
realizations of the LSMPs associated with the extreme precipitation, discussed further in the next section, can provide an additional process-based assessment of the models' simulation of extremes.

With advances in computing resources and motivated generally by the need to better simulate precipitation characteristics, RCMs have been applied at convection permitting resolutions, which require a non-hydrostatic dynamical core and horizontal resolutions of $4 \mathrm{~km}$ or less (Prein et al. 2015). There is no general agreement on improvements of daily mean precipitation in convection permitting regional climate simulations compared to coarser resolution simulations that use convective parameterizations, except perhaps for winter time precipitation in complex terrain where higher resolution allows topographic effects to be better represented (Rasmussen et al. 2011). Daily heavy precipitation is often too high compared to sparse mountainous observations (Kendon et al. 2012; Prein et al. 2013; Chan et al. 2013; Ban et al. 2014). However, more consistent improvements have been found in simulating sub-daily summertime high intensity precipitation or diurnal cycle of precipitation (Ban et al. 2014; Fosser et al. 2014; Chan et al. 2013; Gao et al. 2017) and even proxies of hazardous weather such as tornadoes, thunderstorm and large hail (Gensini and Mote 2014) by explicitly resolving convection. In simulations for two warm seasons, Yang et al. (2017) showed that convection permitting regional simulations can realistically capture the probability distribution of MCS characteristics such as MCS lifetime, event precipitation, and equivalent diameter.

Using a regional model at $1.3 \mathrm{~km}$ resolution over the Rocky Mountains in Colorado, Mahoney et al. (2012) found that despite more vigorous convection and hail generation within clouds in a warmer climate, surface hail is eliminated in the warm season due to melting by the warmer temperature. Kendon et al. (2014) applied a regional climate model at $1.5 \mathrm{~km}$ resolution over a region in the United Kingdom and found intensification of short duration rain in the future that is associated mainly with the convective core of the storm. Using convection permitting simulations at $4 \mathrm{~km}$ resolution over the CONUS, Prein et al. (2017) found that MCS frequency more than triples in North America, with a $15-40 \%$ increase in maximum precipitation rates and larger storm size resulting in up to $80 \%$ increases in total MCS precipitation volume within a $40 \mathrm{~km}$ radius around the storm center. Convection-permitting simulations have also been used to explore how individual AR events might change in a warmer climate, with the resolution important to resolving both the meteorology and the interaction with terrain (Dominguez et al. 2018; Mahoney et al. 2018). These high resolution studies have demonstrated the significant value provided by convection permitting modeling in providing insights about extreme precipitation changes and flood risk in the future.

\subsection{Simulation of LSMPs associated with precipitation extremes}

There has been less study of the large-scale weather patterns associated with extreme precipitation compared to the study of extremes themselves. Evaluating the relationship between LSMPs and extreme precipitation in simulations versus observations is important for establishing the physical credibility of climate simulation of precipitation extremes. In addition, because the spatial scale of LSMPs is wellresolved in both observations and models, the link between LSMPs and extreme precipitation can be used as a basis for both diagnostic downscaling (Cavazos 1999; Castellano and DeGaetano 2016) and for downscaling climate projections (Gao et al. 2014; Castellano and DeGaetano 2017). While the synoptic scales characteristic of LSMPs have, in general, greater predictability than smaller scales (e.g., Lorenz 1969; Droegemeier 1997; Hohenegger and Schar 2007), the predictability of specific LSMPs has not yet received much attention beyond ARs (e.g., DeFlorio et al. 2018).

\subsubsection{Atmospheric rivers}

ARs, discussed in Sect. 3.9, have a width less than $1000 \mathrm{~km}$ and length greater than $2000 \mathrm{~km}$, and their larger-scale characteristics are well resolved by global and regional climate models. In western North America and elsewhere, accurate simulation of the very heavy precipitation associated with ARs requires higher resolution of its complex coastal and mountainous orography than is available in CMIP5-class climate models. As with extratropical cyclones and tropical cyclones, various authors define ARs in different quantitative ways. In order to better understand what these differences imply, the coordinated Atmospheric River Tracking Method Intercomparison Project (ARTMIP) is currently underway (Shields et al. 2018a, b; Rutz et al. 2019).

Leung and Qian (2009) and Salathé et al. (2014) used regional models to simulate atmospheric rivers reaching the west coast of North America and found that the models, applied at $50 \mathrm{~km}$ and $36 \mathrm{~km}$, respectively, reproduced the key features. More specifically, Leung and Qian (2009) found that their 20-year-long simulation driven by global reanalysis boundary conditions captured realistic temperature and precipitation anomaly associated with atmospheric rivers that produced heavy precipitation in the western US. Dettinger (2011) analyzed simulations from seven GCMs in the CMIP3 and found that the number of days with atmospheric rivers making landfall in central California, defined using absolute threshold values of vertically integrated water vapor (IWV) and $925 \mathrm{hPa}$ winds, is generally higher in the global reanalysis than the GCMs, though the range and frequency distribution simulated by the GCMs are quite comparable. Weller et al. (2012) used bivariate extreme value 
theory to demonstrate that the Weather Research and Forecasting (WRF) regional climate model driven by reanalysis has at least some ability to reproduce extreme winter precipitation events associated with North Pacific ARs.

Warner et al. (2015) compared the 99th percentile IWV, $850 \mathrm{hPa}$ winds, and integrated vapor transport (IVT) at ocean grid points along the US west coast simulated by ten GCMs in CMIP5 with a global reanalysis. Although there is a large model spread, the multi-model mean is in close agreement with the reanalysis for IWV and winds, but is generally lower than the reanalysis for IVT. Despite the lower IVT, the models tend to produce higher values of 99th percentile precipitation compared to the NCEP/ NCAR reanalysis. However, the 99th percentile values of IVT correspond to values much higher than that typically used to define atmospheric rivers, so the above statistics correspond only to the most extreme atmospheric river events. Using the 85th percentile of IVT as thresholds for detecting atmospheric rivers for comparable absolute IVT threshold values used in the literature, Gao et al. (2015) compared the simulations of atmospheric river frequency along the west coast of North America from 24 GCMs in CMIP5. The multi-model mean meridional distribution of the number of atmospheric river days compares well with that derived from four global reanalyses, although the numbers are generally higher than the reanalyses during winter, while the opposite is true for spring. Although the multi-model mean of the CMIP5 models generally captures the overall frequency distribution of atmospheric rivers making landfall in western North America, Payne and Magnusdottir (2015) found that the performance of individual models is quite variable, with few correctly resolving the frequency distribution, interannual variability in number and amplitude of moisture flux, and median landfalling latitude.

To determine model sensitivity in simulating atmospheric rivers, Hagos et al. (2015) compared global climate simulations performed at multiple horizontal resolutions between 30 and $240 \mathrm{~km}$. Interpolating the simulations to a common grid at $240 \mathrm{~km}$ grid spacing, they found that the frequency of atmospheric rivers decreases with increasing model resolution, which reflects changes of IWV, vertical profile of water vapor, and the meridional structure of the subtropical westerlies with model resolution. The important links between the subtropical westerlies associated with the jet stream and atmospheric river frequency were further demonstrated by Hagos et al. (2016) based on analysis of a large ensemble of global simulations (Kay et al. 2015) for landfalling atmosphere rivers in western North America and by Gao et al. (2016) based on CMIP5 simulations for landfalling atmospheric rivers in western Europe. Understanding the relationships between model climatology and uncertainty of large-scale conditions, particularly the position of the subtropical and eddy-driven jet streams, and atmospheric rivers may improve modeling of the large-scale meteorological patterns associated with extreme precipitation produced by atmospheric rivers.

\subsubsection{Other large-scale circulation features}

A few analyses also evaluate other underlying, large-scale physical processes in simulations that lead to extreme precipitation (Gutowski et al. 2008, 2010, Holman and Vavrus 2012; Kawazoe and Gutowski 2013a; Notaro et al. 2013; Singh et al. 2013). The models often show more consistency with observations of features leading to extremes, such as synoptic circulation (Holman and Vavrus 2012; Kawazoe and Gutowski 2013a), than for the extreme precipitation itself, highlighting the strengths of the models to capture regional circulation features well. How well those features are represented, however, are also a function of the scale and underlying processes responsible for the pattern. Schumacher and Davis (2010) showed that in medium-range forecasts of heavy precipitation events with diverse causes, those associated with landfalling tropical cyclones had the greatest skill, whereas those associated with warm-season continental convective systems had the least skill.

A key factor for the relationship between LSMPs and extreme precipitation events is moisture convergence by large-scale circulations (e.g., Holman and Vavrus 2012; Kawazoe and Gutowski 2013a), as opposed to tapping into ambient moisture in a region. In this regard, a common feature of synoptic behavior associated with extreme daily precipitation in the simulation analyses of Gutowski et al. (2008) and Kawazoe and Gutowski (2013a) is that the largescale meteorological pattern tends to be quasi-stationary for at least one to 2 days prior to the event. For the central US cases examined by Gutowski et al. (2008) and Kawazoe and Gutowski (2013a), the LSMP consists of a 500-hPa trough to the west and ridge to the east with a surface low that steadily transports moisture into the middle of the US from the Gulf of Mexico. An opposite LSMP was also noted and simulated in Notaro et al. (2013), with a surface high over the central US and a surface low over the northeastern US, associated with heavy snowfall south of the Lakes Erie and Ontario. In this case, the moisture source (Great Lakes) is to the north of the location of heavy precipitation.

\subsubsection{Projections of future LSMP behavior associated with precipitation extremes}

As the water vapor holding capacity of the atmosphere increases with temperature following the Clausius-Clapeyron relationship or about $6-7 \%$ per ${ }^{\circ} \mathrm{C}$ local warming, it is expected that atmospheric rivers may transport more moisture, which may lead to heavier precipitation in a warmer climate. GCM simulations from CMIP3 and CMIP5 confirm 
the increasing IWV associated with atmospheric rivers in the future. However, Dettinger (2011) noted that despite increases in IWV in a warmer climate, the upslope winds associated with atmospheric rivers in central California from seven CMIP3 GCMs analyzed tend to decrease so the changes in IVT, which relate more directly to precipitation intensity, are small. Nevertheless, more notable changes are found in the number of atmospheric river days associated with extreme winters that have high frequency of atmospheric rivers, and exceptionally large IVT values higher than found historically occur occasionally, giving rise to increased flood risk in the future. Similar conclusions about the important thermodynamic contribution from increased IWV to increasing the frequency of atmospheric rivers in a warmer climate were reached by Lavers et al. (2013), Warner et al. (2015), Payne and Magnusdottir (2015), and Gao et al. (2015, 2016) using CMIP3 and CMIP5 models for North Pacific atmospheric rivers. Despite the smaller dynamical contributions from changes in winds or shifts in the jet stream to atmospheric river frequency, Hagos et al. (2016) and Gao et al. $(2015,2016)$ found that uncertainty in projecting the changes in the jet position contributes importantly to uncertainty in projecting changes in atmospheric river frequency in a warmer climate. For atmospheric rivers making landfall in western North America, dynamical or wind changes associated with the jet stream play a notable role in atmospheric river changes in southern California and Alaska (Payne and Magnusdottir 2015; Gao et al. 2015).

ENSO is understood to be one of the strongest large-scale influences characterizing the North American climates and therefore a likely influence on the characteristics of LSMPs. Meehl et al. (2007) using a global climate model found that future El Niño teleconnection patterns are projected to shift eastward and northward over the US in a warmer climate, driving increases in intense precipitation over the southern part of the US continent. While the LSMP implications of these changes have yet to be explored, ENSO has been shown to influence extreme precipitation LSMPs over the southern US (McCabe and Muller 2002; Feldl and Roe 2010). Meehl and Teng (2007) found that, with increased greenhouse gases, the upper-tropospheric base state change over the Northern midlatitudes is characterized by an anomalous wave- 5 pattern ( 5 high-low anomaly pairs spanning the full hemisphere along a latitude band), which changes the El Niño teleconnections and associated circulation over western North America. As LSMPs are often conditioned by larger-scale circulation and teleconnections, it is expected that there may be a corresponding shift in geographical location, intensity, or other characteristic of the various LSMPs associated with extreme precipitation, but this has yet to be explored.

Considering storm tracks, Favre and Gershunov (2009) examined the meridional temperature gradient response by climate change. They found a northward shift of the eastern Pacific storm track due to weakening of the equator-to-pole temperature gradient. This synoptic-scale feedback favors anticyclonic circulations off the US west coast and more cyclonic conditions at higher latitudes, causing a reduction in the frequency of intense precipitation over southwestern North America (California and northern Mexico) (Favre and Gershunov 2009). Fuentes-Franco et al. (2014) also discerned in future projections poorer conditions for precipitation over Mexico and Central America caused by a change in the Caribbean low-level jet.

Studies of extreme precipitation over the central US have found it often occurs when there is a slow moving cut-offlow or deep trough system, with corresponding moisture transport from the Gulf of Mexico and moisture flux convergence (Holman and Vavrus 2012; Kawazoe and Gutowski 2013a). This circulation pattern for extreme precipitation appears to be robust with climate change (Gutowski et al. 2008). In addition, increased atmospheric moisture in this pattern leads to more extreme precipitation over the central US in a warmer climate. Song et al. (2018) found that the North Atlantic Subtropical High (NASH) and North Pacific Subtropical High (NPSH) strengthen more in spring than summer under future warming. Associated with the enhancement of the Great Plain low level jet and northward shift of the NASH in spring, precipitation is enhanced over the northern Great Plains and northeastern US. Meanwhile, enhancement and northward shift of the NPSH in spring increases precipitation in the northwestern US and decreases precipitation in the southwestern US during spring. For the southeastern US region, $\mathrm{Li}$ et al. (2013) and $\mathrm{Li}$ and $\mathrm{Li}$ (2014) emphasized the important role of a projected westward shift in the NASH, which would provide favorable conditions for more frequent summer precipitation extremes over the southeastern US. They found that changes in atmospheric dynamics significantly regulate the regional hydrological cycle.

\section{Summary and discussion}

Large-scale meteorological patterns (LSMPs) are recurrent synoptic-scale patterns in circulation or thermodynamic fields that play a primary role in individual weather events. We have surveyed the relationship of LSMPs to the occurrence of extreme precipitation over North America in terms of definitions and data, dynamical mechanisms, model representation, and climate change trends. While LSMPs are not the sole factor in determining extreme precipitation, they play an important role in many events and have spatial and temporal scales that are well-resolved in both forecast and climate models, have medium-range weather predictability, 
and may provide the potential for statistical downscaling in seasonal and climate change contexts.

Data, definitions, and methodology: There is considerable data-related uncertainty in identifying extremes in the existing observational precipitation datasets and some seasonal and geographic limitations in analyzing the related circulations in atmospheric reanalysis datasets. Of the five observed precipitation datasets compared here, there is only good general agreement at $2^{\circ} \times 2^{\circ}$ resolution for moderately extreme values of rainfall $\left(20 \mathrm{~mm} \mathrm{day}^{-1}\right.$ and below). Many different definitions of "extreme" are in use making it difficult to directly compare the results of different studies. A range of methodologies have been used to identify LSMPs, including composites based on manual synoptic typing, regressionbased approaches, and automated pattern-extracting methods such as self-organizing maps and cluster analysis. Additional factors have sometimes been considered to further subdivide event types, including consideration of moisture transport and dynamical factors. It is possible to make extreme value distributions conditional on an external factor like an LSMP, although this method has not been widely explored yet.

LSMPs and related dynamical mechanisms: Several types of meteorological systems (extratropical cyclones, tropical cyclones, MCS, mesohighs) and several mechanisms (fronts, atmospheric rivers, orographic ascent) have been shown to be important for LSMPs associated with extreme precipitation over North America. Fronts and synoptic storms are important factors in many extreme events, although the extreme precipitation is usually realized through mesoscale processes organized, enhanced, or triggered by the largerscale circulation. The same general category of LSMP (e.g., synoptic storms) can have both important regional differences as well as multiple sub-types, with significant differences in circulation pattern, relationship to other factors (e.g., fronts), and dynamical mechanisms.

Trends: Consideration of trends in terms of LSMPs has been limited so far. Extreme value statistics are a promising technique for assessing trends as they can formally account for both the rate of exceeding a high threshold and the excess over a high threshold (that is, both rate of occurrence and intensity). Application in the context of non-stationary climate extremes has, however, been limited. Both the block maxima and peaks-over-threshold (POT) approaches have advantages and disadvantages.

Model realization of extremes and associated circulations: CMIP5 magnitudes of 20-year return levels are comparable to those in reanalysis precipitation for much of North America but much lower than that obtained from gridded station data although there are substantial observational uncertainties. Agreement is generally better in winter than in summer, when cumulus convection processes are important. Models reproduce probability distributions fairly well until they get to the tails. There are some improvements with winter complex terrain events at convection-permitting resolution $(1-4 \mathrm{~km})$. The general features of atmospheric river events are reproduced, although models generally produced more events than observed, but with the number decreasing as resolution increases. The models are generally better at capturing synoptic-scale features associated with extreme precipitation than extreme precipitation, itself; e.g., they are able to capture circulations associated with large-scale moisture transport for events in the central US and Great Lakes. This is consistent with the historical trend for much higher skill in forecasting mass fields than in forecasting precipitation. However, there has not been much assessment of models' ability to reproduce the LSMPs considered here; that is, assessing whether the models are producing extreme precipitation for the right dynamical reasons.

Projections: Aside from atmospheric rivers, there has been only limited analysis of projections of LSMPs. Changes in atmospheric rivers have been examined, with some studies showing some cancellation of factors-increased frequency but also increased stability. However, results depend strongly on the quantitative atmospheric river definition. There is also some suggestion of a regionally- and seasonally-dependent cancellation of influence between a weakening in storm tracks but increases in moisture availability and transport into the central US.

Knowledge gaps: In terms of our overall understanding of the relationship between LSMPs and extreme precipitation for North America, it is clear that LSMPs are an important factor, but detailed and dynamically-oriented studies have been primarily limited to regional or local analysis. For example, we know that fronts are associated with many extremes but we do not yet have a full understanding of the physical mechanisms by which fronts enhance the favorability for extreme precipitation and how these mechanisms vary regionally and seasonally. The definition of "extreme" varies considerably from study to study and it is not clear how transferable the results are. These limitations circumscribe our current understanding of the underlying dynamics.

Our survey of the previous literature offers a number of perspectives for future research:

- Observational uncertainty in the gridded products necessary to validate climate models is very high for extreme precipitation, even over the well-observed CONUS. Additionally, the available observational data in many areas may not be sufficient to well constrain estimates of the role of covariates in non-stationary extreme value 
models ( $\mathrm{Li}$ et al. 2019). Gridding procedures designed for the tails of the distribution need to be critically examined and new gridded extreme precipitation data products produced, considering both the most accurate representation of the observed data and the most consistent approach to model evaluation.

- Physically-based covariates bring additional physical information to extreme value analyses and this type of activity is still relatively new. It can be especially useful by incorporating a climate change based covariate to allow time dependent statistical models, permitting the analyses of much longer time series.

- The links between broad categories of LSMPs and extreme precipitation are well-established and useful focus areas for future observational research include consideration of different circulation patterns within categories, how the large-scale circulation relates to the embedded mesoscale circulations that are usually the proximate causes of the extreme precipitation, and how these relationships vary by season and region. The relationship between the strength of the LSMPs and the occurrence of extreme values of precipitation is still not well understood in many instances, and seems to have a closer relationship in some cases (fronts) than in others (extratropical cyclones). While a range of definitions of extreme is useful due to the different goals and audiences for extreme precipitation studies, more consideration of the sensitivity of the results to the definition used would be helpful.

- A better understanding of what is needed from forecasting and climate model projections would help guide research. A large portion of analyses of simulations of precipitation extremes focuses on civil engineering needs. Other needs, such as for agriculture, may help broaden the understanding of extremes and their impacts. The engineering need challenges models to simulate well short-term (daily or shorter) extreme events, although higher resolution helps. Comparisons between CMIP5 results and the forthcoming higher-resolution CMIP6 simulations and projections will be informative. Observational sources are challenged to provide daily and subdaily observations for large areas. Increasing resolution in GCMs appears to reduce discretization errors but significant errors in extreme precipitation traced to cumulus convection parameterizations remain. Convection-permitting simulations with grid spacings of a few kilometers have shown both improved and degraded simulation of extreme precipitation compared to coarser resolution simulations depending on season but show promise for insights into certain types of future flood risk. The synoptic scales of LSMPs provide potential for statistical downscaling of forecasts and projections but the ability of models to accurately simulate the LSMP relation- ships and the short-term to subseasonal predictability of LSMPs remains to be fully assessed. The LSMP-extreme precipitation relationships also provide a dynamicallybased perspective for evaluating model simulation of extremes.

Acknowledgements This paper is an output of the US Climate and Ocean-Variability, Predictability, and Change (CLIVAR) Extremes Working Group, and the support of US CLIVAR is gratefully acknowledged. The National Center for Atmospheric Research is sponsored by the National Science Foundation. Mathew Barlow gratefully acknowledges support from NSF AGS-1623912. Seung-Ki Min was supported by the Korea Meteorological Administration Research and Development Program under Grant KMI2018-03610. The comments from four anonymous reviewers and Dr. Francis Zwiers helped to greatly improve the paper.

Open Access This article is distributed under the terms of the Creative Commons Attribution 4.0 International License (http://creativeco mmons.org/licenses/by/4.0/), which permits unrestricted use, distribution, and reproduction in any medium, provided you give appropriate credit to the original author(s) and the source, provide a link to the Creative Commons license, and indicate if changes were made.

\section{References}

Acero FJ, García JA, Gallego MC (2010) Peaks-over-threshold study of trends in extreme rainfall over the Iberian Peninsula. J Clim 24:1089-1105

Adam JC, Lettenmaier DP (2003) Adjustment of global gridded precipitation for systematic bias. J Geophys Res 108:1-14

Agel L, Barlow M, Feldstein SB, Gutowski WJ (2017) Identification of large-scale meteorological patterns associated with extreme precipitation in the US northeast. Clim Dyn. https://doi.org/10.1007/ s00382-017-3724-8

Agel L, Barlow M, Colby F, Binder H, Catto JL, Hoell A, Cohen J (2019) Dynamical analysis of extreme precipitation in the US northeast based on large-scale meteorological patterns. Clim Dyn 52:1739-1760

Alexander L et al (2006) Global observed changes in daily climate extremes of temperature and precipitation. J Geophys Res 111:D05109

Alexander MA, Scott JD, Mahoney K, Barsugli J (2013) Greenhouse gas induced changes in summer precipitation over Colorado in NARCCAP regional climate models. J Clim 26:8690-8697. https ://doi.org/10.1175/JCLI-D-13-00088.1

Archambault HM, Bosart LF, Keyser D, Cordeira JM (2013) A climatological analysis of the extratropical flow response to recurving western North Pacific tropical cyclones. Mon Weather Rev 141:2325-2346

Atallah EH, Bosart LF (2003) The extratropical transition and precipitation distribution of Hurricane Floyd (1999). Mon Weather Rev 131:1063-1081

Atallah E, Bosart LF, Aiyyer AR (2007) Precipitation distribution associated with landfalling tropical cyclones over the Eastern United States. Mon Weather Rev 135:2185-2206

Ban N, Schmidli J, Schear C (2014) Evaluation of the convectionresolving regional climate modeling approach in decade-long simulations. J Geophys Res Atmos 119(13):7889-7907 
Barlow M (2011) Influence of hurricane-related activity on North American extreme precipitation. Geophys Res Lett 38:L04705

Barnes EA, Polvani L (2013) Response of the midlatitude jets, and of their variability, to increased greenhouse gases in the CMIP5 models. J Clim 26:7117-7135

Blake ES, Zelinsky DA (2018) National Hurricane Center tropical cyclone report: Hurricane Harvey (Miami, FL: N H Center), p 76

Bodner MJ, Junker NW, Grumm RH, Schumacher RS (2011) Comparison of atmospheric circulation patterns during the 2008 and 1993 historic Midwest floods. Natl Weather Digest 35:103-119

Bolvin DT, Adler RF, Huffman GJ, Nelkin EJ, Poutiainen JP (2009) Comparison of GPCP monthly and daily precipitation estimates with high-latitude gauge observations. J Appl Meteorol Clim 48:1843-1857

Bosart LF (1984) The Texas Coastal Rainstorm of 17-21 September 1979: an example of synoptic mesoscale interaction. Mon Weather Rev 112:1108-1133

Bosart LF, Carr FH (1978) A case study of excessive rainfall centered around Wellsville, New York, 20-21 June 1972. Mon Weather Rev 106:348-362

Bosart LF, Dean DB (1991) The Agnes Rainstorm of June 1972: surface feature evolution culminating in inland storm redevelopment. Weather Forecast 6:515-537

Bosart LF, Sanders F (1981) The Johnstown flood of July 1977: a long-lived convective system. J Atmos Sci 38:1616-1642

Bosart LF, Lai C-C, Weisman RA (1992) A Case study of heavy rainfall associated with weak cyclogenesis in the Northwest Gulf of Mexico. Mon Weather Rev 120:2469-2500

Bosart LF, Cordeira JM, Galarneau TJ Jr, Moore BJ, Archambault HM (2008) An analysis of multiple predecessor rain events ahead of Tropical Cyclones Ike and Lowell: 10-15 September 2008. Mon Weather Rev 140:1081-1107

Bosilovich MG (2013) Regional climate and variability of NASA MERRA and recent reanalyses: US summertime precipitation and temperature. J Appl Meteorol Climatol 52:1939-1951. https://doi.org/10.1175/JAMC-D-12-0291.1

Bosilovich MG, Akella S, Coy L, Cullather R, Draper C, Gelaro R, Kovach R, Liu Q, Molod A, Norris P, Wargan K, Chao W, Reichle R, Takacs L, Vikhliaev Y, Bloom S, Collow A, Firth S, Labow G, Partyka G, Pawson S, Reale O, Schubert SD, Suarez M (2015) MERRA-2: initial evaluation of the climate, technical report series on global modeling and data assimilation, vol 43, NASA/TM-2015-104606/Vol. 43, pp 136. http:// gmao.gsfc.nasa.gov/reanalysis/MERRA-2/docs/

Bradley AA, Smith JA (1994) The hydrometeorological environment of extreme rainstorms in the southern plains of the United States. J Appl Meteorol 33(12):1418-1431

Brigode P, Mićović Z, Bernardara P, Paquet E, Garavaglia F, Gailhard J, Ribstein P (2013) Linking ENSO and heavy rainfall events over coastal British Columbia through a weather pattern classification. Hydrol Earth Syst Sci 17(4):1455-1473

Caracena F, Maddox RA, Hoxit LR, Chappell CF (1979) Mesoanalysis of the Big Thompson storm. Mon Weather Rev 107:1-17

Carr FH, Bosart LF (1978) A diagnostic evaluation of rainfall predictability for Tropical Storm Agnes, June 1972. Mon Weather Rev 106:363-374

Castellano CM, DeGaetano AT (2016) A multi-step approach for downscaling daily precipitation extremes from historical analogues. Int J Climatol 36:1797-1807

Castellano CM, DeGaetano AT (2017) Downscaling extreme precipitation from CMIP5 simulations using historical analogs. J Appl Meteorol Climatol 56:2421-2439

Catto JL, Pfahl S (2013) The importance of fronts for extreme precipitation. J Geophys Res Atmos 118:10791-710801. https:// doi.org/10.1002/jgrd.50852
Catto JL, Madonna E, Joos H, Rudeva I, Simmonds I (2015) Global relationship between fronts and warm Conveyor Belts and the impact on extreme precipitation. J Clim 28:8411-8429. https ://doi.org/10.1175/jcli-d-15-0171.1

Cavanaugh NR, Gershunov A (2015) Probabilistic tail dependence of intense precipitation on spatiotemporal scale in observations, reanalyses, and GCMs. Clim Dyn 45:2965-2975. https://doi. org/10.1007/s00382-015-2517-1

Cavazos T (1999) Large-scale circulation anomalies conducive to extreme precipitation events and derivation of daily rainfall in Northeastern Mexico and Southeastern Texas. J Clim 12:1506-1523

Cayan DR, Das T, Pierce DW, Barnett TP, Tyree M, Gershunov A (2010) Future dryness in the southwest US and the hydrology of the early 21 st century drought. PNAS 107(50):21271-21276

Ceres RL, Forest CE, Keller K (2017) Understanding the detectability of potential changes to the 100-year peak storm surge. Clim Change 145:221-235

Chan SC, Kendon EJ, Fowler HJ, Blenkinsop S, Ferro CA, Stephenson DB (2013) Does increasing the spatial resolution of a regional climate model improve the simulated daily precipitation? Clim Dyn 41(5-6):1475-1495

Chappell CF (1986) Quasi-stationary convective events. In: Ray PS (ed) Mesoscale meteorology and forecasting. American Meteor Society, New York, pp 289-309

Charba JP, Harrell III AW, Lackner III AC (1992) A monthly precipitation amount climatology derived from published atlas maps: Development of a digital data base. TDL Office Note 92-7 NOAA US Department of Commerce, $\mathrm{p} 20$

Chen C, Knutson T (2008) On the verification and comparison of extreme rainfall indices from climate models. J Clim 21:1605-1621

Coles S (2001) An introduction to statistical modeling of extreme values. Springer, London

Collow ABM, Bosilovich MG, Koster RD (2016) Large-scale influences on summertime extreme precipitation in the Northeastern United States. J Hydrometeorol 17:3045-3061. https://doi. org/10.1175/JHM-D-16-0091.1

Corbosiero KL, Dickinson MJ, Bosart LF (2009) The contribution of Eastern North Pacific Tropical cyclones to the rainfall climatology of the Southwest United States. Mon Weather Rev 137:2415-2435

Corfidi SF (2003) Cold pools and MCS propagation: forecasting the motion of downwind-developing MCSs. Weather Forecast 18:997-1017

Corfidi SF, Merritt JH, Fritsch JM (1996) Predicting the movement of mesoscale convective complexes. Weather Forecast 11:41-46

Covey C, AcutaRao KM, Fiorino M, Gleckler PJ, Taylor KE, Wehner MF (2002) Intercomparison of climate data sets as a measure of observational uncertainty. PCMDI Report \#69 LLNL Report UCRL-ID-147371

Cressman GP (1959) An operational objective analysis system. Mon Weather Rev 87:367-374

Dacre HF, Clark PA, Martinez-Alvarado O, Stringer MA, Lavers DA (2015) How do atmospheric rivers form? Bull Am Meteorol Soc 96(8):1243-1255

Daly C, Taylor GH, Gibson WP (1997) The PRISM approach to mapping precipitation and temperature. In: Proceedings of 10th AMS conference on applied climatology, American Meteorological Society, Reno, NV, Oct 20-23, pp 10-12

Das T, Dettinger MD, Cayan DR, Hidalgo HG (2011) Potential increase in floods in California's Sierra Nevada under future climate projections. Clim Change. https://doi.org/10.1007/s1058 4-011-0298-z 
Davis RS (2001) Flash flood forecast and detection methods. Severe Convective Storms, Meteorol Monogr, No. 50, American Meteor Society, pp 481-525

Davis CA, Trier SB (2002) Cloud-resolving simulations of mesoscale vortex intensification and its effect on a serial mesoscale convective system. Mon Weather Rev 130:2839-2858

Dee DP, Uppala SM, Simmons AJ, Berrisford P, Poli P, Kobayashi S, Andrae U, Balmaseda MA, Balsamo G, Bauer P, Bechtold P, Beljaars ACM, van de Berg L, Bidlot J, Bormann N, Delsol C, Dragani R, Fuentes M, Geer AJ, Haimberger L, Healy SB, Hersbach H, Hólm EV, Isaksen L, Kållberg P, Köhler M, Matricardi M, McNally AP, Monge-Sanz BM, Morcrette J-J, Park B-K, Peubey C, de Rosnay P, Tavolato C, Thépaut J-N, Vitart F (2011) The ERA-Interim reanalysis: configuration and performance of the data assimilation system. Q J R Meteorol Soc 137:553-597. https://doi.org/10.1002/qj.828

DeFlorio MJ, Waliser DE, Guan B, Lavers DA, Ralph FM, Vitart F (2018) Global assessment of atmospheric river prediction skill. J Hydrometeorol 19:409-426

Dettinger MD (2011) Climate change, atmospheric rivers and floods in California-a multimodel analysis of storm frequency and magnitude changes. J Am Water Res Assoc 47:514-523

Dirmeyer PA, Kinter JL (2009) The "Maya Express": floods in the US. Midwest Eos 90:101-102

Dominguez F, Rivera E, Lettenmaier DP, Castro CL (2012) Changes in winter precipitation extremes for the western United States under a warmer climate as simulated by regional climate models. Geophys Res Lett 39:L05803. https://doi. org/10.1029/2011GL050762

Dominguez F, Dall'Erba S, Huang S, Avelino A, Mehran A, Hu H, Schmidt A, Schick L, Lettenmaier D (2018) Tracking an atmospheric river in a warmer climate: from water vapor to economic impacts. Earth Sys Dyn 9:249-266

Donat MG, Sillmann J, Wild S, Alexander LV, Lippmann T, Zwiers FW (2014) Consistency of temperature and precipitation extremes across various global gridded in situ and reanalysis data sets. J Clim 27:5019-5035. https://doi.org/10.1175/JCLID-13-00405.1

Doswell CA III, Brooks HE, Maddox RA (1996) Flash flood forecasting: an ingredients-based methodology. Weather Forecast 11:560-581

Droegemeier KK (1997) The numerical prediction of thunderstorms: challenges, potential benefits, and results from real-time operational tests. WMO Bull 46:324-336

Durkee JD, Campbell L, Berry K, Jordan D, Goodrich G, Mahmood $R$, Foster S (2012) A synoptic perspective of the record 1-2 May 2010 mid-South heavy precipitation event. Bull Am Meteorol Soc 93:611-620

Easterling DR, Kunkel KE, Wehner MF, Sun L (2016) Detection and attribution of climate extremes in the observed record. Weather Clim Extremes 11:17-27. https://doi.org/10.1016/j. wace.2016.01.001

Ely LL, Enzel Y, Cayan DR (1994) Anomalous North Pacific atmospheric circulation and large winter floods in the southwestern United States. J Clim 7:977-987

Favre A, Gershunov A (2009) North Pacific cyclonic and anticyclonic transients in a global warming context: possible consequences for Western North American daily precipitation and temperature extremes. Clim Dyn 32:969-987. https://doi.org/10.1007/s0038 2-008-0417-3

Feldl N, Roe GH (2010) Synoptic weather patterns associated with intense ENSO rainfall in the southwest United States. Geophys Res Lett 37:23

Feng Z, Leung LR, Hagos S, Houze RA, Burleyson CD, Balaguru K (2016) More frequent intense and long-lived storms dominate the trend in central US rainfall. Nat Commun 7:13429. https://doi. org/10.1038/ncomms 13429

Fosser G, Khodayar S, Berg P (2014) Benefit of convection permitting climate model simulations in the representation of convective precipitation. Clim Dyn 2014:1-16

Fritsch JM, Murphy JD, Kain JS (1994) Warm-core vortex amplification over land. J Atmos Sci 51:1780-1807

Fu R, Yin L, Li W, Arias PA, Dickinson RE, Huang L, Chakraborty S, Fernandes K, Liebmann B, Fisher R et al (2013) Increased dry-season length over southern Amazonia in recent decades and its implication for future climate projection. Proc Natl Acad Sci USA 110:18110-18115

Fuentes-Franco R, Coppola E, Giorgi F, Pavia EG, Diro GT, Graef F (2014) Inter-annual variability of precipitation over Southern Mexico and Central America and its relationship to sea surface temperature from a set of future projections from CMIP5 GCMs and RegCM4 CORDEX simulations. Clim Dyn. https://doi. org/10.1007/s00382-014-2258-6

Furrer EM, Katz RW (2008) Improving the simulation of extreme precipitation events by stochastic weather generators. Water Resour Res. https://doi.org/10.1029/2008WR007316

Galarneau TJ Jr, Bosart LF, Schumacher RS (2010) Predecessor rain events ahead of tropical cyclones. Mon Weather Rev 138:3272-3297

Gao X, Schlosser CA, Xie P, Monier E, Entekhabi (2014) An analogue approach to identify heavy precipitation events: evaluation and application to CMIP5 climate models in the United States. J Clim 27:5941-5963. https://doi.org/10.1175/JCLI-D-13-00598.1

Gao Y, Lu J, Leung LR, Yang Q, Hagos S, Qian Y (2015) Dynamical and thermodynamical modulations on future changes of landfalling atmospheric rivers over western North America. Geophys Res Lett 42:7179-7186. https://doi.org/10.1002/2015GL065435

Gao Y, Lu J, Leung LR (2016) Uncertainties in projecting future changes in atmospheric rivers and their impacts on heavy precipitation over Europe. J Clim 29:6711-6726. https://doi. org/10.1175/JCLI-D-16-0088.1

Gao Y, Leung LR, Zhao C, Hagos S (2017) Sensitivity of summer precipitation to model resolution and convective parameterizations across gray zone resolutions. J Geophys Res 122:2714-2733. https://doi.org/10.1002/2016JD025896

Gelaro R et al (2017) MERRA-2 overview: the modern-era retrospective analysis for research and applications, Version 2 (MERRA2). J Clim. https://doi.org/10.1175/JCLI-D-16-0758.1

Gensini VA, Mote TL (2014) Estimations of hazardous convective weather in the united states using dynamical downscaling. J Clim 27(17):6581-6589

Gershunov A, Rajagopalan B, Overpeck J, Guirguis K, Cayan D, Hughes M, Mettinger M, Castro C, Schwartz RE, Anderson M, Ray AF, Barsugli J, Cavazos T, Alexander M (2013) Future climate: projected extremes, chapter 7 in assessment of climate change in the Southwest United States: a report prepared for the National Climate Assessment. In: Garfin G, Jardine A, Merideth R, Black M, LeRoy S (eds) A report by the Southwest climate alliance. Island Press, Washington, DC, pp 126-147

Gershunov A, Shulgina TM, Ralph FM, Lavers D, Rutz JJ (2017) Assessing climate-scale variability of Atmospheric Rivers affecting western North America. Geophys Res Lett. https://doi. org/10.1002/2017GL074175

Gershunov A, Shulgina TM, Clemesha RES, Guirguis K, Pierce DW, Dettinger MD, Lavers DA, Cayan DR, Polade SD, Kalansky J, Ralph FM (2019) Precipitation regime change in Western North America: the role of Atmospheric Rivers. Nat Sci Rep 9:9944. https://doi.org/10.1038/s41598-019-46169-w

Gilleland E, Katz RW (2016) extRemes 2.0: an extreme value analysis package in R. J Stat Softw 72(8):1-39 
Gleckler PJ, Taylor KE, Doutriaux C (2008) Performance metrics for climate models. J Geophys Res 113:D06104. https://doi. org/10.1029/2007JD008972

Glisan JM, Gutowski WJ Jr (2014a) WRF summer extreme daily precipitation over the CORDEX Arctic. J Geophys Res Atmos 119:1720-1732. https://doi.org/10.1002/2013JD020697

Glisan JM, Gutowski WJ Jr (2014b) WRF winter extreme daily precipitation over the North American CORDEX Arctic. J Geophys Res Atmos 119:10738-10748. https://doi.org/10.1002/2014JD0216 76

Gochis D et al (2015) The great Colorado flood of September 2013. Bull Am Meteorol Soc 96:1461-1487

Groisman PY, Knight RW, Karl TR, Easterling DR, Sun B, Lawrimore JM (2004) Contemporary changes of the hydrological cycle over the contiguous United States: trends derived from in situ observations. J Hydrometeorol 5:64-85

Groisman PY, Knight RW, Easterling DR, Karl TR, Hegerl GC (2005) Trends in intense precipitation in the climate record. J Clim 18:1326-1350

Grotjahn R, Faure G (2008) Composite predictor maps of extraordinary weather events in the Sacramento California region. Weather Forecast 23:313-335. https://doi.org/10.1175/2007WAF200 6055.1

Grotjahn R, Barlow M, Black R, Cavazos T, Gutowski W, Gyakum J, Katz R, Kumar A, Leung L-Y, Schumacher R, Wehner M (2014) US CLIVAR workshop on analyses, dynamics, and modeling of large-scale meteorological patterns associated with extreme temperature and precipitation events. US CLIVAR Report 2014-2, US CLIVAR Project Office, Washington, DC, p 42

Grotjahn R, Black R, Leung R, Wehner MW, Barlow M, Bosilovich M, Gershunov A, Gutowski WJ Jr, Gyakum JR, Katz RW, Lee Y-Y, Lim Y-K, Prabhat (2016) North American extreme temperature events and related large scale meteorological patterns: a review of statistical methods, dynamics, modeling and trends. Clim Dyn 46:1151-1184. https://doi.org/10.1007/s00382-015-2638-6

Guan B, Waliser DE, Molotch NP, Fetzer EJ, Neiman PJ (2012) Does the Madden-Julian Oscillation influence wintertime atmospheric rivers and snowpack in the Sierra Nevada? Mon Weather Rev 140:325-342. https://doi.org/10.1175/MWR-D-11-00087.1

Guirguis K, Gershunov A, Shulgina T, Subramanian A, Clemesha RES, Ralph FM (2018a) Circulation drivers of Atmospheric Rivers along the North American West Coast. GRL. https://doi. org/10.1029/2018GL079249

Guirguis K, Gershunov A, Shulgina TM, Clemesha RES, Ralph FM (2018b) Atmospheric Rivers impacting Northern California and their modulation by a variable climate. Clim Dyn. https://doi. org/10.1007/s00382-018-4532-5

Gutowski WJ, Willis SS, Patton JC, Schwedler BRJ, Arritt RW, Takle ES (2008) Changes in extreme, cold-season synoptic precipitation events under global warming. Geophys Res Lett 35:L20710. https://doi.org/10.1029/2008GL035516

Gutowski WJ et al (2010) Regional extreme monthly precipitation simulated by NARCCAP RCMs. J Hydrometeorol 11:1373-1379. https://doi.org/10.1175/2010JHM1297.1

Gyakum JR (2008) The application of Fred Sanders' teaching to current research on extreme cold-season precipitation events in the Saint Lawrence River Valley Region. Meteorol Mono 33:241-250

Hagos S, Leung LR, Yang Q, Zhao C, Lu J (2015) Resolution and dynamical core dependence of atmospheric river frequency in global model simulations. J Clim 28:2764-2776

Hagos SM, Leung LR, Yoon J-H, Lu J, Gao Y (2016) A projection of changes in landfalling atmospheric river frequency and extreme precipitation over Western North America from the large ensemble CESM simulations. Geophys Res Lett 43:1357-1363. https ://doi.org/10.1002/2015GL067392
Halmstad A, Najafi MR, Moradhkani H (2013) Analysis of precipitation extremes with the assessment of regional climate models over the Willamette River Basin, USA. Hydrol Process 27:25792590. https://doi.org/10.1002/hyp.9376

Hamada A, Takayabu YN, Liu C, Zipser EJ (2015) Weak linkage between the heaviest rainfall and the tallest storms. Nat Commun. https://doi.org/10.1038/ncomms 7213

Hanel M, Buishand TS, Ferro CAT (2009) A non-stationary index flood model for precipitation extremes in transient regional climate model simulations. J Geophys Res. https://doi. org/10.1029/2009JD011712

Hart R, Grumm RH (2001) Using normalized climatological anomalies to rank synoptic-scale events objectively. Mon Weather Rev 129:2426-2442

Herold N, Alexander LV, Donat MG, Contractor S, Becker A (2016) How much does it rain over land? Geophys Res Lett 43:341-348

Herrera S, Kotlarski S, Soares PM, Cardoso RM, Jaczewski A, Gutiérrez JM, Maraun D (2018) Uncertainty in gridded precipitation products: influence of station density, interpolation method and grid resolution. Int J Climatol. https://doi.org/10.1002/joc.5878

Higgins J-K, Schemm E, Shi W, Leetmaa A (2000a) Extreme precipitation events in the western United States related to tropical forcing. J Clim 13:793-820

Higgins RW, Shi W, Yarosh E, Joyce R (2000) Improved United States precipitation quality control system and analysis, NCEP/Climate Prediction Center ATLAS No. 7, Camp Springs, MD 20746, USA, p 40

Highfield WE, Norman SA, Brody SD (2013) Examining the 100-year floodplain as a metric of risk, loss, and household adjustment. Risk Anal Int J 33:186-191

Hohenegger C, Schar C (2007) Atmospheric predictability at synoptic versus cloud-resolving scales. Bull Am Meteorol Soc 88:1783-1794

Holman KD, Vavrus SJ (2012) Understanding simulated extreme precipitation events in Madison, Wisconsin, and the role of moisture flux convergence during the late twentieth and twenty-first centuries. J Hydrometor 13:877-894

Houze RA Jr (2004) Mesoscale convective systems. Rev Geophys 42:RG4003. https://doi.org/10.1029/2004rg000150

Huffman GJ, Adler RF, Morrissey MM, Curtis S, Joyce R, McGavock B, Susskind J (2001) Global precipitation at one-degree daily resolution from multi-satellite observations. J Hydrometeorol 2:36-50

Huffman GJ, Adler RF, Bolvin DT, Gu G, Nelkin EJ, Bowman KP, Hong Y, Stocker EF, Wolff DB (2007) The TRMM multi-satellite precipitation analysis: quasi-global, multi-year, combined-sensor precipitation estimates at fine scale. J Hydrometeorol 8:38-55

Junker NW, Schneider RS, Fauver SL (1999) A study of heavy rainfall events during the Great Midwest Flood of 1993. Weather Forecast 14:701-712

Junker NW, Grumm RH, Hart R, Bosart LF, Bell KM, Pereira FJ (2008) Use of normalized anomaly fields to anticipate extreme rainfall in the mountains of Northern California. Weather Forecast 23:336-356

Junker NW, Brennan MJ, Pereira F, Bodner MJ, Grumm RH (2009) Assessing the potential for rare precipitation events with standardized anomalies and ensemble guidance at the hydrometeorological prediction center. Bull Am Meteorol Soc 90:445-453

Kalnay E, Kanamitsu M, Kistler R, Collins W, Deaven D, Gandin L, Iredell M, Saha S, White G, Woollen J, Zhu Y, Leetmaa A, Reynolds R, Chelliah M, Ebisuzaki W, Higgins W, Janowiak J, Mo KC, Ropelewski C, Wang J, Jenne R, Joseph D (1996) The NCEP/NCAR 40-year reanalysis project. Bull Am Meteorol Soc $77: 437-471$ 
Katz RW (2010) Statistics of extremes in climate change. Clim Change 100:71-76

Katz RW (2013) Statistical methods for nonstationary extremes. In: AghaKouchak A, Easterling D, Hsu K, Schubert S, Sorooshian $\mathrm{S}$ (eds) Extremes in a changing climate: detection, analysis and uncertainty. Springer, Dordrecht, pp 15-37

Kawazoe S, Gutowski WJ (2013a) Regional, extreme daily precipitation in CMIP5 simulations. J Hydrometeorol 14:1228-1242

Kawazoe S, Gutowski WJ (2013b) Regional, extreme daily precipitation in NARCCAP simulations. J Hydrometeorol 14:1212-1227

Kay JE, Deser C, Phillips A, Mai A, Hannay C, Strand G, Arblaster J, Bates S, Danabasoglu G, Edwards J, Holland M, Kushner P, Lamarque J-F, Lawrence D, Lindsay K, Middleton A, Munoz E, Neale R, Oleson K, Polvani L, Vertenstein M (2015) The community earth system model (CESM) large ensemble project: a community resource for studying climate change in the presence of internal climate variability. Bull Am Meteorol Soc 96:1333-1349. https://doi.org/10.1175/BAMS-D-13-00255.1

Keim BD (1996) Spatial, synoptic, and seasonal patterns of heavy rainfall in the southeastern United States. Phys Geogr 17:313-328

Kendon EJ, Roberts NM, Senior CA, Roberts MJ (2012) Realism of rainfall in a very high resolution regional climate model. J Clim 25(17):5791-5806

Kendon EJ, Roberts NM, Fowler HJ, Roberts MJ, Chan SC, Senior CA (2014) Heavier summer downpours with climate change revealed by weather forecast resolution model. Nat Clim Change. https:// doi.org/10.1038/NCLIMATE2258

Kharin VV, Zwiers FW, Zhang X, Wehner M (2013) Changes in temperature and precipitation extremes in the CMIP5 ensemble. Clim Change 119:345-357. https://doi.org/10.1007/s1058 4-013-0705-8

Kingsmill DE, Neiman PJ, Moore BJ, Hughes M, Yuter SE, Ralph FM (2013) Kinematic and thermodynamic structures of Sierra Barrier Jets and overrunning atmospheric rivers during a landfalling winter storm in Northern California. Mon Weather Rev 141:2015-2036

Knippertz P, Wernli H, Gläser G (2013) A global climatology of tropical moisture exports. J Clim 26:3031-3045

Kozubowski TJ, Panorska AK, Qeadan F, Gershunov A, Rominger D (2009) Testing exponentiality versus Pareto distribution via likelihood ratio. Commun Stat Simul Comput 38:118-139

Kunkel KE, Easterling DR, Kristovich DAR, Gleason B, Stoecker L, Smith R (2012) Meteorological causes of the secular variations in observed extreme precipitation events for the conterminous United States. J Hydrometeorol 13:1131-1141. https://doi. org/10.1175/jhm-d-11-0108.1

Kunkel KE, Karl TR, Brooks H, Kossin J, Lawrimore J, Arndt D, Bosart L, Changnon D, Cutter S, Doesken N, Emanuel K, Groisman PY, Katz RW, Knutson T, O'Brien J, Paciorek C, Peterson T, Redmond K, Robinson D, Trapp J, Vose R, Weaver S, Wehner M, Wolter K, Wuebbles D (2013) Monitoring and understanding trends in extreme storms: state of knowledge. Bull Am Meteorol Soc 94:499-514. https://doi.org/10.1175/BAMS-D-11-00262.1

Kuo CC, Gan TY, Hanrahan J (2014) Precipitation frequency analysis based on regional climate simulations in central Alberta. J Hydrol 510:436-446. https://doi.org/10.1016/j.jhydrol.2013.12.051

Kyselý J, Picek J, Beranová R (2010) Estimating extremes in climate change simulations using the peaks-over-threshold method with a non-stationary threshold. Glob Planet Change 72:55-68

Lackmann GM (2013) The south-central US flood of May 2010: present and future. J Clim 26:4688-4709

Lackmann GM, Gyakum JR (1999) Heavy cold-season precipitation in the northwestern United States: synoptic climatology and an analysis of the flood of 17-18 January 1986. Weather Forecast 14:687-700
Laing AG, Fritsch JM (2000) The large-scale environments of the global populations of mesoscale convective complexes. Mon Weather Rev 128:2756-2776

Lapenta KD, McNaught BJ, Capriola SJ, Giordano LA, Little CD, Hrebenach SD et al (1995) The challenge of forecasting heavy rain and flooding throughout the eastern region of the national weather service. Part I: characteristics and events. Weather Forecast 10(1):78-90

Lavers DA, Villarini G (2013) Atmospheric rivers and flooding over the Central United States. J Clim 26:7829-7836

Lavers DA, Allan RP, Villarini G, Lloyd-Hughes B, Brayshaw DJ, Wade AJ (2013) Future changes in atmospheric rivers and their implications for winter flooding in Britain. Environ Res Lett 8:034010. https://doi.org/10.1088/1748-9326/8/3/034010

Lavers DA, Ralph FM, Waliser DE, Gershunov A, Dettinger MD (2015) Climate change intensification of horizontal water vapor transport in CMIP5. Geophys Res Lett 42:5617-5625. https:// doi.org/10.1002/2015GL064672

Leung LR, Qian Y (2009) Atmospheric rivers Induced heavy precipitation and flooding in the western US simulated by the WRF regional climate model. Geophys Res Lett 36:L03820. https:// doi.org/10.1029/2008g1036445

Li L, Li W (2014) Thermodynamic and dynamic contributions to future changes in regional precipitation variance: focus on the Southeastern United States. Clim Dyn. https://doi.org/10.1007/s0038 2-014-2216-3

Li L, Li W, Deng Y (2013) Summer rainfall variability over the Southeastern United States and its intensification in the 21st century as assessed by CMIP5 models. J Geophys Res Atmos 118:340-354

Li C, Zwiers F, Zhang X, Li G (2019) How much information is required to well constrain local estimates of future precipitation extremes? Earth's Future 7:11-24

Lin Y, Mitchell KE (2005) The NCEP Stage II/IV hourly precipitation analyses: development and applications. In: 19th conference on hydrology, San Diego, CA, American Meteor Society, p 1.2. https://ams.confex.com/ams/Annual2005/techprogram/paper 83847.htm

Lin Y-L, Chiao S, Wang TA, Kaplan ML, Weglarz RP (2001) Some common ingredients for heavy orographic rainfall. Weather Forecast 16:633-660

Livneh B, Rosenberg EA, Lin C, Nijssen B, Mishra V, Andreadis KM, Maurer EP, Lettenmaier DP (2013) A long-term hydrologically based dataset of land surface fluxes and states for the conterminous United States: update and extensions. J Clim 26:9384-9392

Lorenz EN (1969) The predictability of a flow which possesses many scales of motion. Tellus 21(3):289-307

Loukas A, Quick M (1996) Spatial and temporal distribution of storm precipitation in southwestern British Columbia. J Hydrol 174(1-2):37-56

Lynch SL, Schumacher RS (2014) Ensemble-based analysis of the May 2010 extreme rainfall in Tennessee and Kentucky. Mon Weather Rev 142:222-239

Maddox RA, Hoxit LR, Chappell CF, Caracena F (1978) Comparison of meteorological aspects of the Big Thompson flood and Rapid City flash floods. Mon Weather Rev 106:375-389

Maddox RA, Chappell CF, Hoxit LR (1979) Synoptic and meso- $\alpha$ scale aspects of flash flood events. Bull Am Meteorol Soc 60:115-123

Maddox RA, Canova F, Hoxit LR (1980) Meteorological characteristics of flash flood events over the western United States. Mon Weather Rev 108:1866-1877

Mahoney KM, Alexander MA, Thompson G, Barsugli J, Scott J (2012) Changes in hail and flood risk in high-resolution simulations over Colorado's mountains. Nat Clim Change 2:125-131. https://doi. org/10.1038/nclimate1344

Mahoney K, Jackson D, Neiman P, Hughes M, Darby L, Wick G, White A, Sukovich E, Cifelli R (2016) Understanding the role of 
atmospheric rivers in heavy precipitation in the Southeast United States. Mon Weather Rev 144:1617-1632

Mahoney K, Swales D, Mueller MJ, Alexander M, Hughes M, Malloy K (2018) An examination of an inland-penetrating atmospheric river flood event under potential future thermodynamic conditions. J Clim 31:6281-6297

Mailhot A, Beauregard I, Talbot G, Caya D, Biner S (2012) Future changes in intense precipitation over Canada assessed from multi-model NARCCAP ensemble simulations. Int J Climatol 32:1151-1163

Mannshardt-Shamseldin EC, Smith RL, Sain SR, Mearns LO, Cooley D (2010) Downscaling extremes: a comparison of extreme value distributions in point-source and gridded precipitation data. Ann Appl Stat 4:484-502

Maurer EP, Adam JC, Wood AW (2009) Climate model based consensus on the hydrologic impacts of climate change to the Rio Lempa basin of Central America. Hydrol Earth Syst Sci 13:183-194

McAnelly RL, Cotton WR (1989) The precipitation life cycle of mesoscale convective complexes over the central United States. Mon Weather Rev 117:784-808

McCabe GJ, Muller RA (2002) Effects of ENSO on weather-type frequencies and properties at New Orleans, Louisiana, USA. Clim Res 20(2):95-105

Meehl GA, Teng H (2007) Multi-model changes in El Niño teleconnections over North America in a future warmer climate. Clim Dyn 29:779-790. https://doi.org/10.1007/s00382-007-0268-3

Meehl GA, Tebaldi C, Teng H, Peterson TC (2007) Current and future US weather extremes and El Niño. Geophys Res Lett 34:L20704. https://doi.org/10.1029/2007g1031027

Menne MJ, Durre I, Vose RS, Gleason BE, Houston TG (2012) An overview of the global historical climatology networkdaily database. J Atmos Ocean Tech 29:897-910. https://doi. org/10.1175/JTECH-D-11-00103.1

Milrad SM, Atallah EH, Gyakum JR (2010a) A diagnostic examination of consecutive extreme cool-season precipitation events at St. John's, Newfoundland in December 2008. Weather Forecast 25:997-1026

Milrad S, Atallah E, Gyakum JR (2010b) Synoptic typing of extreme cool-season precipitation events at St. John's, Newfoundland, 1979-2005. Weather Forecast 25:562-586

Milrad SM, Atallah EH, Gyakum JR, Dookhie G (2014) Synoptic typing and precursors of heavy warm-season precipitation events at Montreal, Quebec. Weather Forecast 29:419-444. https://doi.org/10.1175/WAF-D-13-00030.1

Milrad SM, Gyakum JR, Atallah EH (2015) A meteorological analysis of the 2013 Alberta Flood. Antecedent large-scale flow pattern and synoptic-dynamic characteristics. Mon Weather Rev 143:2817-2841

Milrad SM, Lombardo K, Atallah EH, Gyakum JR (2017) Numerical simulations of the 2013 Alberta Flood: dynamics, thermodynamics, and the role of orography. Mon Weather Rev 145:3049-3072

Min SK, Zhang X, Zwiers FW, Hegerl GC (2011) Human contribution to more-intense precipitation extremes. Nature 470:378-381

Mirhosseini G, Srivastava P, Stefanova L (2013) The impact of climate change on rainfall intensity-duration-frequency (IDF) curves in Alabama. Reg Environ Change 13:25-33. https://doi. org/10.1007/s10113-012-0375-5

Mishra V, Dominguez F, Lettenmaier DP (2012) Urban precipitation extremes: how reliable are regional climate models? Geophys Res Lett 39:L03407. https://doi.org/10.1029/2011GL050658

Molod A, Takacs L, Suarez M, Bacmeister J (2015) Development of the GEOS-5 atmospheric general circulation model: evolution from MERRA to MERRA2. Geosci Model Dev 8:1339-1356. https://doi.org/10.5194/gmd-8-1339-2015
Monette A, Sushama L, Khaliq MN, Laprise R, Roy R (2012) Projected changes to precipitation extremes for northeast Canadian watersheds using a multi-RCM ensemble. J Geophys Res 117:D13106. https://doi.org/10.1029/2012JD017543

Monjo R, Gaitán E, Pórtoles J, Ribalaygua J, Torres L (2016) Changes in extreme precipitation over Spain using statistical downscaling of CMIP5 projections. Int J Climatol 36:757-769. https://doi. org/10.1002/joc. 4380

Moore JT, Glass FH, Graves CE, Rochette SM, Singer MJ (2003) The environment of warm-season elevated thunderstorms associated with heavy rainfall over the central United States. Weather Forecast 18:861-878

Moore BJ, Neiman PJ, Ralph FM, Barthold FE (2012) Physical processes associated with heavy flooding rainfall in Nashville, Tennessee, and vicinity during 1-2 May 2010: the role of an atmospheric river and mesoscale convective systems. Mon Weather Rev 140:358-378

Moore BJ, Bosart LF, Keyser D, Jurewicz ML (2013) Synoptic-scale environments of predecessor rain events occurring East of the Rocky Mountains in association with Atlantic Basin tropical cyclones. Mon Weather Rev 141:1022-1047

Moore BJ, Mahoney KM, Sukovich EM, Cifelli R, Hamill TM (2015) Climatology and environmental characteristics of extreme precipitation events in the southeastern United States. Mon Weather Rev 143:718-741

Muller RA (1977) A synoptic climatology for environmental baseline analysis: New Orleans. J Appl Meteorol 16:20-33

Murdock TQ, Sobie SR (2013) Climate Extremes in the Canadian Columbia Basin: a preliminary assessment. Pacific Climate Impacts Consortium, Victoria

National Academies of Sciences, Engineering, and Medicine (2016) Attribution of extreme weather events in the context of climate change. The National Academies Press, Washington, DC. https ://doi.org/10.17226/21852

Neiman PJ, Ralph FM, Wick GA, Lundquist JD, Dettinger MD (2008a) Meteorological characteristics and overland precipitation impacts of atmospheric rivers affecting the West Coast of North America based on eight years of SSM/I satellite observations. J Hydrometeorol 9:22-47

Neiman PJ, Ralph FM, Wick GA, Kuo Y-H, Wee T-K, Ma Z, Taylor GH, Dettinger MD (2008b) Diagnosis of an intense atmospheric river impacting the Pacific Northwest: storm summary and offshore vertical structure observed with COSMIC satellite retrievals. Mon Weather Rev 136:4398-4420

Nelson BR, Prat OP, Seo D-J, Habib E (2016) Assessment and implications of NCEP Stage IV quantitative precipitation estimates for product intercomparisons. Weather Forecast 31(2):371-394

Nesbitt SW, Zipser EJ, Kummerow CD (2004) An examination of version-5 rainfall estimates from the TRMM microwave imager, precipitation radar, and rain gauges on global, regional, and storm scales. J Appl Meteorol 43:1016-1036

Newell RE, Newell NE, Zhu Y, Scott C (1992) Tropospheric rivers?A pilot study. Geophys Res Lett 19:2401-2404

Nielsen-Gammon JW, Zhang F, Odins AM, Myoung B (2005) Extreme rainfall in Texas: patterns and predictability. Phys Geogr 26:340-364

Notaro M, Zarrin A, Vavrus S, Bennington V (2013) Simulation of heavy lake-effect snowstorms across the Great Lakes Basin by RegCM4: synoptic climatology and variability. Mon Weather Rev 141:1990-2014. https://doi.org/10.1175/mwr-d-11-00369.1

Notaro V, Liuzzo L, Freni G, La Loggia G (2015) Uncertainty analysis in the evaluation of extreme rainfall trends and its implications on urban drainage system design. Water 7:6931-6945

Pall P, Wehner M, Stone D (2014) In: Grotjahn R, Li J, Swinbank R, Volkert $\mathrm{H}$ (eds) Probabilistic extreme event attribution in dynamics and predictability of large-scale, high-impact weather and climate events, vol 3. Cambridge University Press, Cambridge, pp 37-46 
Panorska AK, Gershunov A, Kozubowski TJ (2007) From diversity to volatility: probability of daily precipitation extremes. In: Tsonis A, Elsner J (eds) Nonlinear dynamics in geosciences. Springer, New York, pp 465-484

Payne AE, Magnusdottir G (2015) An evaluation of atmospheric rivers over the North Pacific in CMIP5 and their response to warming under RCP 8.5. J Geophys Res Atmos 120:11173-11190. https ://doi.org/10.1002/2015JD023586

Peters JM, Schumacher RS (2014) Objective categorization of heavyrain-producing MCS synoptic types by rotated principal component analysis. Mon Weather Rev 142:1716-1737. https://doi. org/10.1175/MWR-D-13-00295.1

Petersen WA et al (1999) Mesoscale and radar observations of the Fort Collins flash flood of 28 July 1997. Bull Am Meteorol Soc 80:191-216

Pfahl S, Wernli H (2012) Quantifying the relevance of cyclones for precipitation extremes. J Clim 25:6770-6780. https://doi. org/10.1175/jcli-d-11-00705.1

Polade SD, Pierce DW, Cayan DR, Gershunov A, Dettinger MD (2014) The key role of dry days in precipitation regimes under climate change. Nat Sci Rep 4:4364. https://doi.org/10.1038/srep04364

Polade SD, Gershunov A, Cayan DR, Dettinger MD, Pierce DW (2017) Precipitation in a warming world: assessing projected hydro-climate of California and other Mediterranean climate regions. Nat Sci Rep 7:10783. https://doi.org/10.1038/s41598-017-11285-y

Pontrelli MD, Bryan G, Fritsch JM (1999) The Madison County, Virginia, flash flood of 27 June 1995. Weather Forecast 14:384-404

Prein A, Gobiet A, Suklitsch M, Truhetz H, Awan N, Keuler K, Georgievski G (2013) Added value of convection permitting seasonal simulations. Clim Dyn 41(9-10):2655-2677

Prein AF, Langhans W, Fosser G, Ferrone A, Ban N, Goergen K, Keller M, Tölle M, Gutjahr O, Feser F, Brisson E (2015) A review on regional convection-permitting climate modeling: demonstrations, prospects, and challenges. Rev Geophys 53:323-361

Prein A, Liu C, Ikeda K, Trier S, Rasmussen R, Holland G, Clark M (2017) Increased rainfall volume from future convective storms in the US. Nat Clim Change. https://doi.org/10.1038/s41558-017-0007-7

Ralph FM, Dettinger MD (2011) Storms, floods and the science of atmospheric rivers. Eos Trans AGU 92(32):265-266

Ralph FM, Neiman PJ, Wick GA (2004) Satellite and CALJET aircraft observations of atmospheric rivers over the eastern north Pacific Ocean during the winter of 1997/98. Mon Weather Rev 132:1721-1745

Ralph FM, Dettinger MD, Cairns MM, Galarneau TJ, Eylander J (2018) Defining "Atmospheric River": how the glossary of meteorology helped resolve a debate. Bull Am Meteorol Soc 99:837-839

Rasmussen R, Liu C, Ikeda K, Gochis D, Yates D, Chen F, Tewari M, Barlage M, Dudhia J, Yu W et al (2011) High-resolution coupled climate runoff simulations of seasonal snowfall over Colorado: a process study of current and warmer climate. J Clim 24(12):3015-3048

Read LK, Vogel RM (2015) Reliability, return periods, and risk under nonstationarity. Water Res Res 51:6381-6398

Reichle RH, Liu Q (2014) Observation-corrected precipitation estimates in GEOS-5. NASA/TM-2014-104606, vol 35 http://gmao. gsfc.nasa.gov/pubs/tm/docs/Reichle734.pdf

Rienecker MM et al (2011) MERRA: NASA's modern-era retrospective analysis for research and applications. J Clim 24:3624-3648. https://doi.org/10.1175/jcli-d-11-00015.1

Risser MD, Wehner MF (2017) Attributable human-induced changes in the likelihood and magnitude of the observed extreme precipitation in the Houston, Texas region during Hurricane Harvey. Geophys Rev Lett 44:12457-12464

Risser M, Paciorek CJ, Wehner MF, O'Brien TA, Collins WD (2018) A probabilistic gridded product for daily precipitation extremes over the United States. Cli Dyn (in review)
Roberge A, Gyakum JR, Atallah E (2009) Analysis of intense poleward water vapor transports into high latitudes of western North America. Weather Forecast 24:1732-1747

Rootzén H, Katz RW (2013) Design life level: quantifying risk in a changing climate. Water Resour Res 49:5964-5972

Roth M, Buishand TA, Jongbloed G, Klein Tank AMG, Zanten JH (2012) A regional peaks-over-threshold model in a nonstationary climate. Water Res Res. https://doi.org/10.1029/2012WR012214

Rutz JJ, Steenburgh WJ (2012) Quantifying the role of atmospheric rivers in the interior western United States. Atmos Sci Lett 13:257-261. https://doi.org/10.1002/asl.392

Rutz JJ, Steenburgh WJ, Ralph FM (2014) Climatological characteristics of atmospheric rivers and their inland penetration over the Western United States. Mon Weather Rev 142:905-921. https:// doi.org/10.1175/MWR-D-13-00168.1

Rutz JJ, Shields CA, Lora JM, Payne AE, Guan B, O’Brien T, Leung LR, Ralph FM, Wehner M (2019) The atmospheric river tracking method intercomparison project (ARTMIP): quantifying uncertainties in atmospheric river climatology in preparation

Saha $S$ et al (2014) The NCEP climate forecast system version 2. J Clim 27:2185-2208. https://doi.org/10.1175/jcli-d-12-00823.1

Salathé EP, Hamlet AF, Mass CF, Lee S-Y, Stumbaugh M, Steed R (2014) Estimates of twenty-first-century flood risk in the Pacific Northwest based on regional climate model simulations. J Hydrometeorol 15:1881-1899

Sanders F (2000) Frontal focusing of a flooding rainstorm. Mon Weather Rev 128(12):4155-4159

Schär C, Ban N, Fischer EM, Rajczak J, Schmidli J, Frei C, Giorgi F, Karl TR, Kendon EJ, Klein Tank AMG, O'Gorman PA, Sillmann J, Zhang X, Zwiers FW (2016) Percentile indices for assessing changes in heavy precipitation events. Clim Change 137:201-216

Schumacher RS, Davis CA (2010) Ensemble-based forecast uncertainty analysis of diverse heavy rainfall events. Weather Forecast 25:1103-1122. https://doi.org/10.1175/2010WAF2222378.1

Schumacher RS, Galarneau TJ Jr (2012) Moisture transport into midlatitudes ahead of recurving tropical cyclones and its relevance in two predecessor rain events. Mon Weather Rev 140:1810-1827

Schumacher RS, Johnson RH (2005) Organization and environmental properties of extreme-rain-producing mesoscale convective systems. Mon Weather Rev 133:961-976

Schumacher RS, Johnson RH (2006) Characteristics of United States extreme rain events during 1999-2003. Weather Forecast 21:69-85

Schumacher RS, Johnson RH (2008) Mesoscale processes contributing to extreme rainfall in a midlatitude warm-season flash flood. Mon Weather Rev 136:3964-3986

Schumacher RS, Galarneau TJ Jr, Bosart LF (2011) Distant effects of a recurving tropical cyclone on rainfall in a midlatitude convective system: a high-impact predecessor rain event. Mon Weather Rev 139:650-667

Schumacher RS, Clark AJ, Xue M, Kong F (2013) Factors influencing the development and maintenance of nocturnal heavy-rainproducing convective systems in a storm-scale Ensemble. Mon Weather Rev 141:2778-2801

Serinaldi F (2015) Dismissing return periods! Stoch Environ Res Risk Assess 29:1179-1189

Serinaldi F, Kilsby CG (2015) Stationarity is undead: uncertainty dominates the distribution of extremes. Adv Water Res 77:17-36

Shields CA, Rutz JJ, Leung L-Y, Ralph FM, Wehner M, Kawzenuk B, \# Nguyen P (2018a) Atmospheric river tracking method intercomparison project (ARTMIP): project goals and experimental design. Geosci Model Dev 11(6):2455-2474. https://doi. org/10.5194/gmd-11-2455-2018

Shields CA, Rutz JJ, Leung LR, Ralph FM, Wehner M, O'Brien T, Pierce R (2018b) Defining uncertainties through comparison of 
atmospheric river tracking methods. Bull Am Meteorol Soc. https ://doi.org/10.1175/BAMS-D-18-0200.1

Sillmann J, Kharin VV, Zwiers FW, Zhang X, Bronaugh D (2013a) Climate extremes indices in the CMIP5 multi model ensemble: Part 1. Model evaluation in the present climate. J Geophys Res 118:1716-1733

Sillmann J, Kharin VV, Zwiers FW, Zhang X, Bronaugh D (2013b) Climate extremes indices in the CMIP5 multi model ensemble: Part 2: Future climate projections. J Geophys Res 118:2473-2493

Simmons AJ, Willett KM, Jones PD, Thorne PW, Dee DP (2010) Lowfrequency variations in surface atmospheric humidity, temperature, and precipitation: inferences from reanalyses and monthly gridded observational data sets. J Geophys Res 115:D01110. https://doi.org/10.1029/2009JD012442

Singh D, Tsiang M, Rajaratnam B, Diffenbaugh NS (2013) Precipitation extremes over the continental United States in a transient, high-resolution, ensemble climate model experiment. J Geophys Res Atmos 118:7063-7086. https://doi.org/10.1002/jgrd.50543

Solari S, Egüen M, Polo MJ, Losada MA (2017) Peaks over threshold (POT): a methodology for automatic threshold estimation using goodness of fit p-value. Water Res Res 53:2833-2849. https:// doi.org/10.1002/2016WR019426

Song F, Leung LR, Lu L, Dong L (2018) Future changes in seasonality of the North Pacific and North Atlantic subtropical highs. Geophys Res Lett. https://doi.org/10.1029/2018GL079940

Srock AF, Bosart LF (2009) Heavy precipitation associated with Southern Appalachian cold-air damming and Carolina coastal frontogenesis in advance of weak landfalling tropical storm Marco (1990). Mon Weather Rev 137:2448-2470

Stott et al (2013) Attribution of weather and climate-related events. In: Asrar GR, Hurrell JW (eds) Climate science for serving society: research, modelling and prediction priorities. Springer, Berlin, pp 307-337. ISBN 978-94-007-6691-4

Sun X, Renard B, Thyer M, Westra S, Lang M (2015) A global analysis of the asymmetric of ENSO on extreme precipitation. J Hydrol 530:51-65

Swales D, Alexander M, Hughes M (2016) Examining moisture pathways and extreme precipitation in the US Intermountain West using self-organizing maps. Geophys Res Lett 43:1727-1735

Timmermans B, Wehner M, Cooley D, O’Brien T, Thibaud E, Krishnan $\mathrm{H}$ (2018) Consistency of extremes in gridded precipitation datasets. Cli Dyn in review

Toredi A, Naveau P, Zampieri M, Schindler A, Scoccimaro E, Xoplaki E, Dijkstra HA, Gualdi S, Luterbacher J (2013) Projections of global changes in precipitation extremes from Coupled Model Intercomparison Project Phase 5 models. Geophys Res Lett 40:4887-4892

van Oldenborgh GJ, van der Wiel K, Sebastian A, Singh R, Arrighi J, Otto F, Haustein K, Li S, Vecchi G, Cullen H (2017) Attribution of extreme rainfall from Hurricane Harvey. Environ Res Lett 12:124009

Vogel RM, Yaindl C, Walter M (2011) Nonstationarity: flood magnification and recurrence reduction factors in the United States. J Am Water Res Assoc 47:464-474

Wang D, Hagen SC, Alizad K (2013) Climate change impact and uncertainty analysis of extreme rainfall events in the Apalachicola River basin, Florida. J Hydrol 480:125-135. https://doi. org/10.1016/j.jhydrol.2012.12.015

Warner MD, Mass C, Salathé EP Jr (2012) Wintertime extreme precipitation events along the Pacific Northwest coast: climatology and synoptic evolution. Mon Weather Rev 140:2021-2043. https ://doi.org/10.1175/MWR-D-11-00197.1

Warner MD, Mass CF, Salathé EP Jr (2015) Changes in winter atmospheric rivers along the North American west coast in CMIP5 climate models. J Hydrometeorol 16:118-128
Wehner MF (2013) Very extreme seasonal precipitation in the NARCCAP ensemble: model performance and projections. Clim Dyn 40:59-80. https://doi.org/10.1007/s00382-012-1393-1

Wehner MF, Smith RL, Bala G, Duffy P (2010) The effect of horizontal resolution on simulation of very extreme US precipitation events in a global atmosphere model. Clim Dyn 24:241-247

Wehner MF, Reed K, Li F, Prabhat Bacmeister J, Chen C-T, Paciorek C, Gleckler P, Sperber K, Collins WD, Gettelman A, Jablonowski C (2014) The effect of horizontal resolution on simulation quality in the Community Atmospheric Model, CAM5.1. J Model Earth Syst 6:980-997. https://doi.org/10.1002/2013MS000276

Wehner M, Prabhat, Reed K, Daithi Stone D, Collins WD, Bacmeister J (2015) Resolution dependence of future tropical cyclone projections of CAM5.1 in the US CLIVAR Hurricane Working Group idealized configurations. J Clim 28:3905-3925

Weller GB, Cooley DS, Sain SR (2012) An investigation of the pineapple express phenomenon via bivariate extreme value theory. Environmetrics 23:420-439

Westra S, Alexander LV, Zwiers FW (2013) Global increasing trends in annual maximum daily precipitation. J Clim 26:3904-3918. https://doi.org/10.1175/JCLI-D-12-00502.1

Wilson PS, Toumi R (2005) A fundamental probability distribution for heavy rainfall. Geophys Res Lett. https://doi.org/10.1029/2005GL022465

Yang Q, Houze R, Leung LR, Feng Z (2017) Environments of longlived mesoscale convective systems over the central United States in convection permitting climate simulations. J Geophys Res. https://doi.org/10.1002/2017JD027033

Zareie A, Nguyen V-T-V (2013) Urban drainage systems design in the context of climate change. In: Proceedings of the Engineering Institute of Canada Third Climate Change Technology Conference, May 27-29, Montreal, Quebec, CCTC 2013 Paper No. $1569694825, \mathrm{p} 12$

Zhang D-L, Fritsch JM (1987) Numerical simulation of the meso-b scale structure and evolution of the 1977 Johnstown flood. Part II: Inertially stable warm-core vortex and the mesoscale convective complex. J Atmos Sci 44:2593-2612

Zhang X, Wang J, Zwiers FW, Groisman PY (2010) The influence of large-scale climate variability on winter maximum daily precipitation over North America. J Clim 23:2902-2915

Zhang X, Alexander L, Hegerl GC, Jones P, Klein Tank A, Peterson TC et al (2011) Indices for monitoring changes based on daily temperature and precipitation data. WIREs Clim Change 2:851-870

Zhang X, Wan H, Zwiers FW, Hegerl GC, Min SK (2013) Attributing intensification of precipitation extremes to human influence. Geophys Res Lett 40:5252-5257

Zhang J, Howard K, Langston C, Kaney B, Qi Y, Tang L, Grams H, Wang Y, Cocks S, Martinaitis S, Arthur A, Cooper K, Brogden J, Kitzmiller D (2016) Multi-radar multi-sensor (MRMS) quantitative precipitation estimation: initial operating capabilities. Bull Am Meteorol Soc 97:621-638

Zhu Y, Newell RE (1998) A proposed algorithm for moisture fluxes from atmospheric rivers. Mon Weather Rev 126:725-735

Zhu J, Forsee W, Schumer R, Gautam M (2013) Future projections and uncertainty assessment of extreme rainfall intensity in the United States from an ensemble of climate models. Clim Change 118:469-485. https://doi.org/10.1007/s10584-012-0639-6

Zwiers FW et al (2013) Challenges in estimating and understanding recent changes in the frequency and intensity of extreme climate and weather events. In: Asrar GR, Hurrell JW (eds) Climate science for serving society: research, modelling and prediction priorities. Springer, Berlin, pp 339-389. ISBN 978-94-007-6691-4

Publisher's Note Springer Nature remains neutral with regard to jurisdictional claims in published maps and institutional affiliations. 


\section{Affiliations}

Mathew Barlow ${ }^{1}$ (1) - William J. Gutowski Jr. ${ }^{2}$ John R. Gyakum ${ }^{3}$. Richard W. Katz ${ }^{4}$. Young-Kwon Lim ${ }^{5}$. Russ S. Schumacher ${ }^{6}$. Michael F. Wehner ${ }^{7}$. Laurie Agel ${ }^{1} \cdot$ Michael Bosilovich $^{8}$. Allison Collow ${ }^{9}$. Alexander Gershunov ${ }^{10} \cdot$ Richard Grotjahn $^{11}$ - Ruby Leung ${ }^{12}$. Shawn Milrad ${ }^{13}$. Seung-Ki Min ${ }^{14}$

1 University of Massachusetts Lowell, Lowell, MA 02155, USA

2 Department of Geological and Atmospheric Sciences, Iowa State University, Ames, IA 50011, USA

3 Department of Atmospheric and Oceanic Sciences, McGill University, Montreal, QC, Canada

4 National Center for Atmospheric Research, Boulder, CO 80307, USA

5 NASA Goddard Space Flight Center, Global Modeling and Assimilation Office, and Goddard Earth Sciences Technology and Research/I.M. Systems Group, Greenbelt, MD 20771, USA

6 Colorado State University, Fort Collins, CO 80523, USA

7 Lawrence Berkeley National Laboratory, Berkeley, CA 94720, USA

8 NASA GSFC Global Modeling and Assimilation Office, Greenbelt, MD 20771, USA
9 Universities Space Research Association and NASA GSFC Global Modeling and Assimilation Office, Greenbelt, MD 20771, USA

10 Climate, Atmospheric Science and Physical Oceanography (CASPO) Division, Scripps Institution of Oceanography, University of California San Diego, La Jolla, CA 92093, USA

11 Atmospheric Science Program, Department of L.A.W.R. University of California Davis, One Shields Ave., Davis, CA 95616, USA

12 Pacific Northwest National Laboratory, Richland, WA 99352 , USA

13 Meteorology Program, Applied Aviation Sciences Department, Embry-Riddle Aeronautical University Daytona Beach, Daytona Beach, FL 32114, USA

14 Division of Environmental Science and Engineering, Pohang University of Science and Technology, Pohang, Gyeongbuk 37673, South Korea 